\title{
Hypovirus manipulation of Nonself Recognition-Associated Programmed Cell Death in the Chestnut Blight Fungus, Cryphonectria parasitica
}

A thesis presented to the Faculty of Graduate Studies of

\author{
Carleton University
}

By

Fuad Tanha

In partial fulfillment of the requirements for the degree of

Master of Science

2008

${ }^{\circ}$ Copyright
2008, Fuad Tanha 


$\begin{array}{ll}\begin{array}{l}\text { Library and } \\ \text { Archives Canada }\end{array} & \begin{array}{l}\text { Bibliothèque et } \\ \text { Archives Canada }\end{array} \\ \begin{array}{l}\text { Published Heritage } \\ \text { Branch }\end{array} & \begin{array}{l}\text { Direction du } \\ \text { Patrimoine de l'édition }\end{array} \\ \begin{array}{l}\text { 395 Wellington Street } \\ \text { Ottawa ON K1A 0N4 } \\ \text { Canada }\end{array} & \begin{array}{l}\text { 395, rue Wellington } \\ \text { Ottawa ON K1A 0N4 } \\ \text { Canada }\end{array}\end{array}$

Your file Votre référence ISBN: 978-0-494-44144-2 Ourfile Notre référence ISBN: 978-0-494-44144-2

NOTICE:

The author has granted a nonexclusive license allowing Library and Archives Canada to reproduce, publish, archive, preserve, conserve, communicate to the public by telecommunication or on the Internet, loan, distribute and sell theses worldwide, for commercial or noncommercial purposes, in microform, paper, electronic and/or any other formats.

The author retains copyright ownership and moral rights in this thesis. Neither the thesis nor substantial extracts from it may be printed or otherwise reproduced without the author's permission.
AVIS:

L'auteur a accordé une licence non exclusive permettant à la Bibliothèque et Archives Canada de reproduire, publier, archiver, sauvegarder, conserver, transmettre au public par télécommunication ou par l'Internet, prêter, distribuer et vendre des thèses partout dans le monde, à des fins commerciales ou autres, sur support microforme, papier, électronique et/ou autres formats.

L'auteur conserve la propriété du droit d'auteur et des droits moraux qui protège cette thèse. $\mathrm{Ni}$ la thèse ni des extraits substantiels de celle-ci ne doivent être imprimés ou autrement reproduits sans son autorisation.
In compliance with the Canadian Privacy Act some supporting forms may have been removed from this thesis.

While these forms may be included in the document page count, their removal does not represent any loss of content from the thesis.
Conformément à la loi canadienne sur la protection de la vie privée, quelques formulaires secondaires ont été enlevés de cette thèse.

Bien que ces formulaires aient inclus dans la pagination, il n'y aura aucun contenu manquant.

\section{Canada}




\begin{abstract}
Introduction of the pathogenic fungus, Cryphonectria parasitica, to North America devastated the population of American chestnut, reducing it from a dominant overstory tree into a shrub. The appearance of hypovirulent strains provided an opportunity for biological control, due to their ability to transmit dsRNA viral elements into virulent strains. Unfortunately, this program was not a success, in part, at least, because of the fungal vegetative incompatibility system that impeded transmission of the virus from infected to uninfected strains. Vegetative incompatibility in C. parasitica is associated with six unlinked vic loci (vic 1,2,3,4,6, and 7), each with at least two alleles. Fusion of two strains that differ at one or more vic loci can result in Programmed Cell Death (PCD). The focus of this thesis was to characterize the factor(s) encoded by the viral genome that interacts with the vic-associated PCD in C. parasitica. Here, I report a significant reduction in PCD upon fusion of strains differing at vic 3 is associated with hypovirus infection. Using chimeric hypoviruses of CHV1-EP713 and CHV1Euro7, this PCD reduction effect was assigned to the virus ORF A region that encodes proteins $\mathrm{p} 29$ and p40. The p29-effect was studied in some detail. In addition to vic3, p29 caused a significant reduction in PCD rates triggered by differences at all other vic loci studied, including vic2,6 and 7. p29 is a multifunctional protein that was previously documented to alter fungal pigmentation patterns, conidiation and enzyme expression, and p29 acts as suppressor of RNA silencing. My results further showed that the vic3associated PCD reduction is associated with production of p29 RNA rather that the p29 protein. Using dicer-like mutant strains I also showed that RNA silencing is involved in vic3-associated PCD reduction. This information suggests a model in which p29
\end{abstract}


interferes with RNA silencing, that in turn reduces vic-associated PCD. Finally, microscopy analyses of strains with multiple vic differences suggested that there are interactions among vic genes involving independent pathways. 


\section{ACKNOWLEDGEMENTS}

I would like to express my sincere gratitude to my supervisor, Dr. Myron L.

Smith for all his support and encouragement throughout my academic and personal life. This thesis could not have been written without his help and guidance.

I would like to thank my advisors, Dr. Linda Bonen and Dr. P. John Vierula, for their feedback and suggestions; Dr. Donald, L. Nuss (University of Maryland) and Dr. Michael Milgroom (Cornell University) for providing me with constructs and strains; Robert Smith for helping with Western blotting and protein work; Melissa Begin for teaching me real time PCR; Isabel Cruz, the "Adobe-photoshop wizard", for her help in figure editing; and Denis Lafontaine for assisting me with reverse transcription. My deepest thanks go to all these people who had some part in this project.

A special thank you also goes to my family. My mother, Mahboubeh Talebi, for all the love and support that she has been giving me throughout my life and all the sacrifices that she has made for me. Mom, I could never thank you enough. My brothers Jamshid, Freidoon, Farzad and Reza, my sisters Hadigheh and Fatemeh, and my sister inlaw Ramesh for their help and encouragement. I am truly grateful. I know for a fact that this would not have been possible without them. On a final note, I am much indebted to Negar, my wife, whose support, patience, and love was a big factor in completing the project. 


\section{TABLE OF CONTENTS}

ACCEPTANCE SHEET ................................................................................

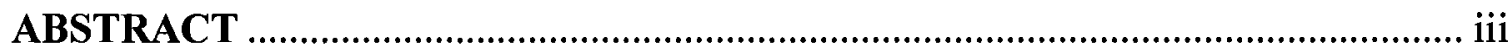

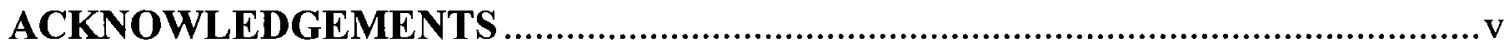

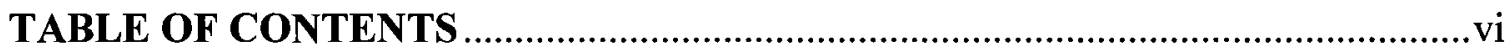

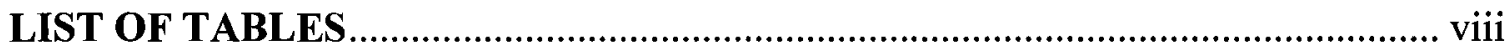

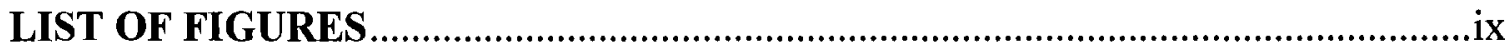

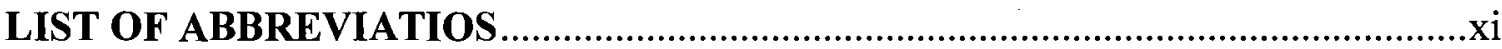

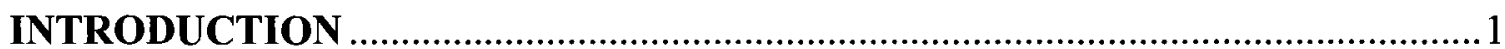

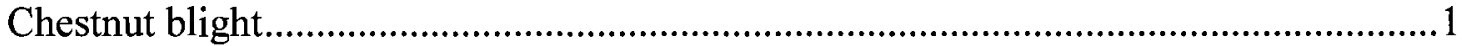

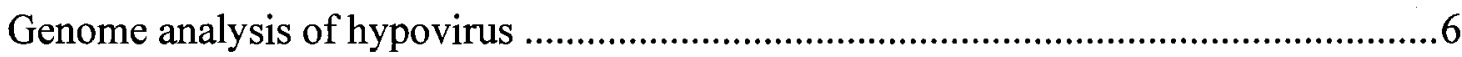

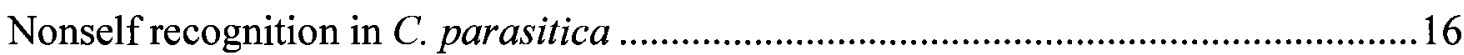

Relationship between virus transmission and VC in C. parasitica ..................................19

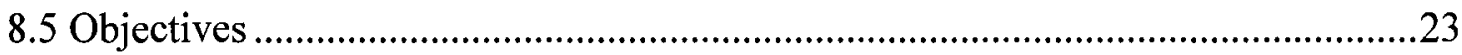

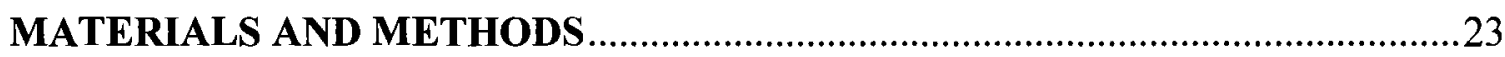

Isolates of $C$. parasitica and growth conditions ............................................................23

C. parasitica spheroplasts preparation .........................................................................

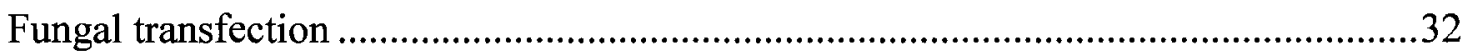

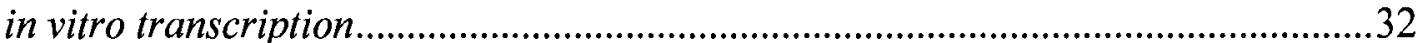

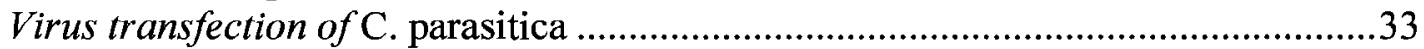

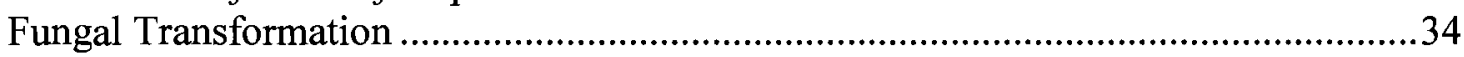

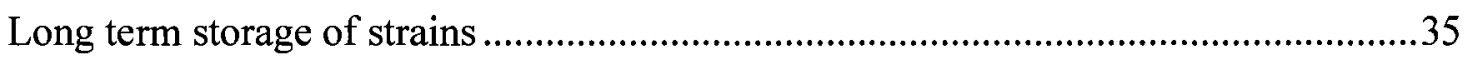

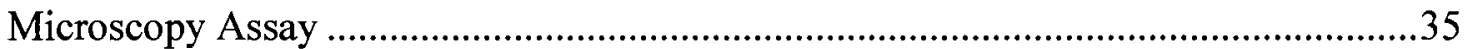

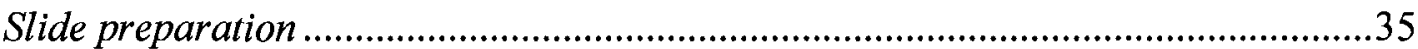

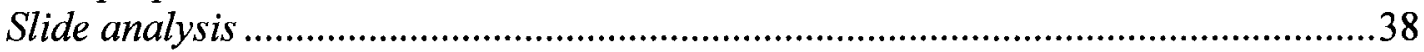

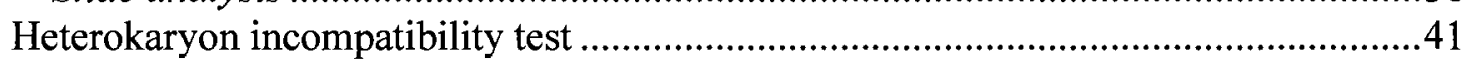

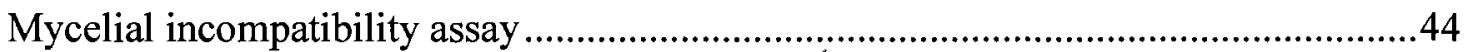

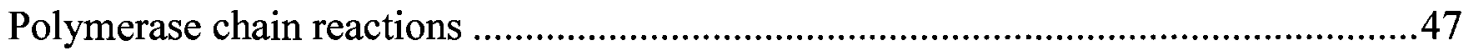

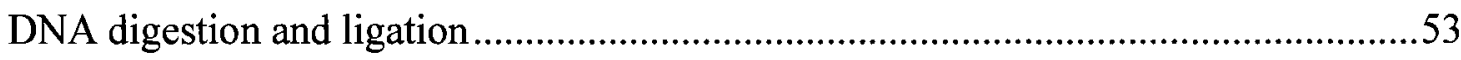


DNA recovery from agarose gels ...........................................................................53

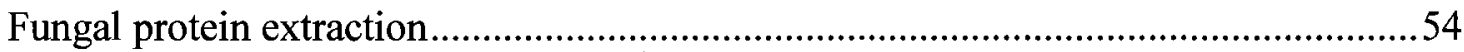

Affinity Purification using M2 Anti-flag Agarose Beads ...............................................54

SDS polyacrylamide gel electrophoresis (SDS-PAGE) ..................................................55

Staining SDS-PAGE gels with coomassie brilliant blue in preparation for mass

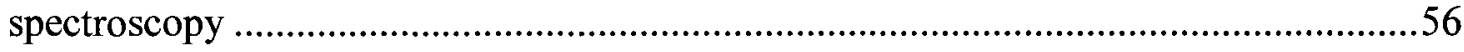

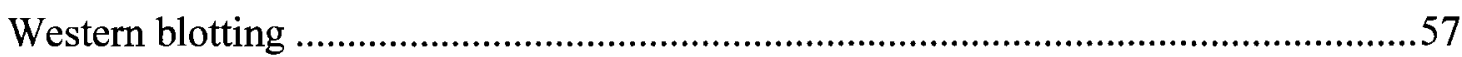

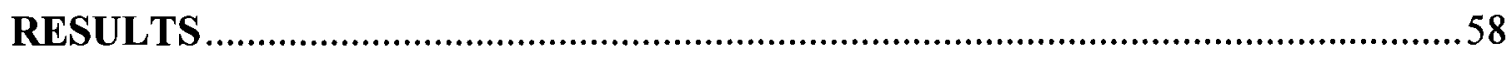

Effect of viral infection on C. parasitica phenotype .....................................................58

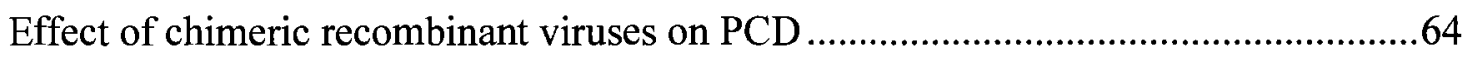

Vegetative incompatibility ..................................................................................68

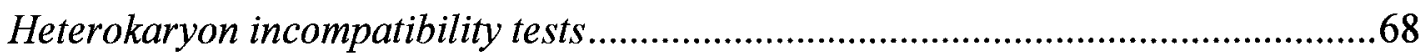

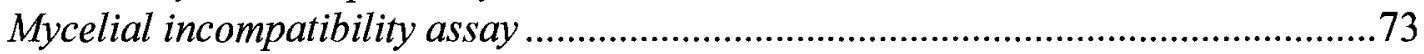

Protein-protein interaction.......................................................................................

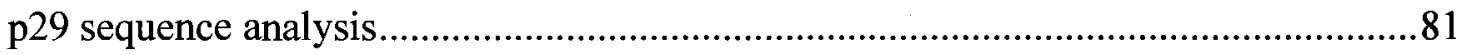

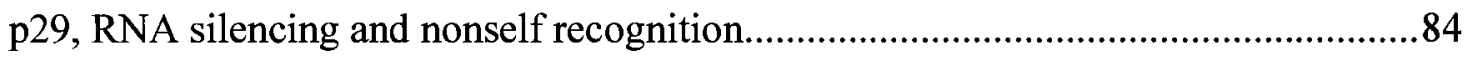

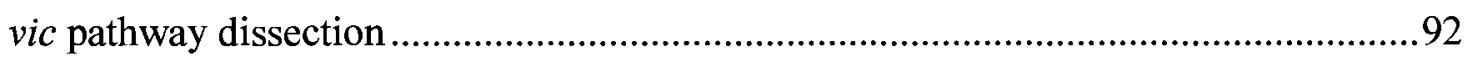

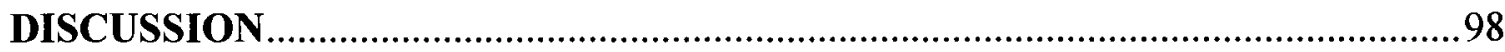

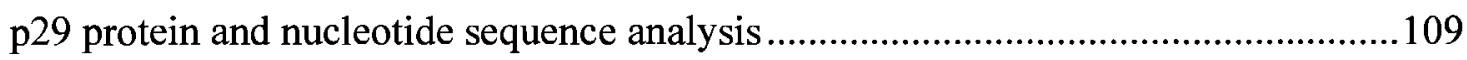

A possible p29-RNA silencing-nonself recognition connection ....................................110

Dissecting the vic pathway using hypovirus p29 factor as a probe ...............................114

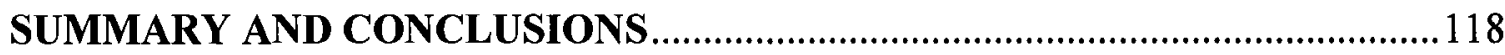

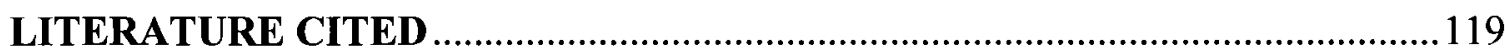




\section{LIST OF TABLES}

Table 1. Strains used in this study. .45

Table 2. Transformation plasmids along with their oligonucleotide primers used in this study.

Table 3. Effect of chimeric hypovirus transfection on colony morphology.......................62

Table 4: Effect of p29 expression on cell death frequencies between pairs of isolates that differ at the single or multiple vic loci........................................................................94 


\section{LIST OF FIGURES}

Figure 1. Diagram of Cryphonectria parasitica on chestnut tree.........................................4 Figure 2. Schematic representation of the organization of four fully sequenced CHV

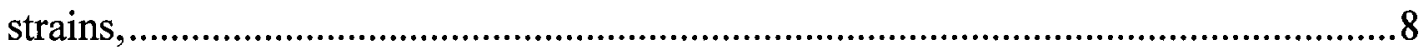

Figure 3. Comparison of cankers formed in chestnut tissues inoculated with virus-free $C$. parasitica strain EP155 (left), EP155 transfected with either CHV1-Euro7 (center) or CHV1-EP713 (right)

Figure 4. Colony morphology of virus-free $C$. parasitica (left), C. parasitica transfected with either CHV1-Euro7 (center) or CHV1-EP713 (right) .......................................14

Figure 5. Schematic diagram of pLDST plasmid used for synthesizing RNA transcripts of inserted hypovirus sequence

Figure 6. Schematic representation of parental hypoviruses CHV1-EP713 and CHV1Euro7 and their chimeric constructs used in this study ............................................27

Figure 7. pCPXHY1 vector used for plasmid transformations .............................................29

Figure 8. Schematic diagram of slide culture technique used for microscopy assays........36

Figure 9. Types of interactions observed under 40x magnification. ..................................39

Figure 10. Schematic representation of technique used for heterokaryon incompatibility test.

Figure 11. Schematic representation of technique used for construction of chimeras. .....49

Figure 12. Colony morphologies of $C$. parasitica isolates with and without transfected viruses.

Figure 13: Clustered bar representation of viral constructs (left) and associated cell death frequencies (right).

Figure 14: Heterokaryon outgrowth (hk) from EP155B and 22.1H pairing (viccompatible) (a). In comparison, the outgrowth is absent in pairing of strains $22.1 \mathrm{H}$ and P74-3 that differ at vic3 (b).

Figure 15: Growth rates of heterokaryotic sectors obtained from confronting hygromycinresistant isolates of $22.1 \mathrm{H}, \mathrm{PXH} 1$ or $\mathrm{PXH} 3$ against each of the 13 benomyl-resistant isolates

Figure 16. Mycelial incompatibility tests between strain pairs with defined vic characteristics.

Figure 17: Western blot of flagged-tag constructs of CHV1-EP713-p29 and CHV1Euro7-p29.

Figure 18: Affinity purified samples of CHV1-EP713-p29 and CHV1-Euro7-p29 using M2 anti-flag agarose beads followed by SDS-PAGE and Coomassie Brilliant Blue staining...... .79

Figure 19: Clustered bar representation of viral constructs (left) and associated PCD

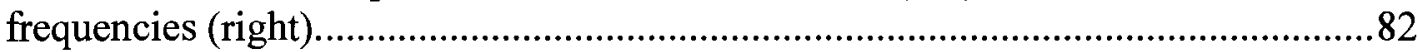

Figure 20: Illustration of PCD frequencies in P74-3 (recipient) and EP155 (donor)........86

Figure 21. Sequence alignment of the wild-type CHV1-EP713-p29 and CHV1-EP713p29stop for first $60 \mathrm{bp}$ of coding regions with corresponding amino acid sequences for each of three forward frames.

Figure 22: Colony morphology of EP155 virus-free (left), EP155 (CHV1-EP713p29stop) (middle) and EP155 (CHV1-EP713-p29) (right). 
Figure 23. Scatter plot representing a comparison between cell death ratio of isolates involving single and double vic differences of vic6 and 7 (A) and vic2 and 3 (B)...96

Figure 24. Schematic diagram of the CHV1-EP713 genome, showing essential domains and residues in $\mathrm{p} 29$ coding region 103

Figure 25. Hypothetical representation showing the difference between the frequency $(F)$ and rate (R) of vic-associated PCD compared to virus-free confrontation (WT) ....107 Figure 26. Illustrates two different models for vic-incompatibility pathway. 116 


\section{LIST OF ABBREVIATIOS}

\begin{tabular}{|c|c|}
\hline $\begin{array}{l}b m l^{\mathrm{R}} \\
\operatorname{ben}^{\mathrm{R}}\end{array}$ & $\begin{array}{l}\text { benomyl resistant beta-tubulin } \\
\text { benomvl resistant }\end{array}$ \\
\hline bp & base pair \\
\hline $\mathrm{cm}$ & centimeters \\
\hline cDNA & complementary deoxyribonucleic acid \\
\hline $\mathrm{CHV}$ & cryphonectria parasitica hypovirus \\
\hline${ }^{\circ} \mathrm{C}$ & degree Celsius \\
\hline DEPC & diethyl pyrocarbonate \\
\hline DNA & deoxyribonucleic acid \\
\hline $\mathrm{ddH}_{2} \mathrm{O}$ & double distilled water \\
\hline dsRNA & double-stranded ribonucleic acid \\
\hline EDTA & ethylenediaminetetracetic acid \\
\hline $\mathrm{g}$ & grams \\
\hline gpd & glyceraldehyde-3-phosphate dehydrogenase gene promoter \\
\hline het & heterokaryon incompatibility locus \\
\hline$h p h$ & hygromycin B phosphotransferase \\
\hline hyg & hygromycin \\
\hline hyg $^{\mathrm{R}}$ & hygromycin resistant \\
\hline $\mathrm{KDa}$ & kilodaltons \\
\hline $\mathrm{Tm}$ & melting temperature \\
\hline$\mu \mathrm{L}$ & microlitre \\
\hline $\mathrm{mL}$ & millilitre \\
\hline $\mathrm{mm}$ & millimeter \\
\hline $\mathrm{mM}$ & millimolar \\
\hline $\mathrm{M}$ & moles per litre \\
\hline NTP & nucleoside triphosphate \\
\hline ORF & open reading frame \\
\hline$\%$ & percent \\
\hline PCR & polymerase chain reaction \\
\hline PDA & potato dextrose agar \\
\hline PDB & potato dextrose broth \\
\hline PDAg & green potato dextrose agar \\
\hline PMSF & phenyl methyl sulforyl fluoride \\
\hline PCD & programmed cell death \\
\hline RNA & ribonucleic acid \\
\hline RPM & revolutions per minute \\
\hline RT & reverse transcription \\
\hline SDS & sodium dodecyl sulfate \\
\hline $\mathrm{VC}$ & vegetative compatibility \\
\hline VCG & vegetative compatibility group \\
\hline vic & vegetative incompatibility locus \\
\hline VSR & viral suppressors of RNA silencing \\
\hline & yolts \\
\hline
\end{tabular}


Chestnut blight

\section{INTRODUCTION}

For the past century researchers have been investigating the mechanisms by which some microorganisms inhibit the growth or metabolic activity of other microorganisms. In the past decade, interest in using these antagonistic microorganisms as biological controls of plant pathogens has increased with the aim of improving the sustainability of agriculture, horticulture and forestry with minimal side-effects to the environment (Duffy et al., 2003). The attempted treatment of the chestnut blight fungus, Cryphonectria parasitica, represents one of the classical cases of biological control of a plant disease.

The American chestnut tree, Castanea dentata, is a member of the family Fagaceae, closely related to oaks and beeches. The chestnut was one of the important forest crops in eastern United States before the 1900's. The wood was valued for building materials and the nuts constituted a major food source for humans as well as deer, wild turkey, bear and other wildlife (Nuss, 1992). The chestnut was the dominant tree in the uplands of North American eastern hardwood forests until being decimated by the chestnut blight. The first evidence of chestnut blight in North America was reported in 1904 in the New York Botanic Gardens. Within 50 years the disease had extended from Maine to Alabama and west to the Mississippi River. The chestnut blight epidemic was caused by the ascomycete fungus Cryphonectria parasitica, which was imported to North America in the late 1800s from the Japanese chestnut tree, Castanea crenata, and accidentally introduced to American chestnut trees (Anagnostakis, 2001). The loss of the American chestnut had major ecological, social and economical consequences. It was estimated that from 1910 to 1950 approximately 3.5 billion trees were lost (Cox, 1991). 
At this point 9 million acres of American chestnut were dead (Anagnostakis, 1982). Financial loss from the disease for only three states, Pennsylvania, South Carolina and West Virginia, for the year of 1912 was estimated at $\$ 82.5$ million (Cox, 1991).

C. parasitica enters into the host plant through wounds, which are formed by broken branches, breaks in bark, or holes produced by woodpecker or bark boring insects (Anagnostakis, 1982) (Figure 1). From the point of infection the mycelium spreads and penetrates throughout the bark, and consequently kills the cambium around the twigs, branches, or trunks. The tree may resist the invasion by production of callus tissue, although the fungus can easily penetrate through this tissue. Certain environmental conditions such as abundant light, water, and nutrients may assist in pathogen resistance of host trees. Unfortunately these conditions are not sufficient to save the tree. Only the root collar (area where the root joins the main stem or trunk) survives the infection and is capable of generating sprouts that can develop into saplings. At a point when the saplings approach flowering, the fungus reinfects the stem to go through the cycle again (Anagnostakis, 2000).

Chestnut blight was also seen in the European chestnut (Castanea sativa) in the 1930's with the same destruction level as observed in America. In Europe, however, a "recovering" chestnut tree was discovered by Biraghi in Italy in 1951 (Heiniger \& Rigling, 1994). He observed that in some cankers the fungal mycelium was confined only to the outer parts of the bark and developed as superficial cankers. The first hypovirulent $C$. parasitica strains were isolated from the recovered trees by Grente near Como (northern Italy) in 1964 (Heiniger \& Rigling, 1994). Isolated hypovirulent strains seemed to have specific phenotypic characteristics such as lower levels of sporulation and 
they lacked orange pigmentation compared to normal, virulent strains. Grente also noticed that inoculation of infected tissue with these hypovirulent strains as well as coinoculation with normal isolates resulted in reduced virulence levels. Preliminary investigations on several European hypovirulent $C$. parasitica strains showed that double-stranded RNA (dsRNA) was responsible for the conversion to a hypovirulence phenotype (Dawe \& Nuss, 2001). 
Figure 1. Diagram of Cryphonectria parasitica on chestnut tree. Conidia from the infected stock are transferred by wind or animals to wounds on otherwise healthy trees. Pathogen invasion through a wound results in canker formation and damaged vasculature of the tree, which consequently destroys the leaves and branches beyond the site of canker formation. Orange pigmented pycnidia bearing conidia appear on the surface of the cankers followed by production of ascospores via the sexual cycle. (Modified from V. Mortensen, ontained at http://chestnut.cas.psu.edu/PDFs/cryphonectria_life_cycle.pdf) 


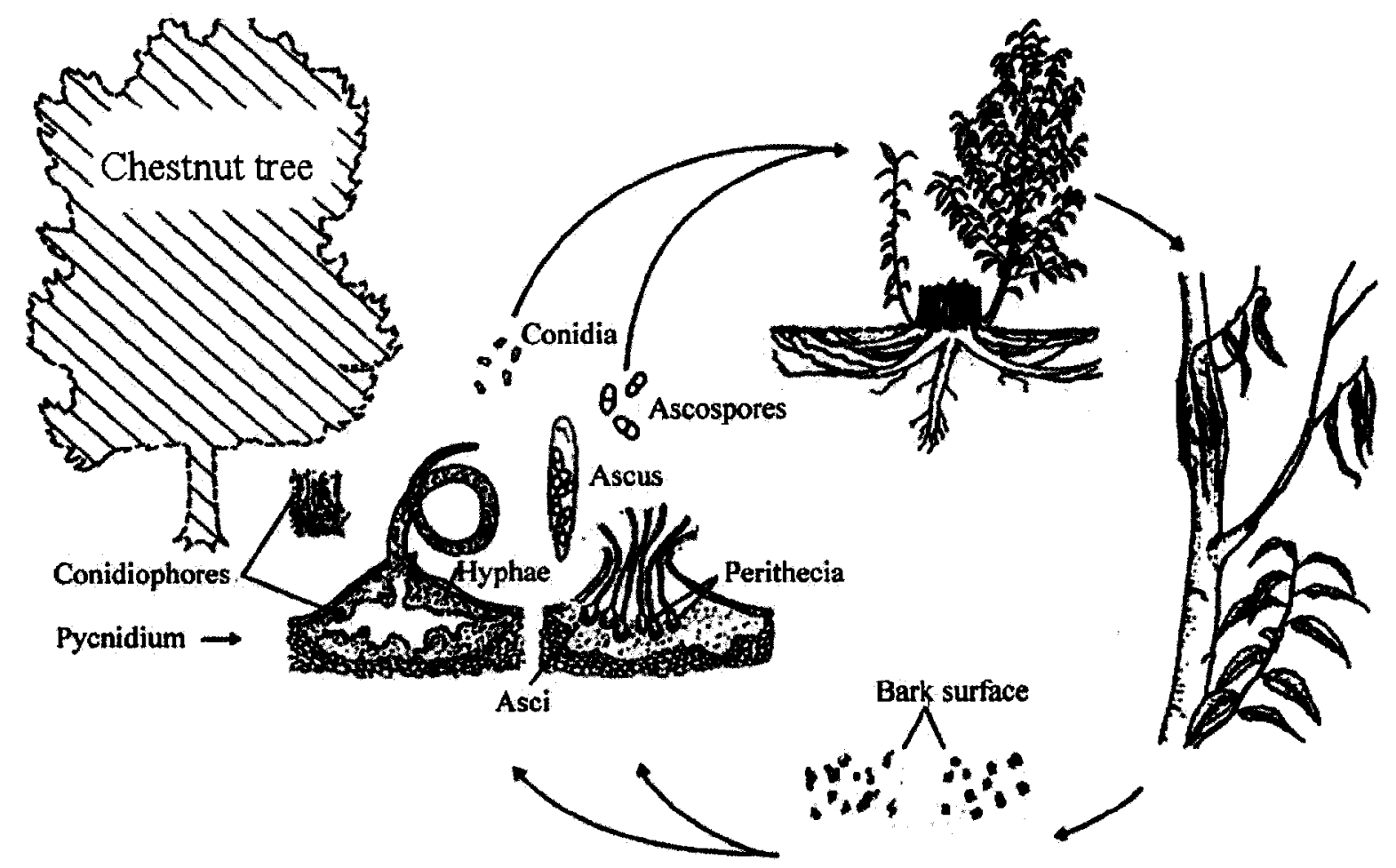


Genome analysis of hypovirus

In order to understand the basis of hypovirulence and develop strategies for using it in biological control, a comprehensive knowledge of the structural properties of hypovirulence-related dsRNA is essential. Complete nucleotide sequences and analysis of dsRNA isolated from European and North American hypovirulent $C$. parasitica strains allowed the International Committee of Taxonomy of Viruses to create a new family, Hypoviridae, with a single genus, Hypovirus (Dawe \& Nuss, 2001). Four "species" of Cryphonectria parasitica hypovirus (CHV) have been described (Milgroom \& Cortesi, 2004): CHV-1 CHV-2, CHV-3 and CHV-4. CHV-1 is common in Europe and thought to have been introduced from Asia. It was also found in a few areas in North America, where it was used for biological control. CHV-1 has been studied more thoroughly than other species due to its role in biological control of chestnut blight in Europe. CHV-2 and CHV-3 are found in New Jersey and Michigan, respectively. In addition, CHV-2 has been found at one location in Asia. Because of high sequence similarity, there is a possibility that $\mathrm{CHV} 2$ strains were introduced into China from North America. Due to its genome organization, CHV-4 belongs to the hypovirus genus. However this hypovirus has little or no effect on the host organism. It is mostly found in eastern North America (Milgroom \& Cortesi, 2004).

To date the genomes of three of the four species have been fully sequenced. Representing two strains of CHV-1, comparative analyses show that CHV1-EP713 and CHV1-Euro7 are comprised of two large open reading frames designated as ORF A and ORF B (Figure 2). ORF A codes for the polyprotein, p69, which is autocatalytically cleaved to produce $\mathrm{p} 29$ and $\mathrm{p} 40$ proteins. This cleavage is facilitated by the presence of 
papain-like cysteine protease domain located within the p29 sequence. Similarly, ORF B is autocatalytically processed to release a $\mathrm{p} 48$ protein and a second, larger peptide that contains polymerase and helicase domains (Dawe \& Nuss, 2001). The junction between ORFs A and B is comprised of a sequence 5'-UAAUG-3', where UAA and AUG segments serve as translation termination and initiation codons for ORF A and ORF B respectively. 
Figure 2. Schematic representation of the organization of four fully sequenced CHV strains, two of CHV-1 and one each of CHV-2 and CHV-3. A fourth species, CHV-4, has not been fully characterized but appears to have a similar genomic structure. (Modified from Dawe \& Nuss, 2001). 
ORE B

\section{ORF A}

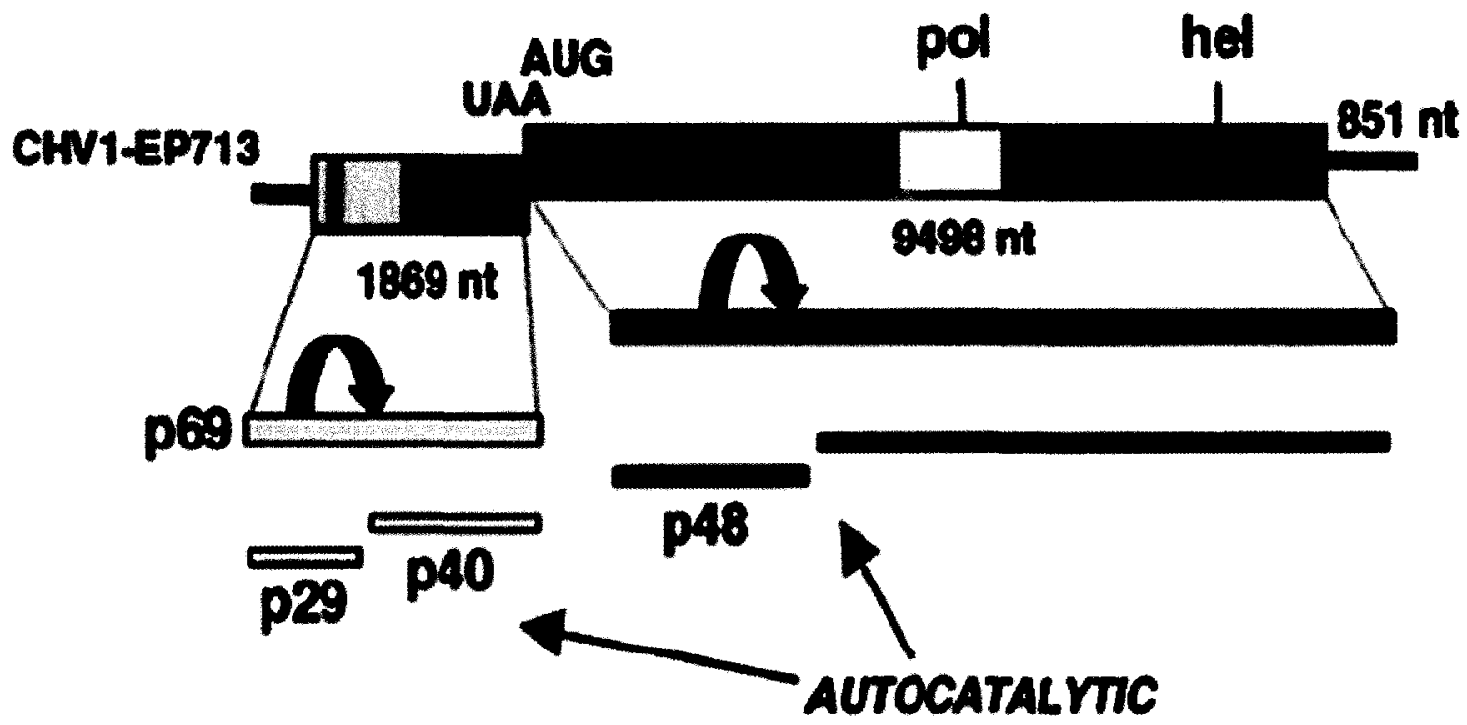

CHN1-Euro7

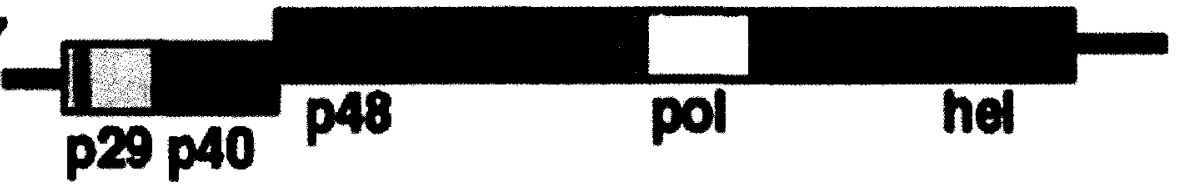

CHN2NB58

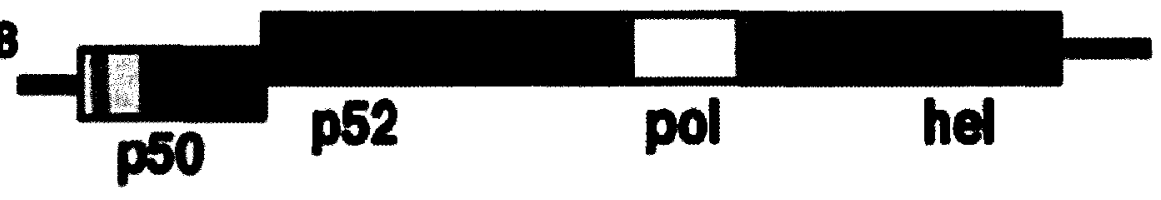

CHV3-CH2

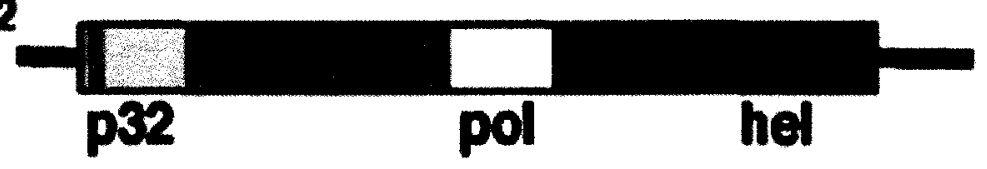

$$
1 \mathbf{K b p}
$$


CHV2-NB58 has a similar genomic organization to that of CHV1 (Figure 2). However, in contrast to CHV1-EP713, in vitro translation studies on CHV2-NB58 revealed that $\mathrm{ORF} A$, which encodes a $50 \mathrm{kDa}$ protein does not undergo autocatalytic cleavage (Hillman et al., 1994). As opposed to CHV1 and CHV2, the CHV3-GH2 genome consists of a single ORF. Amino acid sequence alignment of the three species showed a closer relation between CHV1 and CHV2, with CHV3 being more distantly related (Dawe \& Nuss, 2001).

Among the Hypoviridae affecting C. parasitica, CHV-1 has been given the most attention due to its role as a biological control agent of chestnut blight in Europe. Most relevant to this thesis, two strains, CHV-1-EP713 and CHV-1-Euro7, are known as severe and mild hypovirus genotypes, respectively. This classification is based on differences in their effects on C. parasitica virulence and associated characteristics such as canker morphology, colony growth and sporulation level. Cankers on chestnut bark produced by virus-free strains expand quickly, and bear multiple pycnidia that contain orange conidia (Figure 3). However, the same C. parasitica strains infected with CHV1EP713 produce small cankers that contain a very small number or no pycnidia. The size of cankers produced by strains infected with CHV1-Euro7 are observed to be three to four times larger than the ones produced by EP713 (Cummings-Carlson, 1998). Effects on C. parasitica growth rate and morphology also differentiate these two virus strains. As shown under defined laboratory conditions (Figure 4), C. parasitica strains infected by CHV1-EP713 grow slower and produce few or no asexual spores compared to the corresponding virus-free strain. In contrast, the CHV1-Euro7-infected strain has a higher 
growth rate than the virus-free strain but lacks pigmentation and asexual spore production (Dawe \& Nuss, 2001).

Identification of a viral basis to C. parasitica hypovirulence in European chestnuts provided the impetus for application of $\mathrm{CHV} 1$ strains as biological control agents of North American chestnut blight. However, this strategy did not succeed, apparently because North American strains of $C$. parasitica have a more complex nonself recognition system than their European counterparts. The following sections briefly provide some background into nonself recognition systems of filamentous fungi and how they relate to viral transmission patterns. 
Figure 3. Comparison of cankers formed in chestnut tissues inoculated with virus-free $C$. parasitica strain EP155 (left), EP155 transfected with either CHV1-Euro7 (center) or CHV1-EP713 (right) (Modified from Chen et al., 2000). 

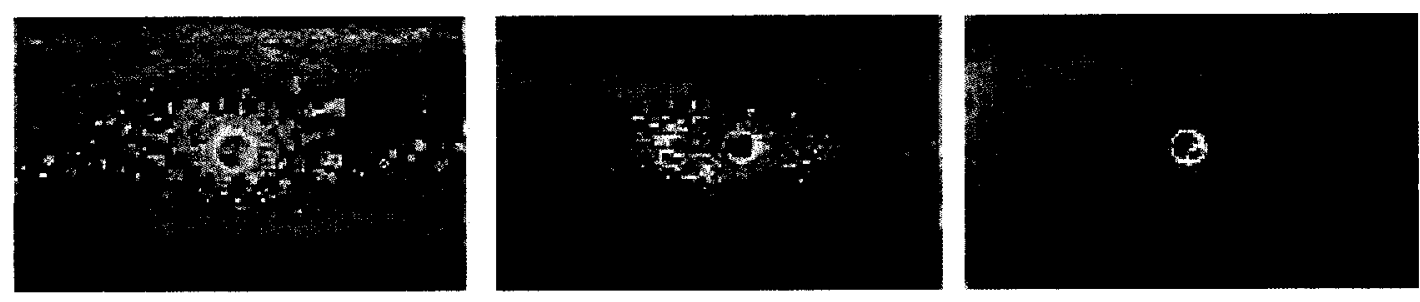
Figure 4. Colony morphology of virus-free C. parasitica (left), C. parasitica transfected with either CHV1-Euro7 (center) or CHV1-EP713 (right) (Modified from Dawe \& Nuss, 2001). 


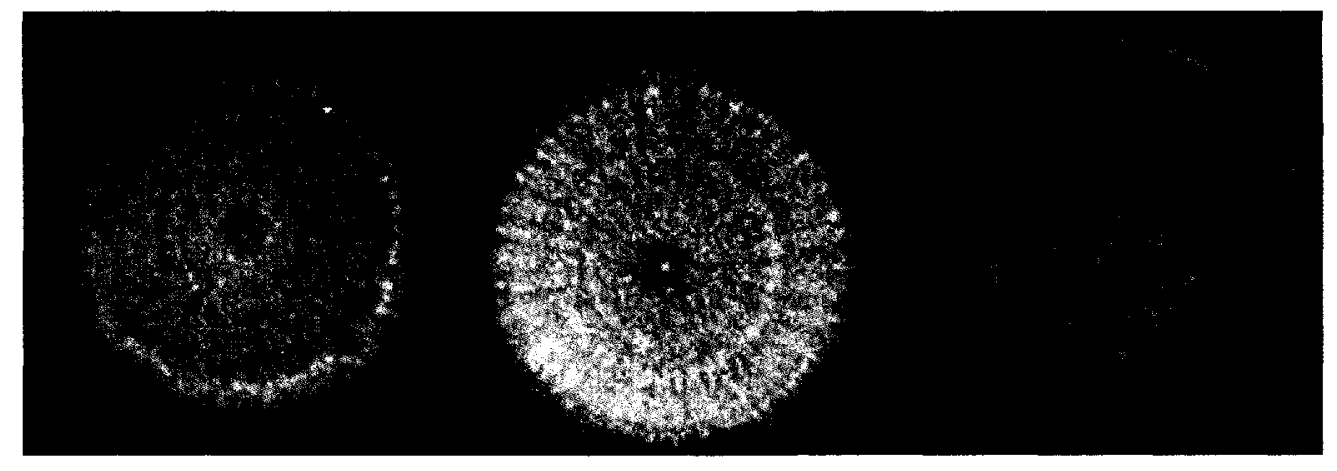


Nonself recognition in C. parasitica

Filamentous fungi grow through hyphal tip extension. This process is facilitated by a structure located near the hyphal tip known as the Spitzenkorper, which is responsible for delivery of the required components for the extension of the cell wall (Glass et al., 2000). Fusion between hyphae is known as anastomosis. It occurs during the growth process to result in the formation of a mycelium, an interconnected network of hyphae. Described for the first time by Buller (Buller, 1933), anastomosis involves the breakdown of two hyphal cell walls and fusion of the plasma membranes. Upon fusion the cells are capable of exchanging nuclei and other organelles, which is important for maintaining the communication and homeostasis within a mycelium during growth and reproduction (Glass et al., 2000).

Distinct fungal individuals with genetically different nuclei are also capable of anastamosis; a process that results in the formation of a heterokaryon. Heterokaryon formation may be beneficial for facilitating mitotic genetic exchange as well as increasing mycelial biomass to facilitate physiological processes such as sexual/asexual reproduction and accessing resources (Gregory, 1984). In many fungi, sexual and asexual incompatibility are quite distinct processes. Two strains that have the ability to fuse and form a heterokaryon during the sexual cycle may not be able to form a successful heterokaryon during the vegetative cycle and vice versa (Leslie, 1993). Sexual compatibility is controlled by the mating-type locus at which cells of compatible mating type contain different, "idiomorphic" DNA sequences. Expression of compatible matingtype idiomorphs establishes the cell-type sexual identity and subsequent expression of 
different classes of transcriptional elements that lead to meiosis and meiospore production (Fraser \& Heitman, 2003).

In contrast, during the asexual phase, fusion between two individuals that are different at one or more het loci (heterokaryon incompatibility, also called vic for vegetative incompatibility), will result in cell death as a result of lytic processes. This phenomenon is known as heterokaryon, vegetative or somatic incompatibility and may, in theory, take place before, during, or after hyphal fusion (Micali \& Smith, 2003; Glass et al., 2000). Post-fusion vegetative incompatibility mechanisms are best characterized in Podospora anserina and Neurospora crassa. In both species vegetative incompatibility was shown to be regulated by either allelic or nonallelic mechanisms. Allelic incompatibility occurs upon fusion of two individuals that carry different alleles at a single het (or vic) locus. Nonallelic incompatibility results from interactions between specific allelic combinations between two different loci.

Vegetative incompatibility is, therefore, a nonself recognition system that is analogous to graft rejection in animals and plants. All filamentous fungi examined have several, usually more than six, vic loci (Saupe, 2000). Vegetative incompatibility in $C$. parasitica is associated with at least six unlinked vic loci (vic 1,2,3,4,6, and 7), each with at least two alleles and each is thought to involve allelic interactions (Cortesi \& Milgroom, 1998). Hence, vegetative compatibility (VC) type can be defined based on the presence of alleles at all vic loci. Fungal strains belonging to different VC groups (VCG) can be identified by three techniques: heterokaryon incompatibility tests, barrage tests, and partial diploid analyses (Micali \& Smith, 2003). 
Heterokaryon incompatibility testing examines whether or not two strains can fuse to form stable heterokaryons. In practice, auxotrophic or antibiotic forcing markers or complementary pigmentation markers can be used to test for heterokaryon formation. For example, heterokaryon formation in Fusarium oxysporum is tested by using strains containing different nit mutations (incapable of reducing nitrate). nit complementation allows a compatible, but not an incompatible, heterokaryon to grow on medium containing nitrate as the only source of nitrogen (Leslie, 1993). In addition to a reduced growth rate, incompatible forced heterokaryons can be recognized by an aberrant appearance such as reduced conidiation and accumulation of dark brown pigment (Micali $\&$ Smith, 2005). Barrage tests are done by simply co-inoculating two strains onto the same plate and allowing them to grow together. The term Barrage was introduced by Vandendries to explain the response that occurred upon hyphal fusion between the two different strains of fungi. A barrage is composed of an area containing dead or dying cells with deposition of dark pigment. It may also appear as a clear zone or other types of demarcation. However such morphological alterations are absent in vegetatively compatible individuals. This phenomenon is seen in many fungi such as Podospora and Neurospora and is the method most widely used for assigning strains to VC groups in $C$. parasitica. Finally, partial diploid analyses can either be done through crosses with a strain bearing a translocated het locus or through transformation of DNA containing the het locus. In either case, having two copies of the duplicated het loci in the nucleus results in a strain that is referred to as a partial diploid and if the two copies represent incompatible alleles then the strain will be "self-incompatible". 
Vegetative incompatibility and barrage tests are often thought to represent different manifestations of the same process. However, at least two studies have shown that this is not always the case (Micali \& Smith, 2003; Smith et al., 2006). These studies showed that differences at loci that are associated with barrage line formation do not necessarily cause heterokaryon incompatibility, and vice versa. The distinct nature of heterokaryon incompatibility and barrage formation may be explained if barrage formation occurs in some cases without hyphal fusion, unlike heterokaryon incompatibility in which fusion is necessary. Barrage formation may occur through inhibitory effects of substances that diffuse from one or both strains, or may involve diffusible substances and cell-surface receptors that interact to trigger barrage formation. These observations suggest that heterokaryon incompatibility represents a "subset" of the vegetative incompatibility system (Smith $e t$ al., 2006).

Relationship between virus transmission and VC in C. parasitica

Extensive studies by the French mycologist Jean Grente illustrated that the hypovirulence phenotype could be transmitted from one strain to another through hyphal fusion (Grente \& Sauret, 1969). This finding set the stage for attempts at biological control of $C$. parasitica through artificial introduction of hypovirulent strain. However, as mentioned above, this program was not successful in North America, presumably due to the restriction of viral elements by the fungus vegetative incompatibility system. The transmission of cytoplasmic elements between strains is thought to be modulated by vegetative incompatibility (Caten, 1972; Liu \& Milgroom, 1996). That biocontrol in Europe was more successful compared to North America is thought to be due to 
differences in the diversity of VC groups in the two fungal populations. Thirty-three VC groups were identified from analysis of the strains obtained from several regions in France and Italy (Anagnostakis \& Kranz, 1986). Strain diversity in some sites in Italy was reported to be from four in Modena to 11 in Calabria, and other European regions were reported to have only one $\mathrm{VC}$ type. On the other hand, $67 \mathrm{VC}$ groups were identified in Connecticut alone and, in 1978, a total of $37 \mathrm{VC}$ types was reported among 202 isolates from West Virginia (Anagnostakis \& Kranz, 1987).

The main source of VC diversity in North American C. parasitica is due to heteroallelism at multiple vic loci combined with sexual recombination. The presence of perithecia, the sexual fruiting body of this fungus, was reported by investigators in a number of European countries, but they are uncommon in most areas (Heiniger \& Rigling, 1994). The absence of perithecia does not necessary preclude the occurrence of genetic recombination. Data from six unlinked restriction fragment length polymorphism (RFLP) loci and DNA fingerprinting suggest that C. parasitica may have a mixed mating system with self-fertilization and outcrossing in the same population (Milgroom et al., 1993). Work of Rizwana and Powell also showed that UV light may induce changes in vegetative compatibility in C. parasitica, which may result in increased diversity of $\mathrm{VC}$ groups in natural populations (Rizwana \& Powell, 1992). Besides diversity of VC types in natural populations, other factors may contribute to the unsuccessful spread and persistence of hypovirulence such as overall reduction of robustness of hypovirulent strains and reduction of sporulation by some hypovirulent strains (Nuss, 1992). Nevertheless, the relatively higher VCG diversity in North America may explain the 
observed inability to control chestnut blight using VCG as a biological control as evident from laboratory transmission studies.

Cortesi el al. (2001) quantified the effect of heteroallelism at each of six vic loci on virus transmission. Significant variation was associated with respect to the different loci. It was shown that hypovirus transmission occurred in $100 \%$ of paired isolates that had no vic differences, or when vic4 differed between strains. Heteroallelism at vic3 and 6 resulted in $76 \%$ and $32 \%$ transmission, respectively. However, when strain pairs were heteroallelic at vic1,2 or 7 the frequency of virus transmission was dependent on the allelic constitution ( 1 or 2 ) of the donor and recipient isolates. That is, virus transmission was significantly asymmetrical in these cases. The average transmission frequencies with pairs of strains heteroallelic at one of vic1, 2 or 7 were $56 \%, 25 \%$ or $78 \%$, respectively.

Microscopic examinations with fungi have revealed some common characteristics of cells undergoing incompatible fusions, including septal plugging, vacuolization of the cytoplasm, organelle degradation and shrinkage of the cytoplasm away from cell wall (Glass et al., 2000). These alterations in cells are similar to characteristics associated with eukaryotic Programmed Cell Death (PCD) in higher eukaryotes. In higher eukaryotes PCD is involved in tissue development and immune system functions by eliminating non-functional cells or the cells that are infected with viral pathogens. Due to the presence of internal sensors, normal cells are prevented from entering into the PCD pathway. Cell death as a result of PCD is associated with chromatin condensation, DNA fragmentation, membrane blebbing, cell shrinkage, and compartmentalization of the dead cells into apoptotic bodies. The correlations between Programmed Cell Death (PCD) and vegetative incompatibility associated with six vic genes was investigated by Biella et al. 
(2002). Cytological results illustrated that all six vic genes elicit what appears to be a common PCD pathway based on similar appearance of cells leading up to death. The analysis of incompatibility reactions in $N$. crassa at the ultrastructural level showed similar phases leading up to PCD as were observed in C. parasitica (Jacobson et al. 1998), which may suggest that the PCD pathway is conserved in fungi. DNA fragmentation, one of the early features of PCD, was observed by TUNEL assays (terminal deoxyribonucleotidyl transferase) of het-c and $u n-24$ incompatible cells of $N$. crassa (Marek et al., 2003; A. Moss and ML Smith, unpublished).

Biella et al. (2002) also demonstrated that there is a negative correlation between the frequencies of cell death and virus transmission with pairs of isolates that differ at single vic loci. This suggested that PCD inhibited virus transmission. This study also revealed that the asymmetric cell death in pairs of individuals that were heteroallelic at vicl, 2 , and 7 correlated with asymmetric virus transmission. So, delay or reduced frequencies of cell death in a recipient isolate provides more opportunity for transmission of viral elements from an incompatible infected donor isolate. In addition, Biella and coauthors provided preliminary evidence that virus infection may have a negative or positive effect on the frequency of $\mathrm{PCD}$, and suggested that there may be a virus-vic gene interaction in this host-pathogen system (Biella et al., 2002). For example, a lower frequency of cell death in a virus-free recipient upon fusion with an infected donor could be the result of suppression of the incompatibility system by the virus. On the other hand, higher rates of cell death could be a response by the fungus to reduce virus transmission. 


\subsection{Objectives}

The objectives of this project were sequentially built upon to: (1) verify preliminary findings by Biella et al. (2002) that virus-vic gene interaction occur in this host-pathogen system, (2) use chimeric recombinant viruses from CHV1-EP713 and CHV1-Euro7 to identify factors, which interact with vic3-associated PCD in $C$. parasitica, (3) investigate the effects of ORF A from CHV1 genome on heterokaryon incompatibility and barrage formation, (4) determine the mechanism by which p29 affects PCD using analysis of protein-protein interactions, (5) analyze the p29 sequence to determine the domain responsible for PCD reduction, (6) investigate whether there is a connection between the role of $\mathrm{p} 29$ altering RNA silencing and nonself recognition, and (7) dissect the vic pathway using hypovirus p29 factor as a probe.

\section{MATERIALS AND METHODS}

Isolates of C. parasitica and growth conditions

Isolates used in this study are given in Table 1. Strains containing hygromycin B resistance or benomyl resistance plasmids are designated by "B" or " $\mathrm{H}$ ", respectively, following the original strain number. All the strains were grown on a laboratory benchtop at $\sim 22^{\circ} \mathrm{C}$. Benomyl resistant strains were obtained by transformation of spheroplasts of original strains with plasmids carrying the $b m l^{R}$ gene, as explained in Smith el al. (2006) and maintained on potato dextrose agar (PDA; Becton, Dickinson and Company, Sparks, MD) supplemented with $0.15 \mu \mathrm{g} / \mathrm{mL}$ benomyl (PDA+ben; Bonide Products, Inc., Yorkville NY). The hygromycin B-resistant isolate, $22.1 \mathrm{H}$, carries the $E$. coli hygromycin B phosphotransferase gene $h p h$ and was acquired from A. Churchill 
(Boyce Thompson Institute, Ithaca, New York). It was maintained on PDA supplemented with $30 \mu \mathrm{g} / \mathrm{mL}$ hygromycin (PDA+hyg; Roche Molecular Biochemicals, Mannheim Germany).

Plasmid pLDST (Figure 5) carries the full-length infectious cDNA clone of the parental hypovirus CHV1-EP713. Chimeric hypoviruses (Chen et al. 2000); R1, R2, R6, R12, R13, R14 (Figure 6) and mutants of $\Delta$ p29 (deletion of p29 region of CHV1-EP713), $\triangle \mathrm{p} 40$ (deletion of $\mathrm{p} 40$ region of CHV1-EP713), and $\Delta \mathrm{p} 69$ (deletion of p60 region of CHV1-EP713) are all described in Suzuki et al. (2003). pE7T-N plasmid contains the full length cDNA clone of CHV1-Euro7. Infection of each virus construct was established by transfection of virus-free EP155 isolate with in vitro synthesized viral transcripts, as explained by Chen et al (1994) with minor modifications. Plasmids PXH1 and PXH3 were constructed by insertion of $\mathrm{p} 29$ and $\mathrm{p} 40$ coding regions of CHV1-EP713 ORF A (Craven et al., 1993) into the pCPXHY1 transformation vector (Figure 7), respectively. This vector has unique cloning sites between the $C$. parasitica glyceraldehyde-3-phosphate dehydrogenase gene promoter (Pgpd) and terminator (Tgpd) for expression of cDNA inserts. This vector was used for construction of transformation plasmids CHV1-EP713-p29-flag, CHV1-Euro7-p29-flag, CH1, CH2, CH4, CH8 and CHV1-EP713-p29stop. Viral infection was achieved via transformation into a virus-free EP155 isolate. All C. parasitica isolates that were transfected or transformed were maintained on PDA, and then stored on glass microfibre filters at $-20^{\circ} \mathrm{C}$. 
Figure 5. Schematic diagram of pLDST plasmid used for synthesizing RNA transcripts of inserted hypovirus sequence (red) (Figure based on information from D. Nuss). 


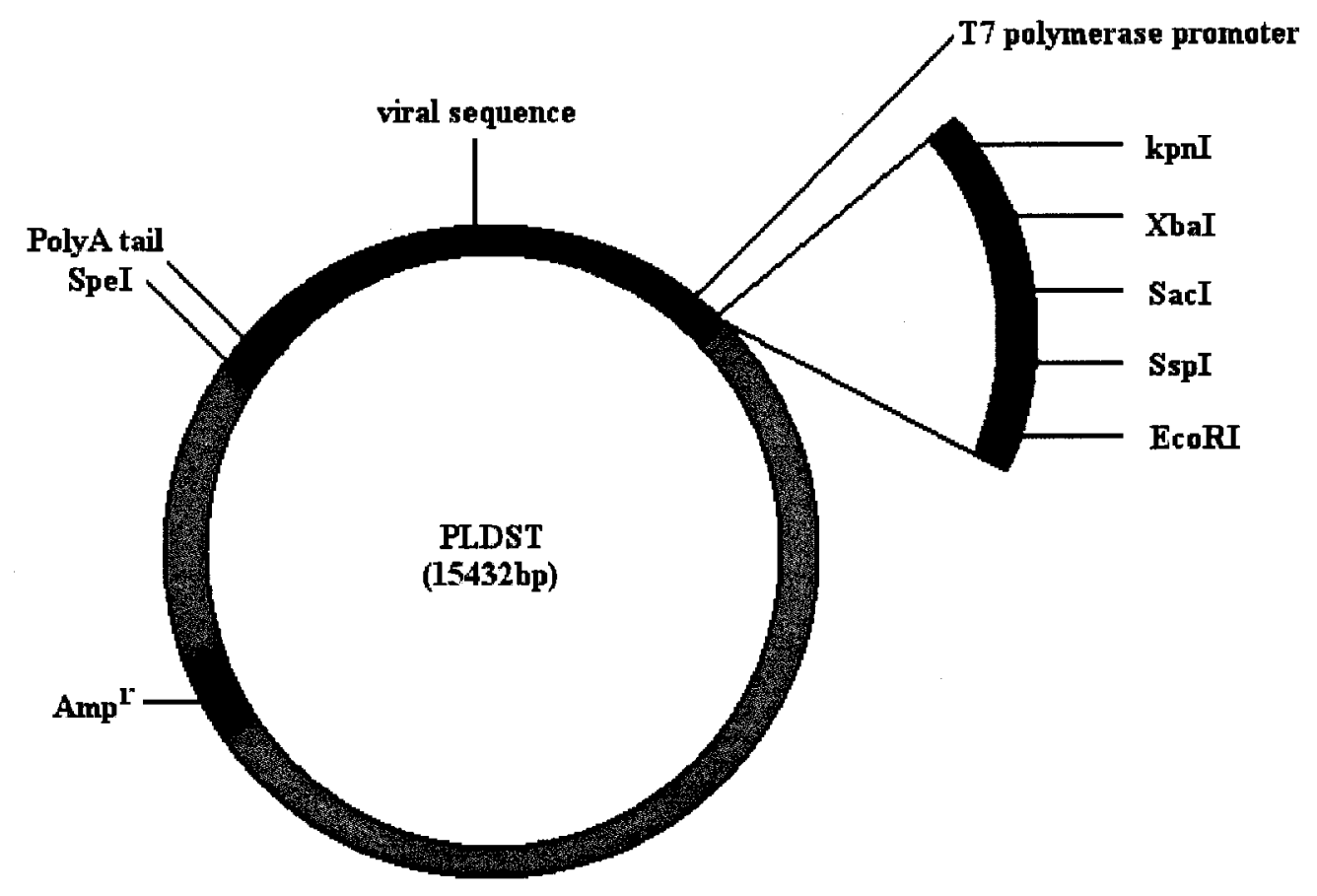


Figure 6. Schematic representation of parental hypoviruses CHV1-EP713 and CHV1Euro7 and their chimeric constructs used in this study (Modified from Parsley et al., 2002). 
ORF B

\section{ORF A}

Nar I

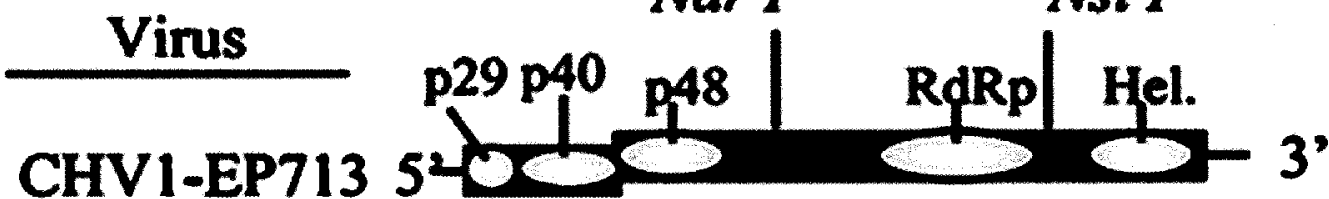

CHV1-Euro7 5- 3 '

Rl

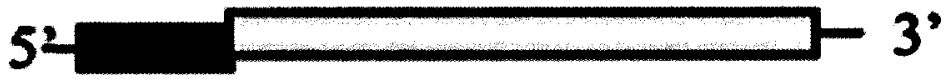

R2

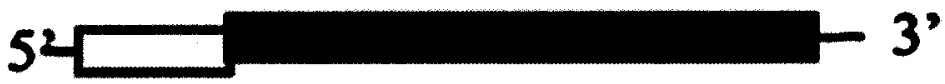

R13

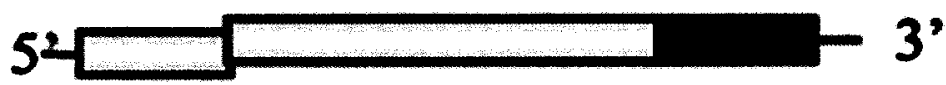

R14

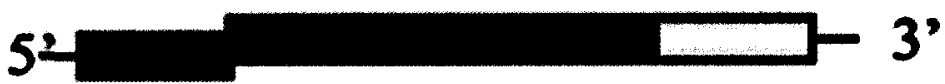

R12

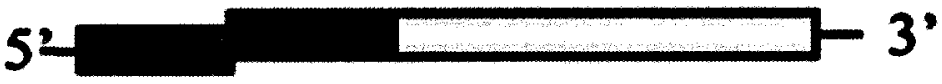

R6

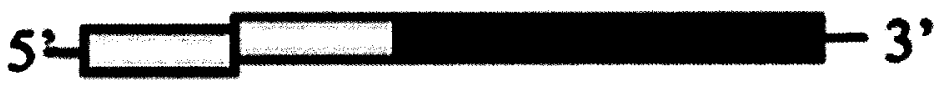


Figure 7. pCPXHY1 vector used for plasmid transformations (Craven et al., 1993) 


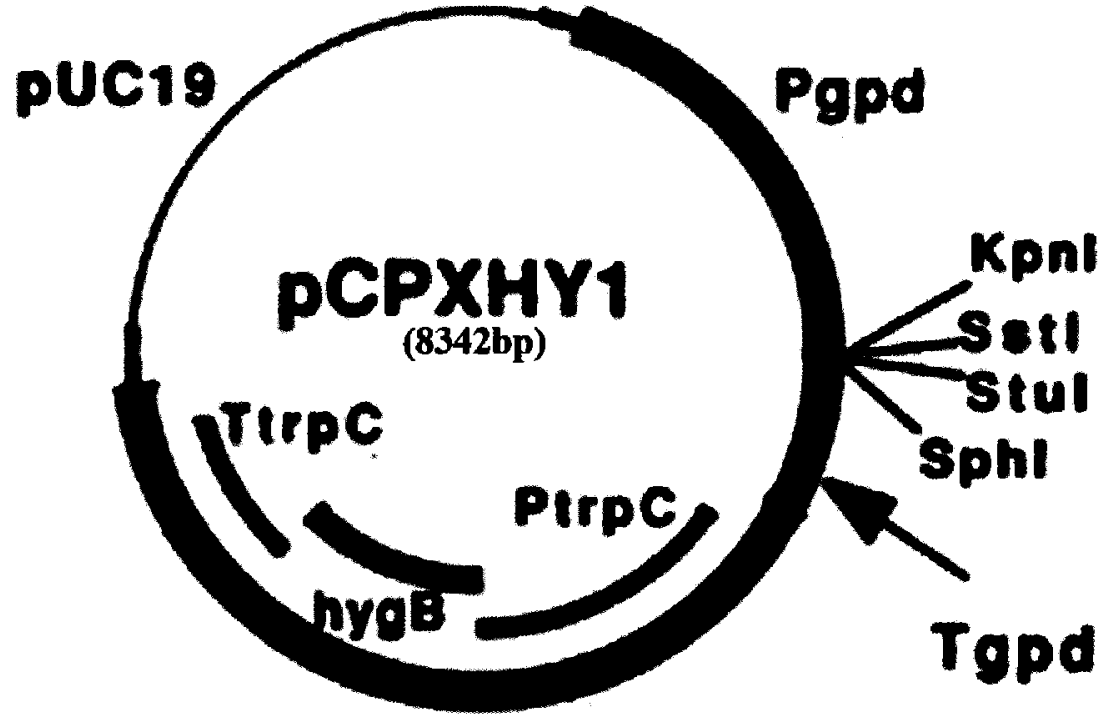


C. parasitica spheroplasts preparation

Spheroplasts were prepared using the Churchill et al. method (1990) with slight modifications. EP155 isolate was grown for approximately three weeks on PDA, homogenized in $200 \mathrm{~mL}$ Potato Dextrose Broth (PDB; Becton, Dickinson and Company) and allowed to regenerate overnight at $30^{\circ} \mathrm{C}$ with shaking at $150 \mathrm{rpm}$. The hyphal fragments were collected by centrifugation at $2,500 \mathrm{rpm}$ for 5 minutes at $4{ }^{\circ} \mathrm{C}$, washed twice with $0.6 \mathrm{M} \mathrm{MgSO}_{4}$ (Bioshop, Burlington Ontario), resuspended in $0.6 \mathrm{M} \mathrm{MgSO}_{4}$, and harvested by filtration using qualitative filter paper, grade 2 (Whatman, Maidstone, UK). Cells were resuspended in filter-sterilized Osmotic Medium [OM; $1.2 \mathrm{M} \mathrm{MgSO}_{4}$, $10 \mathrm{mM}$ sodium phosphate (Fisher Scientific, Ottawa Ontario) pH $5.8 ; 10 \mathrm{~mL} / \mathrm{g}$ mycelium] and transferred into a $250 \mathrm{~mL}$ flask and placed on ice. $\beta$-glucuronidase $(0.2$ $\mathrm{mL} / \mathrm{g}$ mycelium; Sigma-Aldrich, Oakville Ontario) and lysing enzymes from Trichoderma harzianum (20 mg/mL in OM; Sigma-Aldrich) were added to the flask and placed on ice for 5 minutes. Bovine serum albumin ( $12 \mathrm{mg} / \mathrm{mL}$ in OM; Sigma-Aldrich) was added to the cell suspension followed by incubation with shaking for 2 hours at $30^{\circ} \mathrm{C}$ at $80 \mathrm{rpm}$. For every $5 \mathrm{~mL}$ of cell suspension $10 \mathrm{~mL}$ of trapping buffer [0.4 M D-sorbitol (Sigma-Aldrich), $100 \mathrm{mM}$ Tris-HCl (Bioshop) pH 7.0] was added to the digestion solution, mixed thoroughly and filtered through autoclaved glass wool in a $50 \mathrm{~mL}$ syringe. This step was repeated until spheroplasts were completely separated from hyphal fragments and PDA residues. Spheroplasts were pelleted by centrifugation at $5,000 \mathrm{rpm}$ for 5 minutes at $4{ }^{\circ} \mathrm{C}$, and the pellet was washed once and resuspended in $1 \mathrm{M}$ sorbitol. 
Fungal transfection

in vitro transcription

Plasmid pLDST was used for synthesis of viral coding strand transcripts. Transcripts that were synthesized using this system included the full-length infectious cDNA clone of the parental hypovirus CHV1-EP713, chimeric hypoviruses (R1, R2, R6, $\mathrm{R} 12, \mathrm{R} 13$ and R14) and deletion mutants $(\Delta \mathrm{p} 29, \Delta \mathrm{p} 40$ and $\Delta \mathrm{p} 69)$. These transcribed segments are represented in Figure 13. The transcribed region within the pLDST plasmid is flanked at the 5' end by a T7 bacteriophage promoter (TAATACGACTCACTATAG) and at the 3' terminus by 22 adenosine residues, which coincides with that of the LdsRNA natural polyadenylate tail. Plasmids were amplified in DH5 $\alpha$ cells (Invitrogen, Burlington, Ontario), followed by extraction using Wizard plus miniprep DNA purification system (Promega, Nepean Ontario). For transcription, plasmids were linearized by digestion with SpeI (New England biolabs, Pickering Ontario), phenol/chloroform-extracted, EtOH-precipitated and resuspended in nuclease-free water. Prior to the transcription step glass instruments and centrifuge tubes were baked overnight at $240{ }^{\circ} \mathrm{C}$ in order to inactive any contaminating RNase. In addition, RNasefree pipette tips were used and all the solutions were treated with $0.1 \%$ diethyl pyrocarbonate (DEPC; Sigma-Aldrich) for 24 hours and autoclaved. Transcripts were generated using MEGAscript T7 Kit (Applied Biosystems, Streetsville Ontario). Reagents were mixed in the following order; nuclease free water (to final volume of 20 $\mu \mathrm{L})$, NTPs $(8 \mu \mathrm{L})$, SpeI-linearized pLDST plasmid ( $1 \mu \mathrm{g}), 10 \mathrm{X}$ reaction buffer $(2 \mu \mathrm{L})$, and enzyme mix $(2 \mu \mathrm{L})$. The reactions were incubated at $37^{\circ} \mathrm{C}$ for 2 hours followed by addition of $1 \mu \mathrm{L}$ DNAseI and 15 minutes incubation at $37^{\circ} \mathrm{C} .15 \mu \mathrm{L}$ of nuclease-free 
water and ammonium acetate (Sigma-Aldrich) were added and mixed thoroughly to stop the reactions. Synthesized RNAs were then extracted as followed: equal volume of phenol/chloroform/isoamyl alcohol (25:24:1), equal volume of chloroform/isoamyl alcohol (24:1), back-extracting the organic phase using $50 \mu \mathrm{L}$ nuclease-free water, and finally combining the aqueous phases. One volume of isopropanol was added to the aqueous phase and chilled at $-20^{\circ} \mathrm{C}$ overnight prior to centrifugation at $14,000 \mathrm{rpm}$ for 20 minutes at $4{ }^{\circ} \mathrm{C}$. Supernatants were removed and pellets containing RNA transcript were vacuum-dried and resuspended in $25 \mu \mathrm{L}$ nuclease-free water.

Virus transfection of $\mathrm{C}$. parasitica

EP155 virus-free spheroplasts $\left(1.5 \times 10^{7}\right.$ cells $\left./ 0.5 \mathrm{~mL}\right)$ were washed twice with 1 M sorbitol, centrifuged at $10,500 \mathrm{rpm}$ for 6 minutes at $4^{\circ} \mathrm{C}$, and resuspended in $0.5 \mathrm{~mL}$ cold $1 \mathrm{M}$ sorbitol. Approximately $10 \mu \mathrm{L}$ of RNA transcript solution $(0.5 \mu \mathrm{g} / \mu \mathrm{L})$ was mixed with $100 \mu \mathrm{L}$ spheroplasts along with 200 units RNasin (New England Biolabs) and incubated on ice for 5 minutes. A suitable concentration for transfection can be determined by running $1 \mu \mathrm{L}$ of transcript solution on agarose gel and staining with ethidium bromide. If the band is visible in the gel when viewed over a UVtransilluminator, then it is concentrated enough for transfection. The spheroplasttranscript solution was transferred to a $2 \mathrm{~mm}$ electroporation cuvette (BioCan Scientific Inc., Mississauga Ontario) and electroporated with Bio-Rad Gene Pulser (Bio-Rad, Mississauga Ontario) at $1.5 \mathrm{kV}, 200 \mathrm{ohm}, 25 \mu \mathrm{F}$. Immediately following electroporation, $750 \mu \mathrm{L}$ of cold $1 \mathrm{M}$ sorbitol was added before a 10 minute incubation on ice. $200 \mu \mathrm{L}$ of the electroporated cells were placed at the center of a $10 \mathrm{~cm}$ Petri dish and $20 \mathrm{~mL}$ of regeneration medium [0.1\% yeast extract (EMD Chemical Inc., Mississauga Ontario), 
$0.1 \%$ casein hydrolysate (Fluka, Oakville Ontario), $1 \mathrm{M}$ sucrose (Bioshop), and 1.6\% agar (Bioshop)] was poured into the dish from the edge of the plate towards the center. This keeps the cells at the center of the dish during the regeneration process. Plates were incubated overnight at room temperature, at which time excess sorbitol was discarded and plates were inverted and incubated at room temperature. After $2-4$ days, when hyphal growth was evident, small pieces of agar containing hyphae from the edge of the cultures were transferred to PDA plates for observation and further work.

Fungal Transformation

One-hundred $\mu \mathrm{L}$ of EP155 virus-free spheroplast solution and, $10 \mu \mathrm{L}(5-10 \mu \mathrm{g})$ of plasmid DNA were mixed together in a $15 \mathrm{~mL}$ Falcon tube and incubated on ice for 30 minutes. One mL of PTC buffer [40\% Polyethylene glycol 4000 (Bioshop), $100 \mathrm{mM}$ Tris- $\mathrm{HCl}$, pH 8.0, $100 \mathrm{mM} \mathrm{CaCl}_{2}$ (Fisher Scientific)] was added to the tube, mixed gently and incubated at room temperature for 30 minutes. One mL of STC (1 M D-sorbitol, 100 mM Tris- $\mathrm{HCl}, \mathrm{pH} 8.0,100 \mathrm{mM} \mathrm{CaCl}_{2}$ ) was added and mixed gently. The reaction mixture was placed onto empty Petri dishes as droplets of 100,250 , and $500 \mu \mathrm{L}$ to ensure the separation of individual transformants. $12.5 \mathrm{~mL}$ of Regeneration Medium at $46-48{ }^{\circ} \mathrm{C}$ was added slowly into the dishes from the edge toward the center to keep the cells at the center of dish. Plates were incubated at room temperature overnight and then $12.5 \mathrm{~mL}$ of Regeneration Medium $\left(46-48^{\circ} \mathrm{C}\right)$ containing $60 \mu \mathrm{g} / \mathrm{mL}$ hygromycin B was added as a top layer to all plates. Plates were incubated for a few days at room temperature until growth of colonies was evident in the medium. Individual colonies were transferred to PDA+hyg medium. 
Long term storage of strains

All strains, including those that were transformed or transfected, were grown on PDA plates to a radius of approximately $2 \mathrm{~cm}$ (usually about $48 \mathrm{~h}$ ). Autoclaved glass microfibre filters (GF/C; Whatman) were then placed on PDA plate at a distance of approximately $2 \mathrm{~mm}$ from the margin of the colony. Strains were incubated at room temperature until the glass fibre filters were completely covered with mycelium. The filters were then removed and transferred into small autoclaved paper envelopes, allowed to dry under the laminar flowhood (Microzone Corporation, Nepean Ontario) for 24 hours and stored at $-20^{\circ} \mathrm{C}$ in a sealed container containing desiccant.

Microscopy Assay

Slide preparation

Hyphal fusion between pairs of isolates was investigated using the protocol provided by Biella et al. (2002) with minor modifications. All isolates were inoculated on PDA plates and incubated at room temperature until the radius of colonies reached 2-3 $\mathrm{cm}$. Sterile glass microscope slides, $7.5 \times 2.5 \mathrm{~cm}$, were coated with a thin layer of molten PDA medium $\left(65^{\circ} \mathrm{C}\right)$ and allowed to dry on a bent glass rod, within a sterile glass Petri dish (Figure 8). Two layers of filter paper (\#1; Whatman) were placed underneath of the bent glass rod. Agar blocks of $\sim 0.5 \mathrm{~cm}^{3}$ were excised from the colony margin of each of two strains to be paired and placed approximately $1 \mathrm{~cm}$ apart on the slide such that the top surfaces were facing each other. Two $\mathrm{mL}$ of sterile $\mathrm{ddH}_{2} \mathrm{O}$ was poured onto the filter papers to maintain humidity in the chamber. Petri dishes were wrapped loosely with a plastic bag and incubated for 48 hours in the dark at room temperature. 
Figure 8. Schematic diagram of slide culture technique used for microscopy assays. 


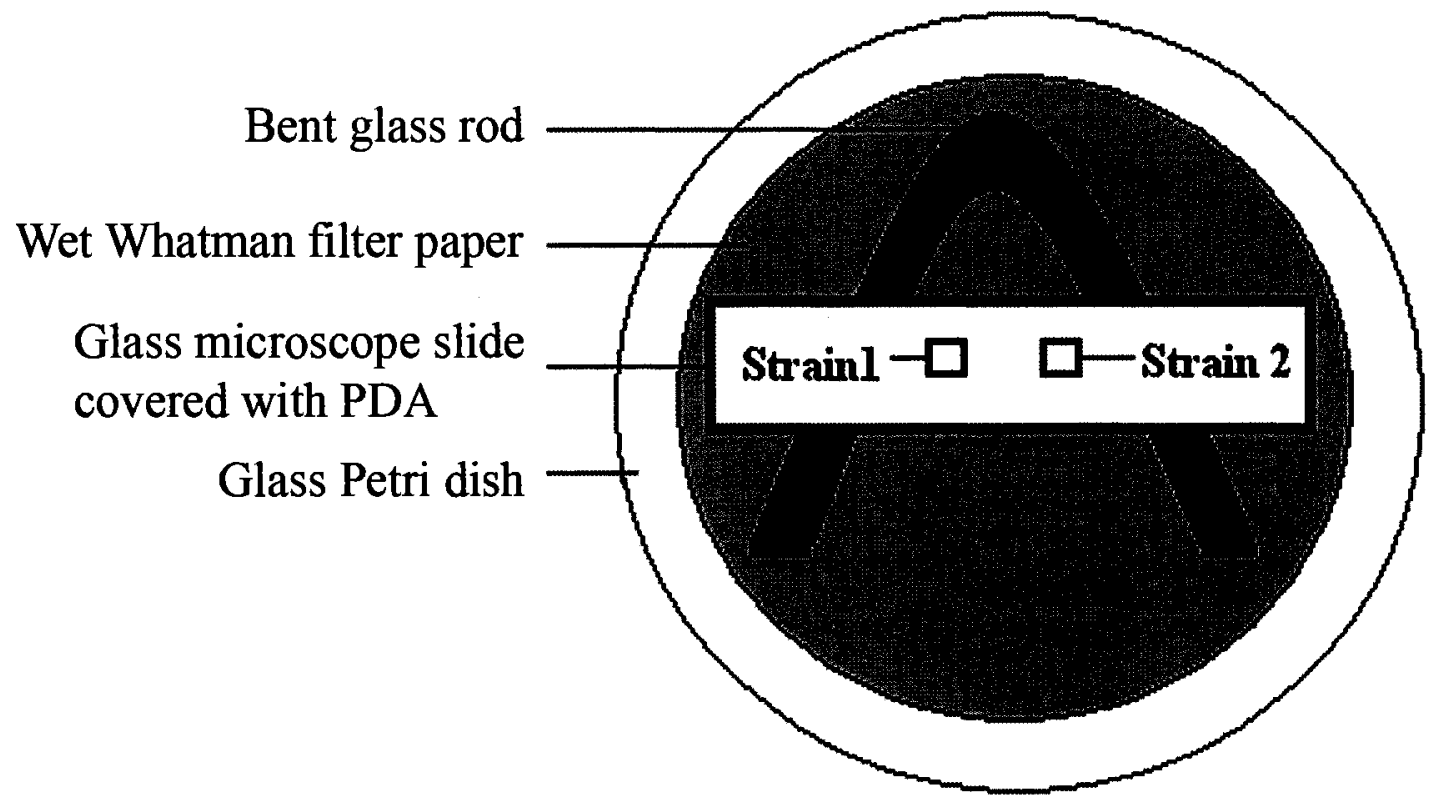




\section{Slide analysis}

To determine the cell death frequencies for each pair of isolates, slides were examined with Zeiss Axioplan 2 imaging microscope (Toronto, Ontario) under 20x and $40 \mathrm{x}$ objective lenses. The zone of interaction between the mycelia of two isolates was observed for cell fusion. Starting at a point of contact between two hyphae, each hypha was traced back from the fusion point toward the block to make sure that the fusion was between different isolates. Observation of areas with a high density of hyphae was avoided, since the individual hypha could not be easily traced back. Cytoplasmic shrinkage was selected as the criterion to identify cells undergoing PCD (Figure 9). For each hyphal contact, we recorded whether one, both, or neither of the two hyphae was undergoing PCD. Cell death frequency was expressed for each of the paired strains as the number of cells undergoing PCD over the number of hyphal contacts. 
Figure 9. Types of interactions observed under 40x magnification. Point of fusion in each panel is shown with arrow. (a) Compatible interaction without sign of PCD in hyphae of either strain. (b \& c) Incompatible fusions between p74-3 and EP155 infected with CHV1Euro7. In panel B isolate EP155-CHV1Euro7 shows vacuolization (v). In panel C, EP155-CHV1Euro7 shows cytoplasmic collapse (c). (d) Fusion of P74-3 and EP155-CHV1EP713 with both isolates displaying different stages of cell death. [v = vacuolization; $\mathrm{s}=$ cytoplasmic shrinkage; $\mathrm{c}=$ collapse of cell contents] 


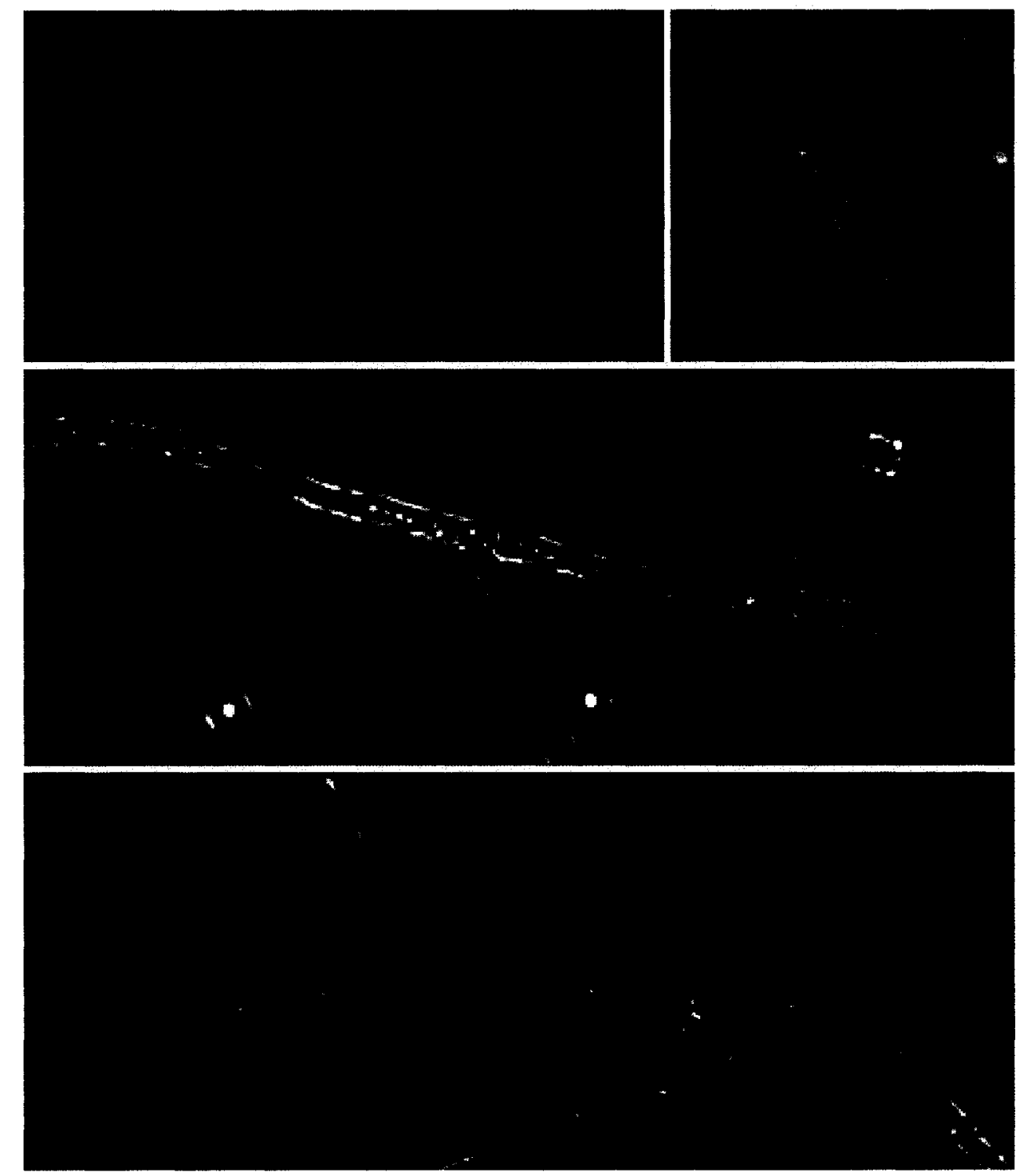


Heterokaryon incompatibility test

This test was done using the method described by Smith et al (2006) with slight modifications. Each strain was inoculated on PDA and incubated at room temperature until the colony radius reached $2-3 \mathrm{~cm}$. An autoclaved cellophane disk was placed onto a fresh PDA plate and allowed to dry (Figure 10). A $3 \mathrm{~mm}^{3}$ agar block from the colony margin of a benomyl-resistant strain was excised and placed on the cellophane disk at a distance of 2-3 $\mathrm{mm}$ from a similar inoculation block of a hygromycin-resistant strain. The Petri dishes were incubated at $30^{\circ} \mathrm{C}$ until contact of two mycelia was observed (usually about $24 \mathrm{~h}$ ). After contact, the cellophane disk was transferred to a new plate containing PDA and $0.15 \mu \mathrm{g} / \mathrm{mL}$ benomyl and $30 \mu \mathrm{g} / \mathrm{mL}$ hygromycin B (PDA+ben+hyg), and the colony margins were marked on the bottom of the Petri dish with indelible marker for subsequent observations of additional growth. Three days after the transfer, plates were examined for the presence of heterokaryotic outgrowths. To verify the outgrowth as heterokaryotic, small blocks from the outgrowth margin were transferred to PDA+ben+hyg plates and observed for rapid growth indicating double resistance. For pairings in which outgrowths were not evident, blocks were taken from the point of contact, transferred to PDA+ben+hyg, incubated at $30{ }^{\circ} \mathrm{C}$ and monitored for growth every day for a week. 
Figure 10. Schematic representation of technique used for heterokaryon incompatibility test. 


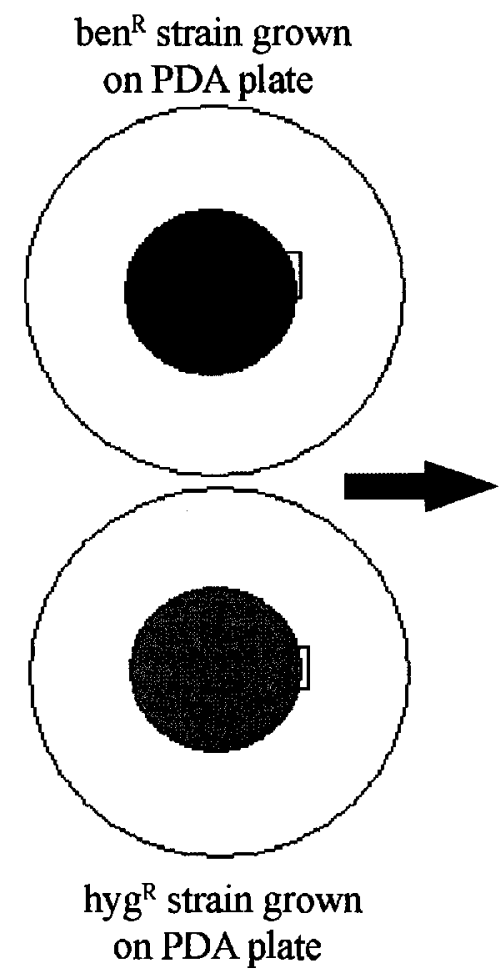

PDA plate overlayed with cellophane disk and inoculated with ben ${ }^{R}$ and hyg ${ }^{\mathrm{R}}$ strains

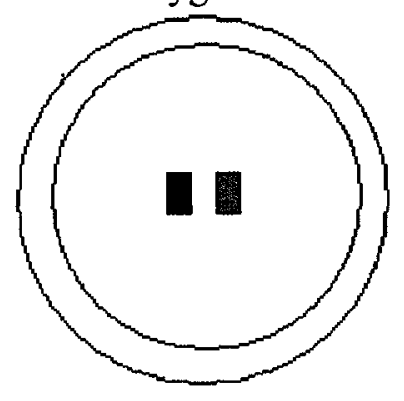

Transfer of Cellophane disk after growth of strains to $\mathrm{PDA}+\mathrm{Hyg}+\mathrm{Ben}$

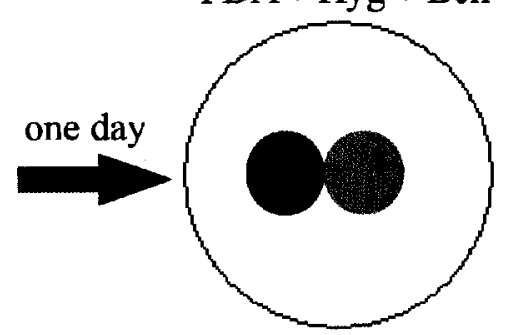

hk

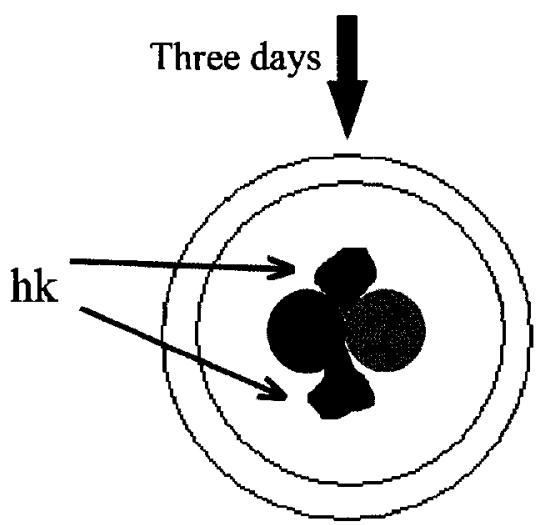

Examine for heterokaryon sectors (hk) on PDA + Hyg + Ben plate 
Mycelial incompatibility assay

Strains to be paired were inoculated separately onto PDA and incubated at room temperature until the colony radius reached $2-3 \mathrm{~cm}$. Two $\mathrm{mm}^{3}$ agar blocks from the colony margin of each strain were placed approximately $5 \mathrm{~mm}$ apart on PDAg plates (Powell, 1995). One litre of this medium contained $39 \mathrm{~g}$ PDA, $7 \mathrm{~g}$ malt extract (Becton, Dickinson and Company), $2 \mathrm{~g}$ yeast extract, $0.8 \mathrm{~g}$ tannic acid (BDH Chemicals Ltd, Poole England), $0.1 \mathrm{~g}$ methionine (Life Technologies Inc., Grand Island NY), $2 \mathrm{mg}$ biotin (Life Technologies Inc.), $2 \mathrm{mg}$ thiamine (added after autoclaving; Life Technologies Inc.), $20 \mathrm{~g}$ agar and $50 \mathrm{mg}$ bromocresol green (BDH Chemicals Ltd). Each PDAg plate contained eight pairs of isolates. Plates were incubated at $25^{\circ} \mathrm{C}$ for 10 days in the dark. Pairings that did not form a dark line were scored as compatible and pairs that did form a dark line were scored as incompatible. 
Table 1. Strains used in this study. 


\begin{tabular}{|c|c|c|c|}
\hline Isolate & vic genotype ${ }^{1}$ & EU-type & origin $^{2}$ \\
\hline EP155B & $2211-22$ & EU-5(vc40) & ATCC\#38755 from A. Churchill \\
\hline $22.1 \mathrm{H}$ & $2211-22$ & EU-5(vc40) & $h y g^{R}$ of EP155-2 from A. Churchill \\
\hline P1-11B & $2211-22$ & EU-5(vc40) & $\mathrm{PC} 17 \times \mathrm{PC} 7$ \\
\hline P10-2B & $2211-22$ & EU-5(vc40) & VO29 x PC7 \\
\hline P11-23B & $1211-22$ & EU-31 & P1-11 x P3-3 \\
\hline P1-5B & 1211-22 & EU-31 & $\mathrm{PC} 17 \times \mathrm{PC} 7$ \\
\hline$P 1-6 B$ & $2111-22$ & EU-6 & $\mathrm{PC} 17 \times \mathrm{PC} 7$ \\
\hline P42-7B & $2111-22$ & EU-6 & P1-11 x LI13 \\
\hline P74-3B & $2221-22$ & EU-60 & P1-11 x P50-16 \\
\hline P78-6B & $2221-22$ & EU-60 & P50-4 x P74-7 \\
\hline P4-4B & $2212-22$ & EU-1(ve10) & VO54 x PC7 \\
\hline P5-1B & $2212-22$ & EU-1(vc10) & VO54 x VO64 \\
\hline P10-18B & $2211-12$ & EU-21 & VO29 $\times$ PC7 \\
\hline MJ1-3-20B & 2211-12 & EU-21 & P17-8 x JA17 \\
\hline P24-33B & $2211-21$ & EU-18 & P4-4 x SA26 \\
\hline P32-35B & $2211-21$ & EU-18 & PC39 x VA35 \\
\hline EP29 16L1 & 2221-11 & EU-46 & MG Milgroom \\
\hline EP392 39L1 & 2111-11 & EU-9 & MG Milgroom \\
\hline P67-7 & $2121-22$ & EU-59 & $P 1-6 \times$ P25-6 \\
\hline P21-14 & $2122-22$ & EU-38 & P49-6 x P54-5 \\
\hline
\end{tabular}

${ }^{1}$ Alleles of each vic locus are given in order from vic1, 2, 3, 4, , 6, 7. Alleles that differed from those of EP155 are in bold.

${ }^{2}$ All strains expect EP155B and 22.1H are from crosses set up by MG Milgroom of Cornell University, Ithaca NY. 
Polymerase chain reactions

All constructs along with their specific primers prepared by polymerase chain reactions (PCRs) are listed in Table 2. Primers were manually designed and the melting temperatures were adjusted using OligoAnalyzer program (Integrated DNA Technologies, http://www.idtdna.com/home/home.aspx). All the primers were synthesized by Sigma-Aldrich Company. Expected amplicon sizes were verified by agarose gel electrophoresis in 1\% (w/v) agarose (Amresco, Guelph, Ontario) and ethidium bromide (Sigma-Aldrich) in 1x TAE [0.04 M Tris-acetate, $0.001 \mathrm{M}$ EDTA (Sigma-Aldrich)] and visualized by Alpha-Innotech UV illuminator (San Leandro, CA). Amplicons of the correct size were then sequenced at StemCore Laboratories (OHRI, Ottawa Ontario). PCR reactions were done in a final volume of $20 \mu \mathrm{L}$ and contained 2 $\mu \mathrm{L}$ of template ( $5 \mathrm{ng} / \mu \mathrm{L}$ ), $1 \mathrm{X}$ PCR buffer (Bioshop), forward and reverse primers, $1.5 \mu \mathrm{L}$ $\mathrm{MgCl}_{2}$ (25 mM; Bioshop), $0.4 \mu \mathrm{L}$ dNTPs (100 mM; Bioshop) and $0.2 \mu \mathrm{L}$ Taq DNA polymerase (5 units $/ \mu \mathrm{L}$; Bioshop). PCR reactions were performed in a Biometra ${ }^{\circledR}$ (Goettingen, Germany) TGradient thermocycler with the following reaction conditions: initial denaturation at $95^{\circ} \mathrm{C}$ for 5 minutes then 30 cycles of $95^{\circ} \mathrm{C}$ for 30 seconds, annealing for 30 seconds (temperature varies depending on the primer pairs), and polymerization at $72^{\circ} \mathrm{C}$ for 30 seconds. These cycle parameters were followed by $72{ }^{\circ} \mathrm{C}$ for 10 minutes and $4{ }^{\circ} \mathrm{C}$ for an indefinite time. $\mathrm{CH} 1$ and $\mathrm{CH} 2$ chimeras were constructed by the site-directed mutagenesis technique with sequence overlap extension as shown in (Figure 11). The procedure consisted of two rounds of PCR. The first round resulted in generation of two PCR products with overlapping ends from two different templates in separate reactions. In the subsequent round, PCR fragments were combined in a reaction 
to allow the overlapping ends to anneal and form a new template. The fused product was amplified further by PCR with external primers. 
Figure 11. Schematic representation of technique used for construction of chimeras. 


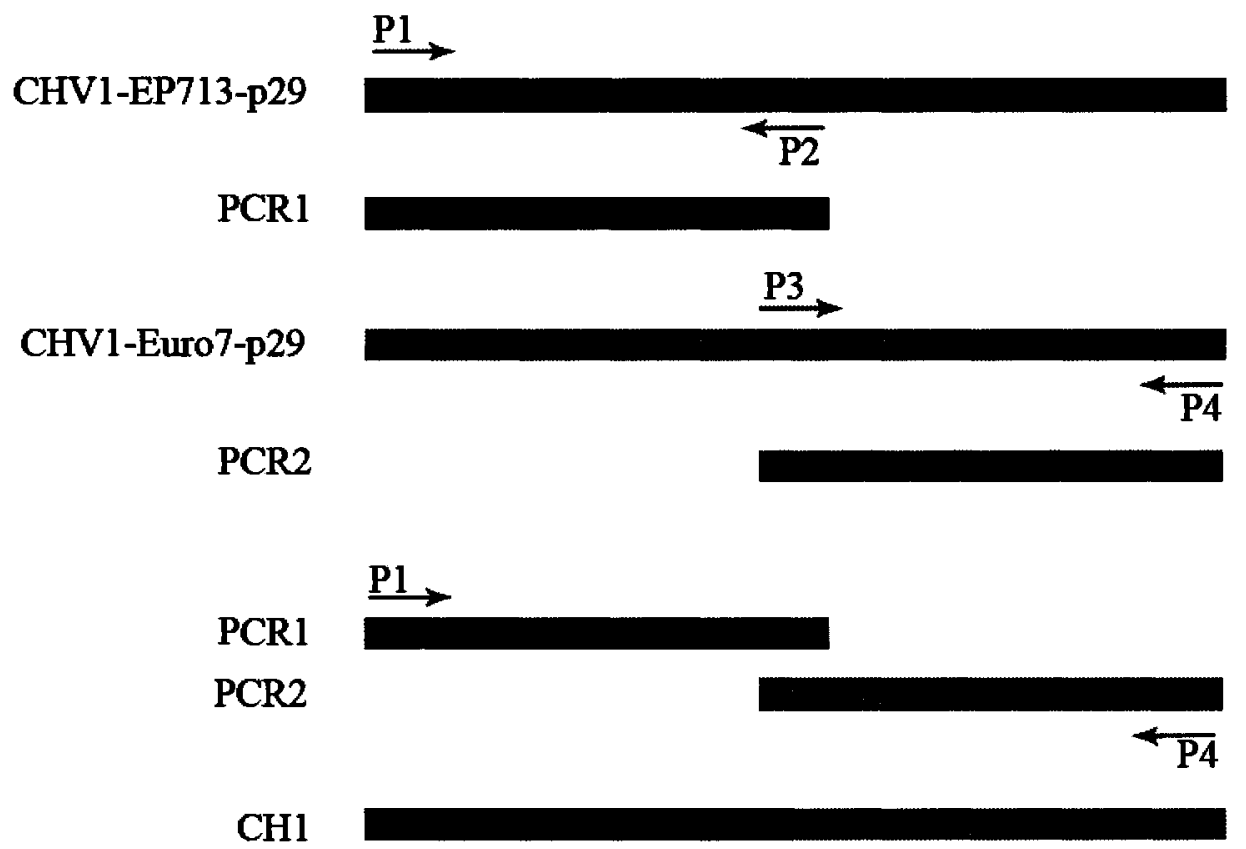


Table 2. Transformation plasmids along with their oligonucleotide primers used in this study. 


\begin{tabular}{|c|c|c|c|c|c|c|c|c|c|c|}
\hline & 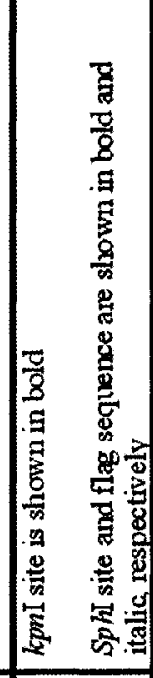 & 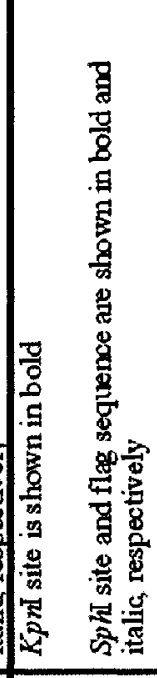 & 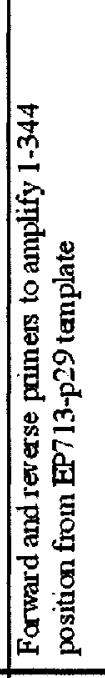 & 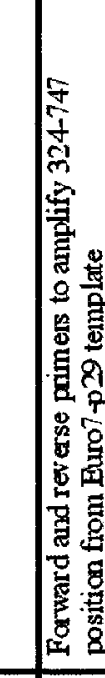 & \begin{tabular}{l|l} 
\\
\\
\end{tabular} & 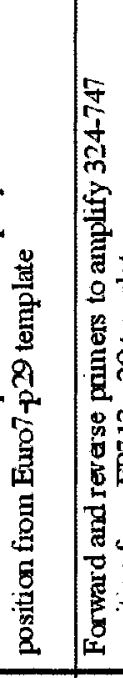 & . & 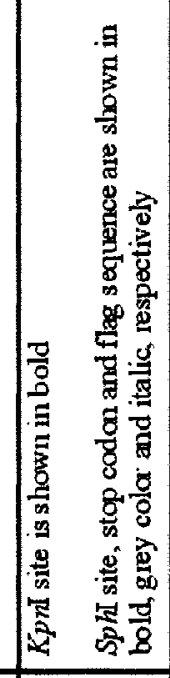 & 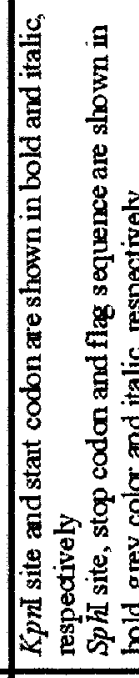 & 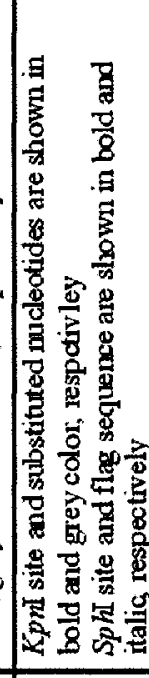 \\
\hline$\varepsilon$ & 说 & $\mid \begin{array}{ll}0 \\
0\end{array}$ & $\mid \begin{array}{ll}0 & 0 \\
0 & 0 \\
0 & 0\end{array}$ & $\begin{array}{l}0 \\
0\end{array}$ & 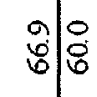 & : & ii & 品 & $\mid \begin{array}{ll}0 & 8 \\
0 & 0 \\
0 & 0\end{array}$ & 官 \\
\hline 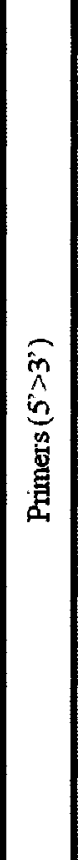 & 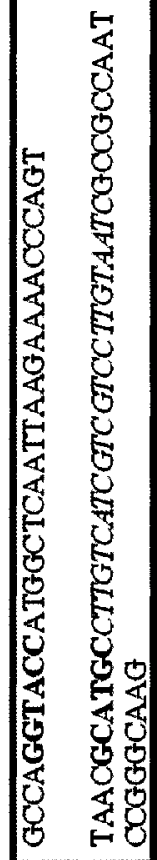 & 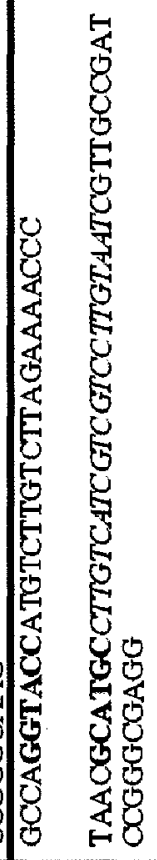 & 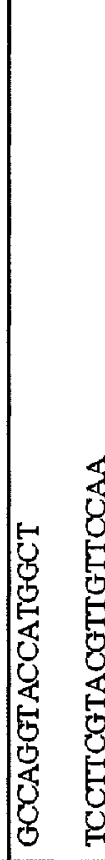 & 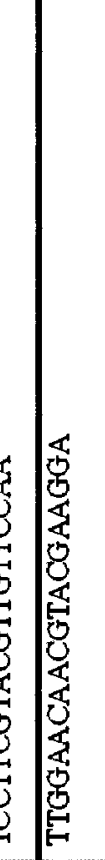 & 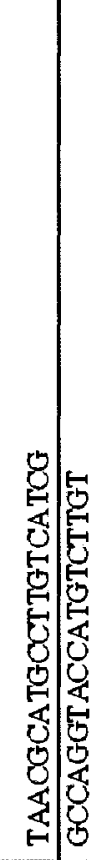 & 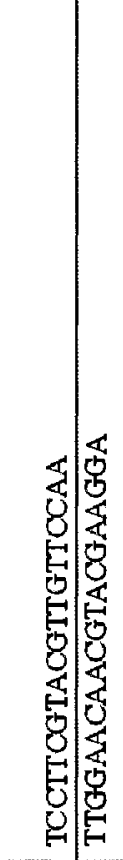 & 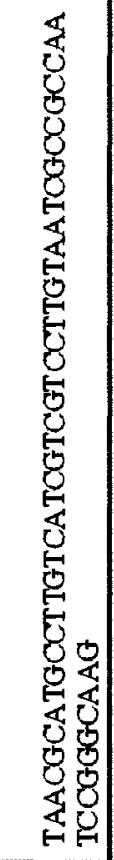 & 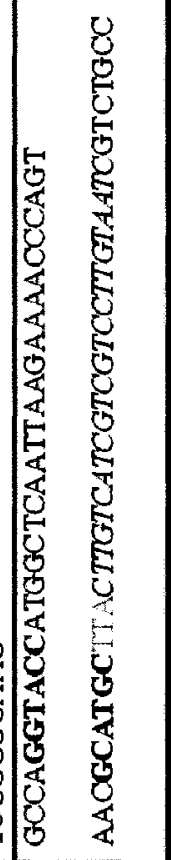 & 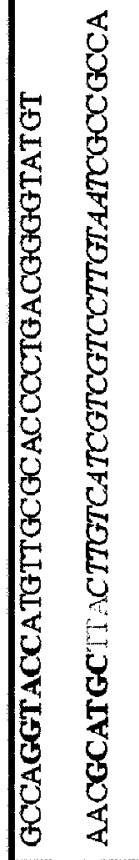 & 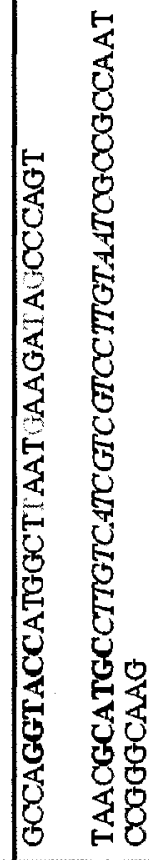 \\
\hline & 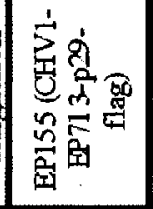 & 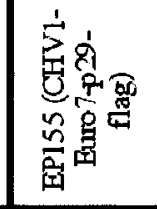 & & 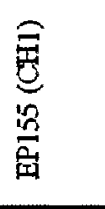 & & $\widehat{\mathcal{E}}$ & & $\begin{array}{l}\text { 焉 } \\
\text { 各 } \\
\text { 空 }\end{array}$ & $\begin{array}{l}\text { 愛 } \\
\text { 量 } \\
\text { 框 }\end{array}$ & 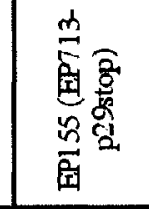 \\
\hline & 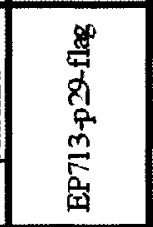 & 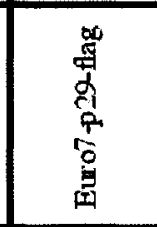 & & 案 & & U & & सु & $\dot{E}$ & $\begin{array}{l}5 \\
\text { के } \\
\text { के } \\
\text { के } \\
=\end{array}$ \\
\hline
\end{tabular}


DNA digestion and ligation

All PCR products were cloned into pCR2.1-TOPO vector using the TOPO TA cloning kit and the manufacture's protocol (Invitrogen). Inserts were then excised from TOPO TA by mixing $1 \mu \mathrm{g}$ of DNA, $5 \mu \mathrm{L}$ of digestion buffer (\#1; New England Biolabs), $1 \mu \mathrm{L}$ BSA (10 mg/mL; New England Biolabs), 2 units each of SphI and KnpI (New England) and up to $50 \mu \mathrm{L}$ of $\mathrm{ddH}_{2} \mathrm{O}$. Digests were incubated at $37^{\circ} \mathrm{C}$ for 2 hours, confirmed for expected fragment sizes and recovered following agarose gel electrophoresis. After DNA recovery, inserts were ligated into vector pCPXHY1. Each ligation reaction was composed of $30 \mathrm{ng}$ of insert, $90 \mathrm{ng}$ of vector digested as described above with SphI and KnpI, $2 \mu \mathrm{L}$ of 10X T4 DNA ligase buffer (New England Biolabs) and 5 units of T4 DNA ligase (New England Biolabs). Reactions were brought to $25 \mu \mathrm{L}$ of $\mathrm{ddH}_{2} \mathrm{O}$ and incubated overnight at $4{ }^{\circ} \mathrm{C}$.

DNA recovery from agarose gels

Following agarose gel electrophoresis, DNA bands were excised and mixed with 3 volumes of $\mathrm{NaI}$ (Sigma-Aldrich) and incubated at $55^{\circ} \mathrm{C}$ to melt the gel material. Ten $\mu \mathrm{L}$ of Glass Milk was then added to the solution and incubated overnight at $4{ }^{\circ} \mathrm{C}$. The sample was centrifuged at $14,000 \mathrm{rpm}$ for 30 seconds, the supernatant discarded and the pellet was washed twice with new wash buffer $(50 \mathrm{mM} \mathrm{NaCl}, 10 \mathrm{mM}$ Tris $\mathrm{pH}$ 7.6, 2.5 mM EDTA, 50\% EtOH). The pellet was dried briefly and then resuspended in $15 \mu \mathrm{L}$ $\mathrm{ddH}_{2} \mathrm{O}$, incubated for 5 minutes at $55^{\circ} \mathrm{C}$ and centrifuged at $14,000 \mathrm{rpm}$ for 1 minute. This step was repeated after transferring the supernatant to a fresh tube. Any glass milk 
residue was removed by centrifugation followed by measuring the DNA concentration with a NanoDrop 1000 spectrophotometer (Thermo Scientific, Wilmington, DE).

Fungal protein extraction

Total protein was extracted from each of three isolates of EP155 transformed with either CHV1-EP713-p29-flag, CHV1-Euro7-p29-flag or CHV1-EP713-p29. For this, each strain was inoculated onto a cellophane membrane that was overlayed on PDA and incubated at room temperature for 15 to 20 days. The mycelium was scraped off the membrane using a sterile spatula, and ground in a mortar and pestle with liquid nitrogen. Powder was transferred to an eppendorf tube along with $100 \mathrm{mg}$ of $0.5 \mathrm{~mm}$ glass beads (BioSpec Products Inc., Bartlesville OK) and 1 volume of disruption buffer [20 mM Tris.Cl (pH 7.9), $10 \mathrm{mM} \mathrm{MgCl}_{2}$ (Sigma-Aldrich), $1 \mathrm{mM}$ EDTA, 5\% glycerol (SigmaAldrich), 0.1 M DTT (Sigma-Aldrich), 0.3 M ammonium sulfate (BDH Chemicals Ltd.), $100 \mathrm{mM}$ PMSF (MP biomedicals, Solon $\mathrm{OH}$ ) and 1 protease inhibitor cocktail tablets (Roche)]. The tubes were vortexed at 13,000 rpm for 30 seconds and incubated on ice for 2 minutes. This step was repeated five times and tubes were centrifuged for one hour at $12,000 \mathrm{rpm}$ at $4^{\circ} \mathrm{C}$. Supernatant was removed and the protein concentration of each sample was measured using the Quick Start Bradford Protein Assay protocol from BioRad.

Affinity Purification using M2 Anti-flag Agarose Beads

The following components were mixed together in a $15 \mathrm{~mL}$ Falcon tube on ice: $100 \mu \mathrm{L}$ of anti-FLAG M2 antibodies bound to agarose beads (Sigma-Aldrich) along with 
$1 \mathrm{~mL}$ of Buffer A [50\% 2X Buffer $\{40 \mathrm{mM}$ Tris- $\mathrm{HCl}(\mathrm{pH} 8.0), 10 \mathrm{mM} \mathrm{MgCl} 2,20 \%$ glycerol, $0.2 \%$ Tween 20$\}, 25 \% 2 \mathrm{M} \mathrm{KCl}, 0.1 \%$ PMSF, $0.07 \% \beta$-mercaptoethanol (Sigma-Aldrich), and one mini-protease tablet]. The mixture was centrifuged for 3 minutes at $1000 \mathrm{rpm}$ and the supernatant was removed. The pellet was further centrifuged for 30 seconds at $1000 \mathrm{rpm}$ to completely remove the buffer. Extracted protein $(250 \mu \mathrm{g})$ was added to the tube, mixed gently and incubated for one hour at $4{ }^{\circ} \mathrm{C}$ on a platform shaker (Reliable Scientific Inc., Nesbit MS). After incubation, samples were centrifuged at $1000 \mathrm{rpm}$ for 3 minutes and supernatant was removed. The agarose beads were washed three times with Buffer A to remove any unbound protein. Bound protein was then eluted by incubating the beads with $30 \mu \mathrm{g} / \mathrm{mL}$ FLAG peptide (SigmaAldrich) for 30 minutes at $4{ }^{\circ} \mathrm{C}$ on a platform shaker followed by centrifugation at 1000 rpm for 3 minutes at $4{ }^{\circ} \mathrm{C}$.

SDS polyacrylamide gel electrophoresis (SDS-PAGE)

In this section a BioRad Mini Protean 3 gel system (Bio-Rad) was used. The glass plates were cleaned using ethanol and assembled according to the manufacturer's instructions. The resolving gel ( $12 \%$ acrylamide) was prepared by mixing the following components in order in a $50 \mathrm{~mL}$ falcon tube; $4800 \mu \mathrm{L}$ ddH $_{2} \mathrm{O}, 6300 \mu \mathrm{L}$ of $40 \%$ acrylamide/Bis solution (Bio-Rad), $3800 \mu \mathrm{L}$ of $1.5 \mathrm{M}$ Tris (pH 8.8), $150 \mu \mathrm{L} 10 \%$ sodium dodecyl sulfate (SDS; Bioshop), and $150 \mu \mathrm{L}$ of $10 \%$ ammonium persulfate (APS; SigmaAldrich). Ten $\mu \mathrm{L}$ of N, N, N', N'-Tetramethylethylenediamine (TEMED; SigmaAldrich) was added to the mixture, swirled quickly and poured into the gap between the glass plates. One $\mathrm{cm}$ of space at the top was left empty and overlaid with $\mathrm{ddH}_{2} \mathrm{O}$. The 
gel was allowed to polymerize for 20 minutes at room temperature. After polymerization, water was removed and the stacking gel was added. The stacking gel was prepared by mixing; $4060 \mu \mathrm{L}$ of ddH2O, $880 \mu \mathrm{L}$ of $40 \%$ acrylamide/Bis solution, $1660 \mu \mathrm{L}$ of $1.5 \mathrm{M}$ Tris (pH 8.8), $66 \mu \mathrm{L} 10 \%$ SDS and $66.8 \mu \mathrm{L}$ of $10 \%$ APS. After addition of $10 \mu \mathrm{L}$ of TEMED, the solution was swirled quickly and added onto the polymerized resolving gel. A clean comb was inserted into the stacking gel without creating any air bubbles and the gel was incubated at room temperature for another 20 minutes. After polymerization and removing the comb, the gel was mounted to the electrophoresis apparatus, placed in the chamber and filled with reservoir buffer [25 mM Tris, $250 \mathrm{mM}$ glycine (Sigma-Aldrich), 0.1\% SDS]. Each protein sample was prepared by mixing $15 \mu \mathrm{g}$ of protein with $10 \mu \mathrm{L}$ of SDS gel-loading buffer ( $50 \mathrm{mM}$ Tris, $\mathrm{pH} 6.8$, $100 \mathrm{mM}$ dithiothreitol, $2 \%$ SDS, $0.1 \%$ bromophenol blue, $10 \%$ glycerol) and incubating at $80^{\circ} \mathrm{C}$ for 10 minutes. Samples were centrifuged at high speed for one minute and loaded into wells of the gel along with $10 \mu \mathrm{L}$ of precision plus protein kaleidoscope standard (Bio-Rad). After attaching the apparatus to the power supply, a voltage of 150 $\mathrm{V}$ was applied until the dye moved into the resolving gel. The voltage was then increased to $225 \mathrm{~V}$ and allowed to run until the bromophenol blue reached to the bottom of the resolving gel.

Staining SDS-PAGE gels with coomassie brilliant blue in preparation for mass spectroscopy

All the following steps should be carried out using clean dishes and the gel should be covered with saran wrap at all times and never touched with bare hands. The SDS- 
PAGE gel was fixed in $100 \mathrm{~mL}$ of methanol/acetic acid (Anachemia, Mississauga ON) $(25 \%: 10 \% \mathrm{v} / \mathrm{v})$. A staining solution was prepared by dissolving $0.25 \mathrm{~g}$ of Coomassie Brilliant blue (Fluka) in $90 \mathrm{~mL}$ of $50 \%$ methanol and $10 \mathrm{~mL}$ of glacial acetic acid followed by filtration using $25 \mathrm{~mm}$ syringe filters (Cellulose Acetate membrane; Ultident, St. Laurent QC). The gel was immersed in $100 \mathrm{~mL}$ of staining solution and incubated for 2 hours on a platform shaker. After removing the staining solution, the gel was destained for 4 hours in $25 \%$ methanol with $10 \%$ acetic acid and $65 \% \mathrm{ddH}_{2} 0$. The destaining solution was changed 3 to 4 times during this period. The gel was stored in $7.5 \%$ acetic acid, wrapped in saran wrap at $4{ }^{\circ} \mathrm{C}$. Mass spectroscopy was performed at the National Research Council Canada (Ottawa, Ontario) using Liquid Chromatography coupled to electrospray ionization mass spectrometry (LC/MS).

\section{Western blotting}

Two porous pads, two Mini Trans-Blot filter papers (Bio-Rad) and one piece of nitrocellulose membrane (Bio-Rad) cut to similar size as the SDS-PAGE gel were soaked in transfer buffer (39 mM glycine, $48 \mathrm{mM}$ Tris base, $20 \%$ methanol) prior to assembly. After running SDS-PAGE gels, the apparatus was disassembled and the glass plates were slowly separated from the gel. The stacking gel was removed from the resolving gel and the transfer apparatus was set up on a gel holder cassette in the order from anode $(+)$ to cathode (-): porous pad, filter paper, nitrocellulose filter, gel, filter paper and porous pad. A glass pipette was used to roll and remove air bubbles as each layer was applied. The cassette was placed into the trans-blotting module and positioned into the buffer tank along with an ice pack and fresh transfer buffer. Thirty volts was applied overnight at 
$4^{\circ} \mathrm{C}$. On the following day, the transfer apparatus was disassembled and the protein standard markers were marked on the membrane using a fine pencil. The membrane was incubated at room temperature in the following solutions: 1 hour with gentle shaking in blocking solution [5\% fat-free dried milk in 1\% Tris-Buffered Saline Tween-20 (TBST; 9 $\mathrm{mL}$ of Tris $\mathrm{HCl} \mathrm{pH} 8.0,27 \mathrm{~mL}$ of $5 \mathrm{M} \mathrm{NaCl}$ and $900 \mathrm{~mL}$ Tween-20 in $900 \mathrm{ddH}_{2} \mathrm{O}$ )]; vigorous shaking $4 \times 15$ min each in 1\% TBST; very gently shaking for 1 hour in $10 \mathrm{~mL}$ of blocking solution with $10 \times \mu \mathrm{L}$ anti-FLAG M2 peroxidase conjugate antibody (1:1000) (Sigma-Aldrich); finally, vigorous shaking for $15 \mathrm{~min}$ in $1 \%$ TBST. After removing the excess buffer, the membrane was incubated with Chemiluminescent peroxidase substrate 3 (Sigma-Aldrich) according to manufacture's protocol, wrapped in plastic wrap and exposed to Kodak BioMax light film (Sigma-Aldrich) for 2 minutes and developed with Kodak developer (Sigma-Aldrich) and Kodak fixer (Sigma-Aldrich) according to manufacture's instructions.

\section{RESULTS}

Effect of viral infection on C. parasitica phenotype

The effects of wild-type and chimeric hypoviruses in altering the phenotypic traits of $C$. parasitica are shown in Figure 12. The key characteristics that were evaluated were growth rate and mycelial pigmentation patterns. Compared to the EP155 virus-free strain (A2 in Figure 12), the EP155 strain transfected with CHV1-EP713 had a slower growth rate and lacked conidia resulting in a non-pigmented colony (data not shown). In contrast, the CHV1-Euro7 transfected EP155 strain (A3) had an intermediate level of pigmentation and slightly slower growth rate compared to the EP155 strain. The 
phenotypes of EP155 strains bearing chimeric viruses were compared with the above virus-free, and transfected CHV1-EP713 and CHV1-Euro7 forms of EP155 (Table 3). The transfected isolates all had similar growth rates to CHV1-Euro7, except for those bearing the R1 (B1) and R6 (B3) chimeras, which grew more slowly, similar to EP155CHV1EP713. In terms of pigmentation, most isolates had a similar pattern as EP155CHV1Euro7. Among transfected strains only EP155 (R6) and EP155 (R13) (C1) had phenotypes that were similar to those described in the papers published by Nuss's group (Chen et al., 2000; Suzuki et al., 2003). 
Figure 12. Colony morphologies of $C$. parasitica isolates with and without transfected viruses. Across the top are isolates of virus-free P74-3 (A1) and EP155 (A2) and EP155 transfected with CHV1-Euro7 (A3) and chimeric viruses (B1, R1; B2, R2; B3, R6; B4, R12; C1, R13; C2, R14; C3, PXH3; C4, PXH1; D1, $\Delta$ p29; D2, $\Delta$ p69; D3, $\Delta$ p40). Isolates were maintained on PDA for 10 days on the laboratory bench at room temperature prior to photographing. 


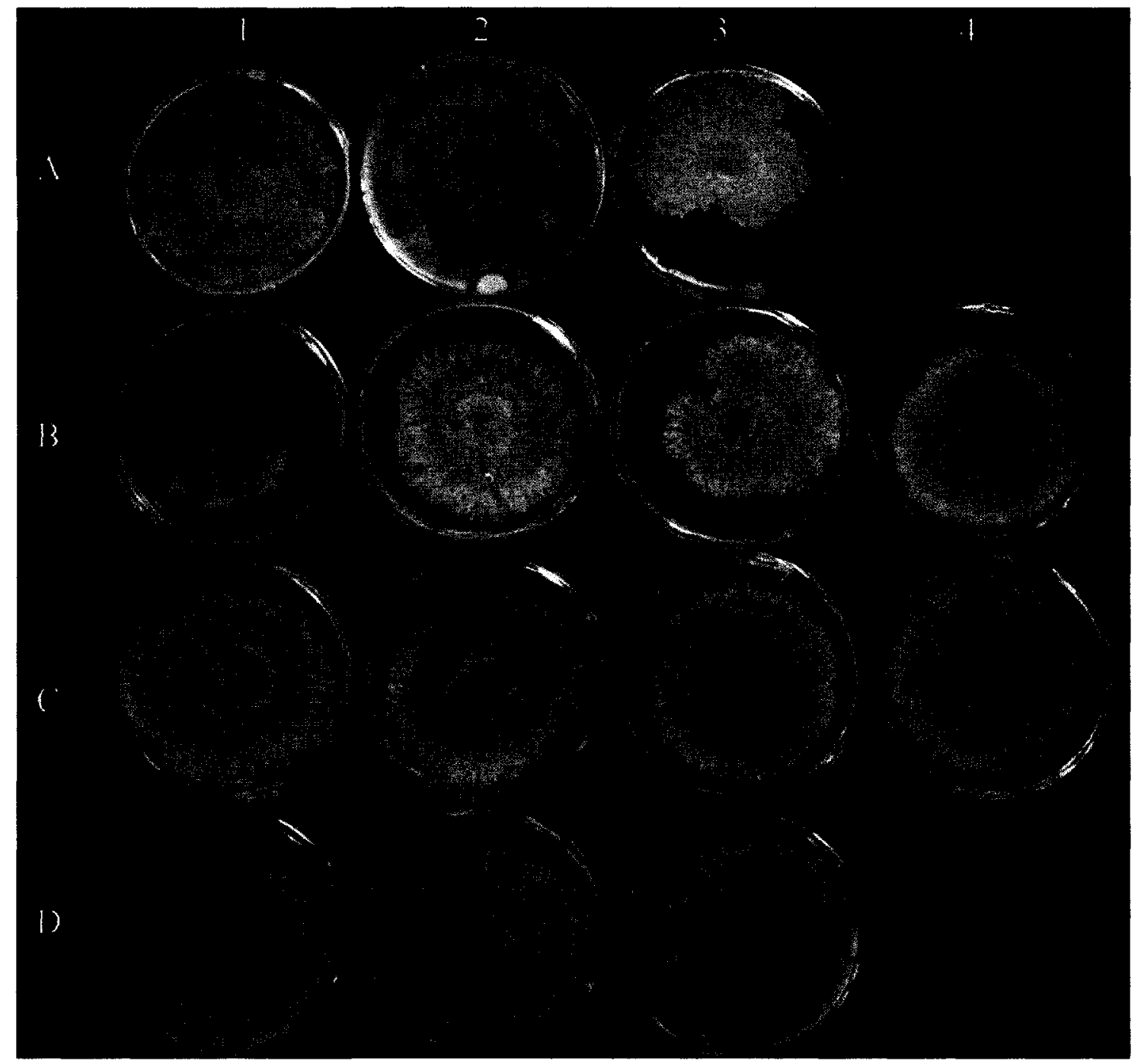


Table 3. Effect of chimeric hypovirus transfection on colony morphology. Pigmentation level of transfected strains were compared with EP155 virus-free $(++)$, and transfected with CHV1-EP713 (-) and CHV1-Euro $7(+)$. Growth rates are based on the diameter $(\mathrm{mm})$ of each colony grown on PDA under standard laboratory conditions over 10 days period. 


\begin{tabular}{|c|c|c|c|}
\hline Strain & Pigmentation & Growth rate (mm/day) & Position on Figure 12 \\
\hline EP155 (wild-type) & ++ & 8.5 & A2 \\
\hline EP155 (CHV1-EP713) & - & 4.3 & - \\
\hline EP155 (CHV1-Euro7) & + & 6.8 & A3 \\
\hline EP155 (R1) & ++ & 4.9 & B1 \\
\hline EP155 (R2) & - & 6.8 & B2 \\
\hline EP155 (R6) & + & 6.5 & B3 \\
\hline EP155 (R12) & ++ & 6.8 & C1 \\
\hline EP155 (R13) & + & 7.8 & C2 \\
\hline EP155 (R14) & + & 7.7 & D1 \\
\hline EP155 ( $\triangle \mathrm{p} 29)$ & + & 7.7 & D3 \\
\hline EP155 ( $\Delta \mathrm{p} 40)$ & + & 7.8 & D2 \\
\hline EP155 ( $\Delta \mathrm{p} 69)$ & + & 7.7 & \\
\hline
\end{tabular}


Effect of chimeric recombinant viruses on PCD

Infected and non-infected isolates are designated throughout this thesis as donor and recipient, respectively. Strains bearing transfected constructs are designated by the strain number followed by the construct designation in parentheses. Confrontations between P74-3 and each of EP155, EP155 (CHV1-EP713) and EP155 (CHV1-Euro7) were used as controls in all microscopy experiments and as reference points to compare the effects on PCD of various virus constructs. Confrontations between the uninfected strains, P74-3 and EP155, yielded very high PCD rates of $\sim 91 \%$, representing the incompatibility effects associated with vic3 allelic differences in these two isolates. Confrontations of P74-3 and EP155 (CHV1-EP713) resulted in significantly lower frequencies of PCD at contact points (32\% and $24 \%$ in donor and recipient, respectively) compared to those involving P74-3 and EP155. Confrontations between P74-3 and EP155 (CHV1-Euro7) yielded a less pronounced drop in PCD frequencies (52\% and $41 \%$ in donor and recipient, respectively).

As illustrated in the left portion of Figure 13, chimeric hypoviruses were prepared by interchanging different domains of CHV1-EP713 and CHV1-Euro7 using restriction sites available within the viral genomic cDNAs. For example, the R1 chimera was constructed with the ORF A of the CHV1-EP713 and ORF B of CHV1-Euro7. Confrontations between P74-3 and each of EP155 (R1), EP155 (R14) and EP155 (R12) resulted in relatively low PCD frequencies, similar to confrontations involving EP155 (CHV1-EP713). On the other hand, pairing P74-3 with either EP155 (R13) or EP155 (R6) resulted in PCD frequencies that were more similar to those involving EP155 (CHV1-Euro7). Surprisingly, R2 resulted in very high PCD frequencies that were similar 
to those involving the non-infected strains. Nevertheless, the combined results suggested that vic3-associated PCD reduction is correlated to ORF A characteristics.

Strains transfected with CHV1-EP713 constructs with deletions in ORF A, namely $\Delta \mathrm{p} 69, \Delta \mathrm{p} 40$ and $\Delta \mathrm{p} 29$, suggested that regions encoding both $\mathrm{p} 29$ and $\mathrm{p} 40$ proteins are involved in reducing the rate (or frequency) of vic3-associated PCD (Figure 13). The $\Delta$ p69 construct had negligible effects on PCD compared to uninfected pairings.

Deletions of either $\mathrm{p} 29$ or $\mathrm{p} 40$ had intermediate reductions in PCD compared to the noninfected control confrontations. In any event, analysis of these deletion constructs further support our previous results that ORF A is associated with reduction in vic3associated PCD. Further supporting this ORF A role, EP155 strains were transformed to constitutively express copies of either p29 or p40. Confronting either of these two strains with P74-3 yielded very few hyphal contacts that had evidence of PCD (Figure 13). 
Figure 13: Clustered bar representation of viral constructs (left) and associated cell death frequencies (right). Isolate P74-3 is the virus recipient and EP155 is the donor of virus constructs. Donors were transfected with freshly prepared dsRNA (below horizontal line) or transformed (above the line) with plasmids PXH3 and PXH1 that constitutively express p 40 and $\mathrm{p} 29 \mathrm{cDNA}$, respectively. Bars at right show mean cell death frequencies $( \pm$ SD) for recipient (blue) and donor (red) cells based on microscopical examination of over 100 hyphal contacts for each strain pair. 


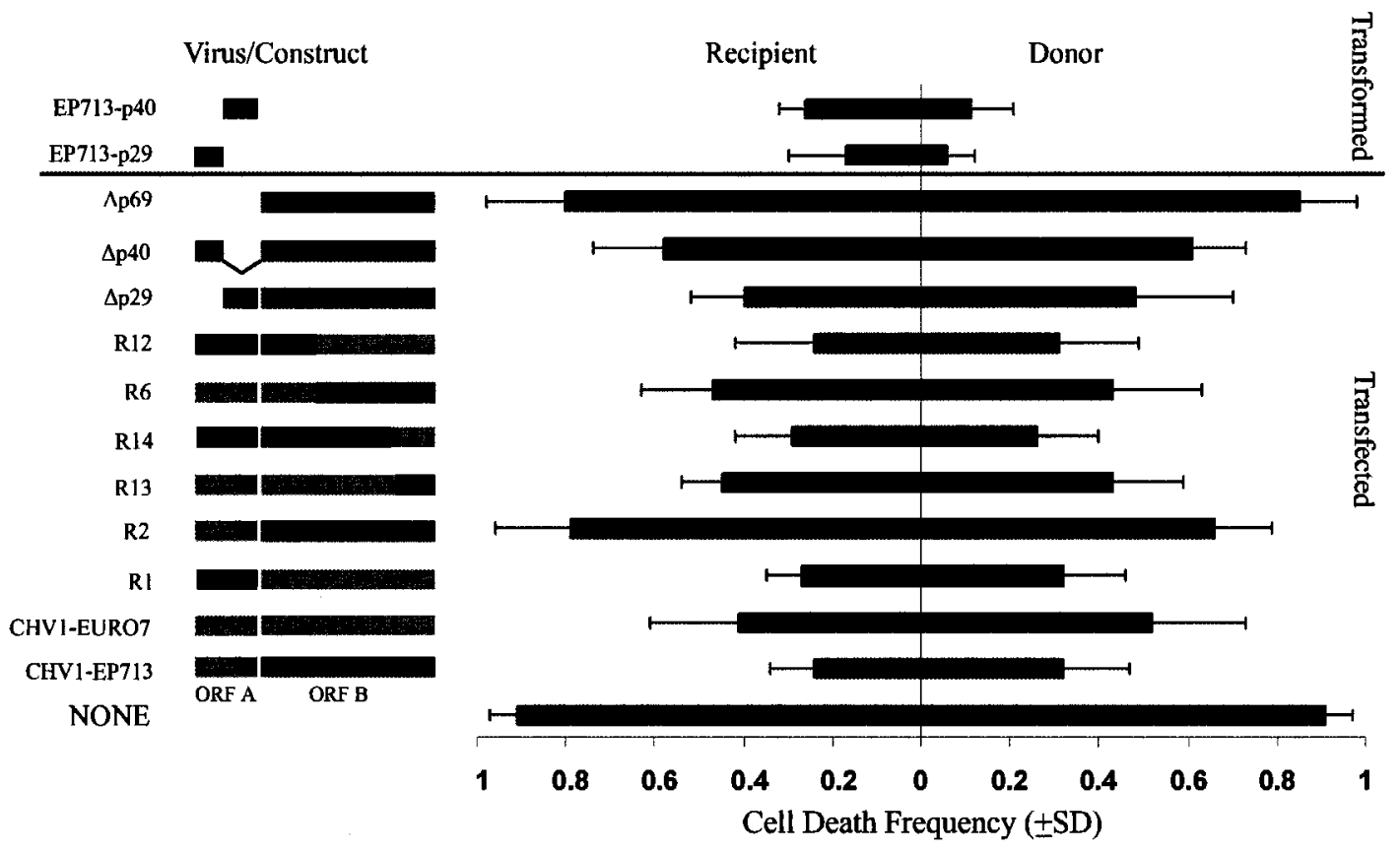


Vegetative incompatibility

Heterokaryon incompatibility tests

This assay was performed by confronting each of the hygromycin-resistant isolates 22.1H, EP155 (PXH1) or EP155 (PXH3) against each of 13 benomyl-resistant isolates containing the same or different alleles at one of each of six vic loci. Strain $22.1 \mathrm{H}$ is a hygromycin resistant derivative of EP155. As detailed in Figure 7 plasmids PXH1 and PXH3 confer hygromycin resistance and constitutively express cDNAs of the p29 and p40 components of ORF A, respectively. The colonies were inoculated as pairs and allowed to grow together on cellophane overlaid on PDA. After contact, the cellophane with paired colonies was transferred to PDA+hyg+ben medium and observed for 1 week for the presence or absence of heterokaryotic outgrowths (Figure 14). Outgrowths were observed when pairs of isolates contained the same alleles at all six vic loci or differed only at vic4, as previously reported by Smith et al. (2006). In order to verify the outgrowths as heterokaryotic, small blocks from the margins of outgrowths were transferred to the PDA+ben+hyg plates and the growth rates were recorded (Figure 15). In cases where no outgrowths were observed, blocks were taken from the point of contact between the pairs of isolates. Pairings that differed at any of vic1, 2, 3, 6, or 7 did not show any outgrowths regardless of whether p29 or p40 were expressed, and were not observed to grow upon transfer to fresh PDA+ben+hyg. Heterokaryon incompatibility characteristics were not, therefore, altered by the viral components that had effectively reduced PCD. 
Figure 14: Heterokaryon outgrowth (hk) from EP155B and $22.1 \mathrm{H}$ pairing (vic-

compatible) (a). In comparison, the outgrowth is absent in pairing of strains $22.1 \mathrm{H}$ and P74-3 that differ at vic3 (b). 
a)

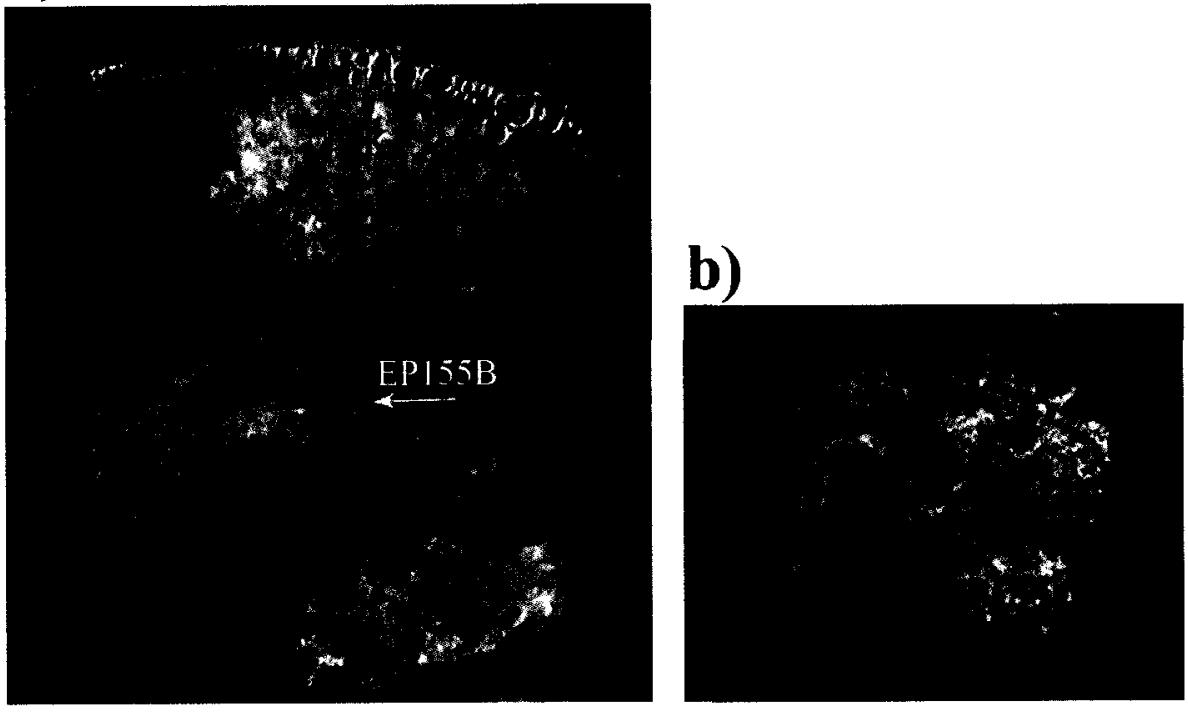


Figure 15: Growth rates of heterokaryotic sectors obtained from confronting hygromycinresistant isolates of 22.1H, PXH1 or PXH3 against each of the 13 benomyl-resistant isolates labeled across the bottom. vic differences for pairings are specified across the top. 


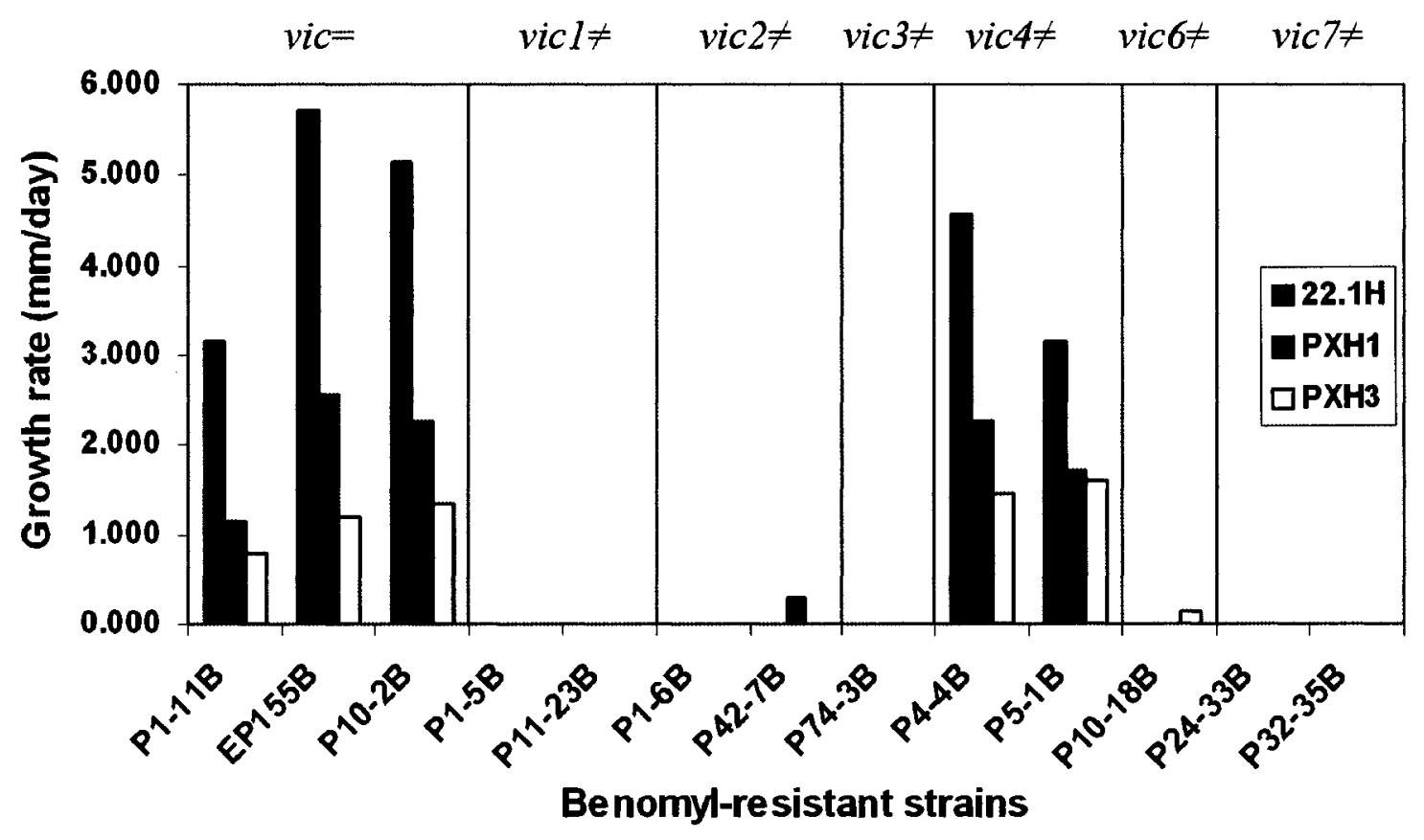




\section{Mycelial incompatibility assay}

This test was performed on PDAg plates containing bromocresol green by confronting each of the three isolates EP155, EP155 (PXH1) and EP155 (PXH3) separately with each of 14 benomyl-resistant isolates having specific vic genotype differences (Figure 16). The formation of a dark line (barrage) is associated with the fusion and subsequent cell death between two incompatible mycelia. As expected, no barrage was seen in pairings of vic-compatible strains. vic-incompatible strains (including those expressing p29 or p40) developed well-defined barrages with the exception of EP155 (PXH1) + P4-4B, which differ at vic4. vic4 is considered the "weakest" vic locus (Biella et al., 2002), since vic4 heteroallelism does not interfere with heterokaryon formation (see Figure 15). That the barrage line between vic4-incompatible strains EP155 (PXH1) and P4-4B was poorly defined or absent (based on multiple barrage tests) suggests that expression of the p29 element has a subtle effect on mycelial incompatibility. Overall, based on these barrage tests neither p29 nor p40 significantly alters the mycelial incompatibility characteristics associated with vic gene differences. 
Figure 16. Mycelial incompatibility tests between strain pairs with defined vic characteristics. Each of three strains, EP155, EP155 transformed with PXH1, and EP155 transformed with PXH3, was paired separately to 14 strains that have same vic genotype to EP155 or differ at a single vic locus, as designated across the top. Barrage lines are evident as dark lines where the paired colonies grow together. 

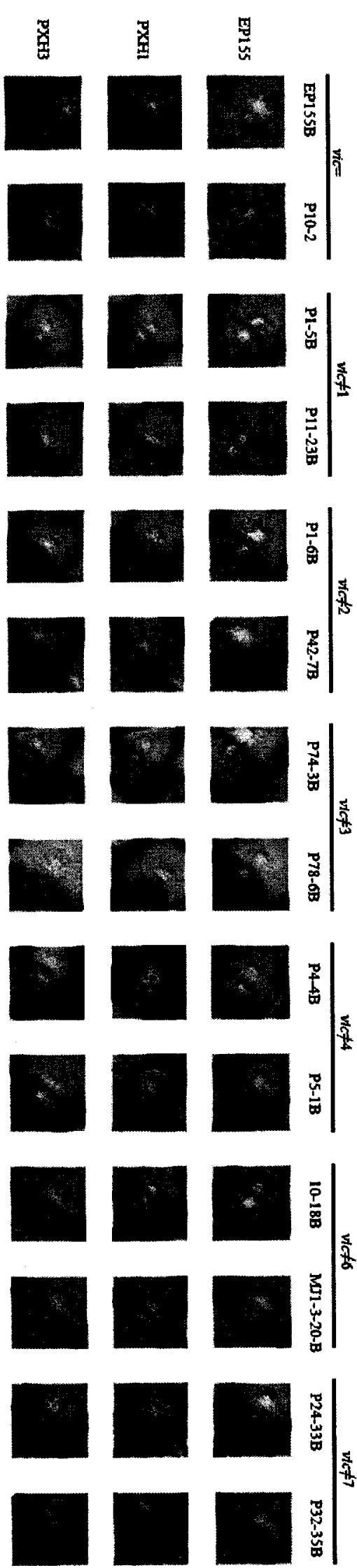
Protein-protein interaction

To study how the $\mathrm{p} 29$ protein effects PCD rates based on our microscopy assays, we made flag-tagged constructs of p29 from each of CHV1-EP713 and CHV1-Euro7 and expressed these in the fungal host, EP155. It was hypothesized that these constructs may allow for the isolation and identification of fungal protein(s) that interact with p29. Crude protein extracts of strains containing CHV1-EP713-p29-flag and CHV1-Euro7p29-flag constructs had different banding patterns from each other as visualized through Western blotting (Figure 17). The molecular weight of both of these p29-flag proteins was expected to be $\sim 30 \mathrm{KDa}$. Three bands with molecular weights of $\sim 60 \mathrm{KDa}, 42 \mathrm{KDa}$ and $30 \mathrm{KDa}$ were found to be common in both flag-tagged protein samples. No immunoreactive proteins were observed in protein from a no-flag control. Affinity purification using M2 anti-flag agarose beads yielded two bands with molecular weights of $60 \mathrm{KDa}$ and $30 \mathrm{KDa}$ (Figure 18). Unfortunately sequence analysis of these bands mostly revealed antibody fragments. 
Figure 17: Western blot of flagged-tag constructs of CHV1-EP713-p29 and CHV1Euro7-p29. Positions of 30 and $42 \mathrm{KDa}$ are shown with arrows. The expected size for the positive control, provided by RP Smith, is approximately $85 \mathrm{KDa}$. 


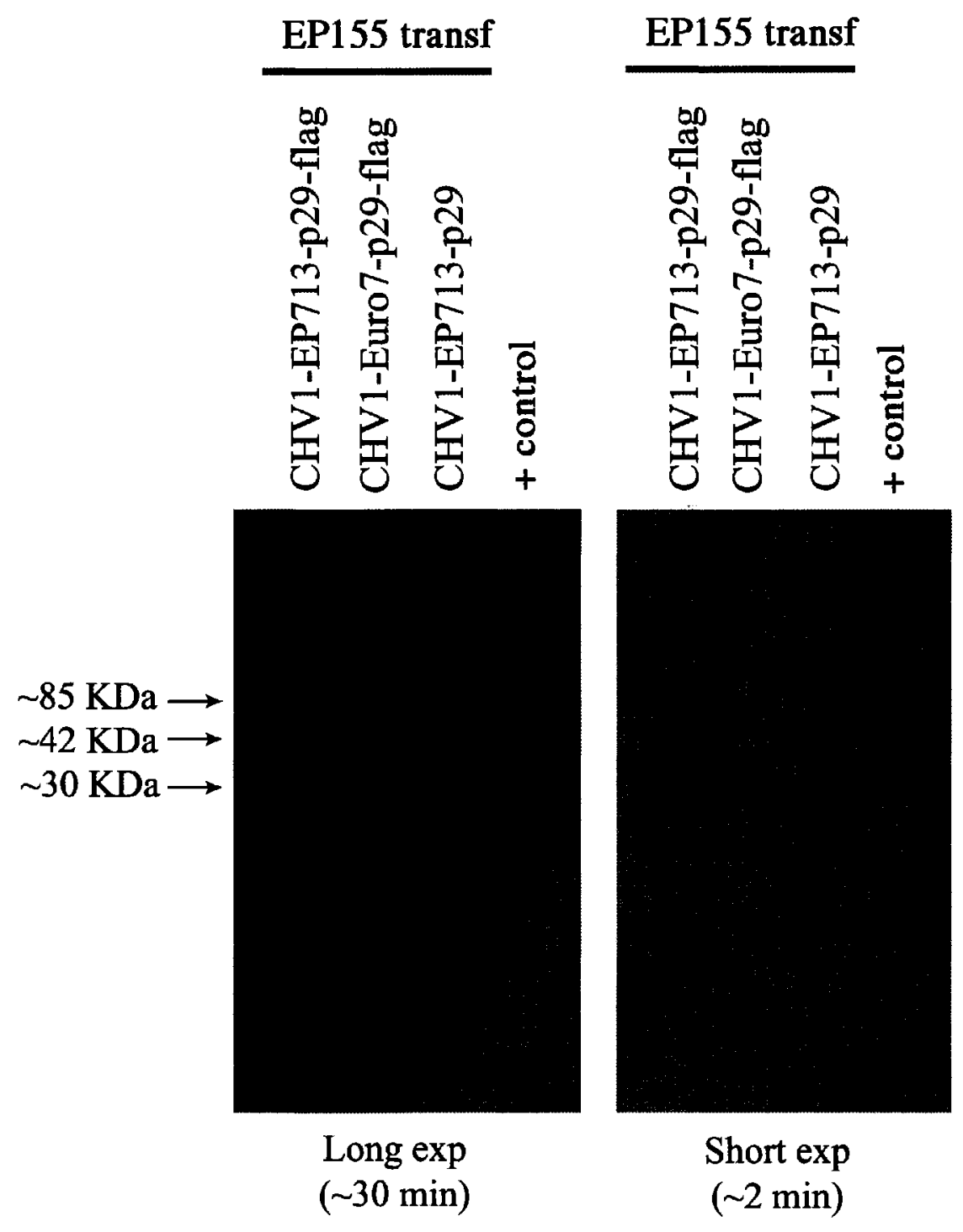


Figure 18: Affinity purified samples of CHV1-EP713-p29 and CHV1-Euro7-p29 using M2 anti-flag agarose beads followed by SDS-PAGE and Coomassie Brilliant Blue staining revealed two bands with molecular weights of $\sim 60 \mathrm{KDa}$ and $\sim 30 \mathrm{KDa}$. 


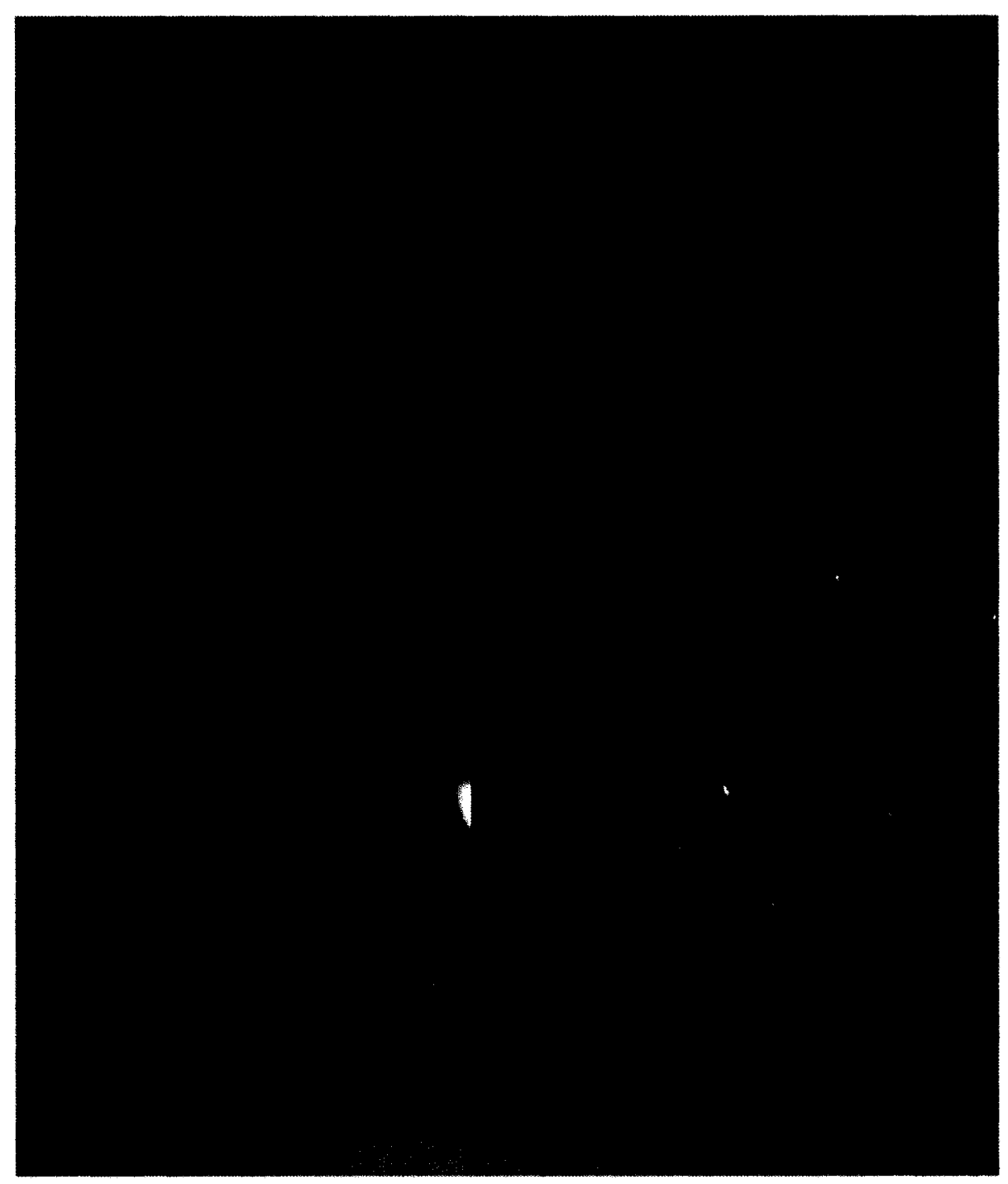


p29 sequence analysis

The p29 sequence was analyzed in order to identify the domain responsible for vic3-associated $\mathrm{PCD}$ reduction. $\mathrm{CH} 1$ and $\mathrm{CH} 2$ chimeras of $\mathrm{p} 29$ were constructed by replacing the first 300 bp of CHV1-Euro7-p29-flag with the first 300bp of CHV1-EP713p29 (Figure 19). $\mathrm{CH} 4$ and $\mathrm{CH} 8$ constructs were made by deleting the last and first 150 nucleotides, respectively, from CHV1-EP713-p29. These fragments were inserted behind the Pgpd promoter within the plasmid pCPXHY1 and then transformed into EP155. Microscopy assays were performed to examine PCD frequencies in contacts between these transformed strains and P74-3 (Figure 19). Expression of each of these constructs resulted in a reduction in observed PCD frequencies over that of no-virus controls. All of the constructs, except chimera $\mathrm{CH} 2$, had PCD rates that resembled those associated with expression of the p29-Euro7 construct. Of these modified forms of p29, $\mathrm{CH} 2$, which has the 5' end of p29-Euro7 and the 3' end of p29-EP713, had the greatest effect on PCD reduction. This suggested that the 3' portion of the p29 gene is the major player in reducing PCD, but this is not supported by results with the $\mathrm{CH} 8$ construct. The $\mathrm{CH} 8$ construct has the 5' region of p29-EP713 deleted but maintains all of its 3' region. In general, these results suggest that there is no well-defined subdomain within p29 that is involved in the reduction of vic 3 -associated PCD. 
Figure 19: Clustered bar representation of viral constructs (left) and associated PCD frequencies (right). These results are means $( \pm \mathrm{SD})$ based on a minimum of 50 contacts for each pairing. The constructs were expressed in EP155 (the donor) while P74-3 (the recipient) was virus free. 


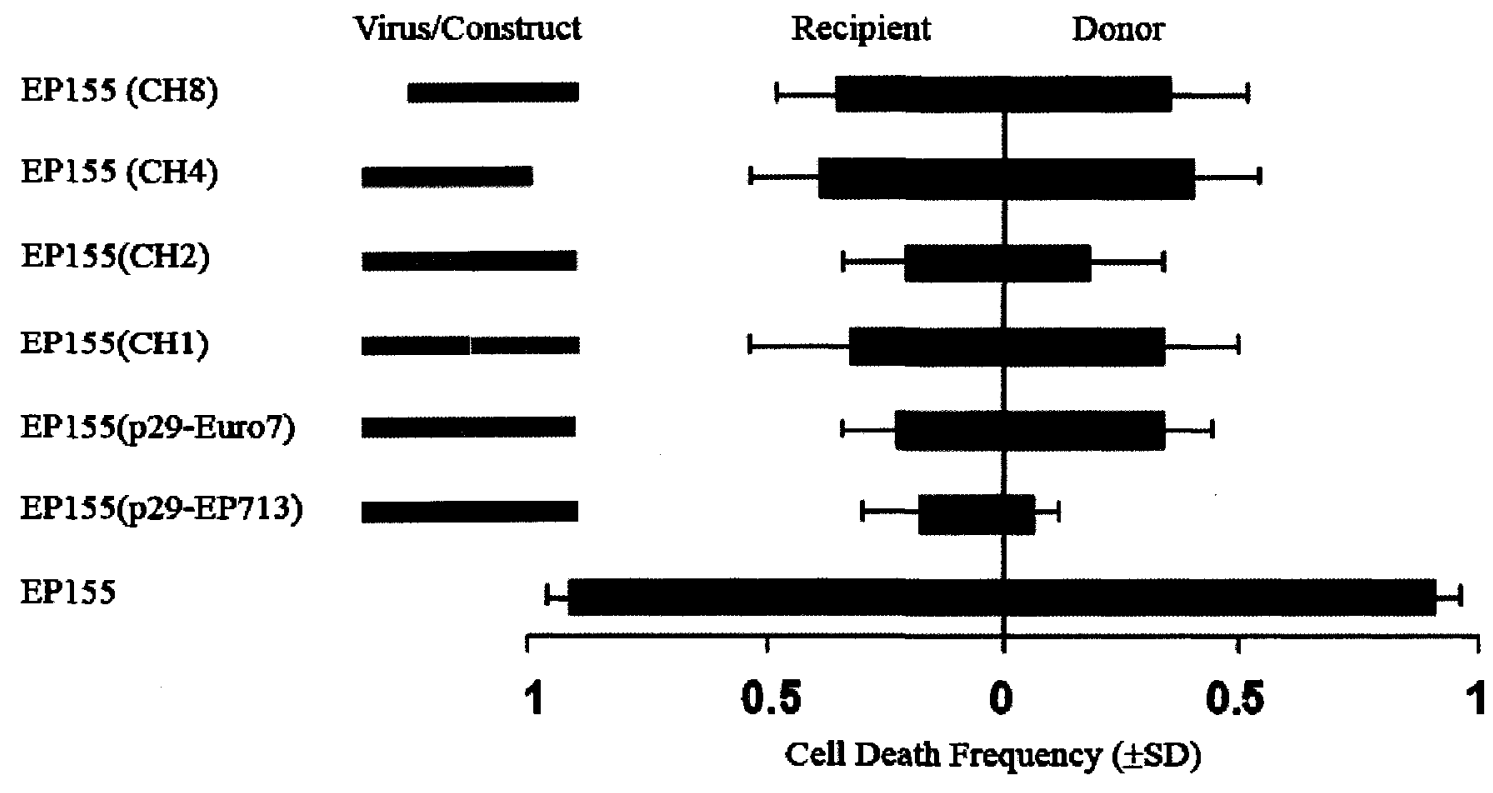


p29, RNA silencing and nonself recognition

Segers el al. (2007) showed that dicer-like protein $d c l-2$, but not $d c l-1$ is essential for RNA silencing in C. parasitica. Our microscopy analysis of vic3-associated PCD using $d c l-1$ and $d c l-2$ mutants revealed interesting parallels between RNA silencing and vic-associated PCD (Figure 20). Confrontations between strains P74-3 and EP155 ( $\Delta d c l$ 2), and between P74-3 and EP155 ( $\Delta d c l-1 / \Delta d c l-2)$, resulted in reduced vic3-associated PCD rates that were similar to those observed when the EP155 partner expresses CHV1EP713-p29. However, hyphal contacts between P74-3 and EP155 ( $\Delta d c l-1)$ had high rates of PCD in cells surrounding hyphal contact points. This suggested that the virus may be using the RNA silencing pathway to affect reduced PCD rates in incompatible fusion events. This possible link suggested that the p29 effect on PCD could be mediated by an RNA effector.

In order to determine if the effect of $\mathrm{p} 29$ on PCD reduction is mediated by RNA or by protein, three stop codons were inserted into the beginning of the CHV1-EP713p29 sequence (Figure 21). Introduction of these translation termination sites eliminated the p29 phenotypic effects of reduced colony growth rate and decreased pigmentation and conidiation in EP155 colonies (Figure 22), but did not compromise the cell death frequency effect (Figure 20). These results strongly suggest that reduction in vic3associated PCD is mediated by RNA synthesized from ORF A, and specifically from the p29-encoding region. Furthermore, the data indicates that the p29 effects on colony morphology (pigmentation patterns, etc.) are independent of reduction in vic3-associated PCD; the former is dependent with p29 protein synthesis while the later is likely associated with p29 RNA. Furthermore, the involvement of p29 RNA in reducing PCD 
is consistent with the idea that this element interferes somehow with the RNA silencing pathway. 
Figure 20: Illustration of PCD frequencies in P74-3 (recipient) and EP155 (donor). Donor strain was transformed with constructs as indicated at left. Mean cell death frequencies $( \pm \mathrm{SD})$ in recipient and donor strains are indicated in red and blue, respectively. Except for EP155 ( $\triangle \mathrm{dcl}-1)$, all other strains yielded similar PCD rates as did EP155 transformed with wild-type p29-EP713. 


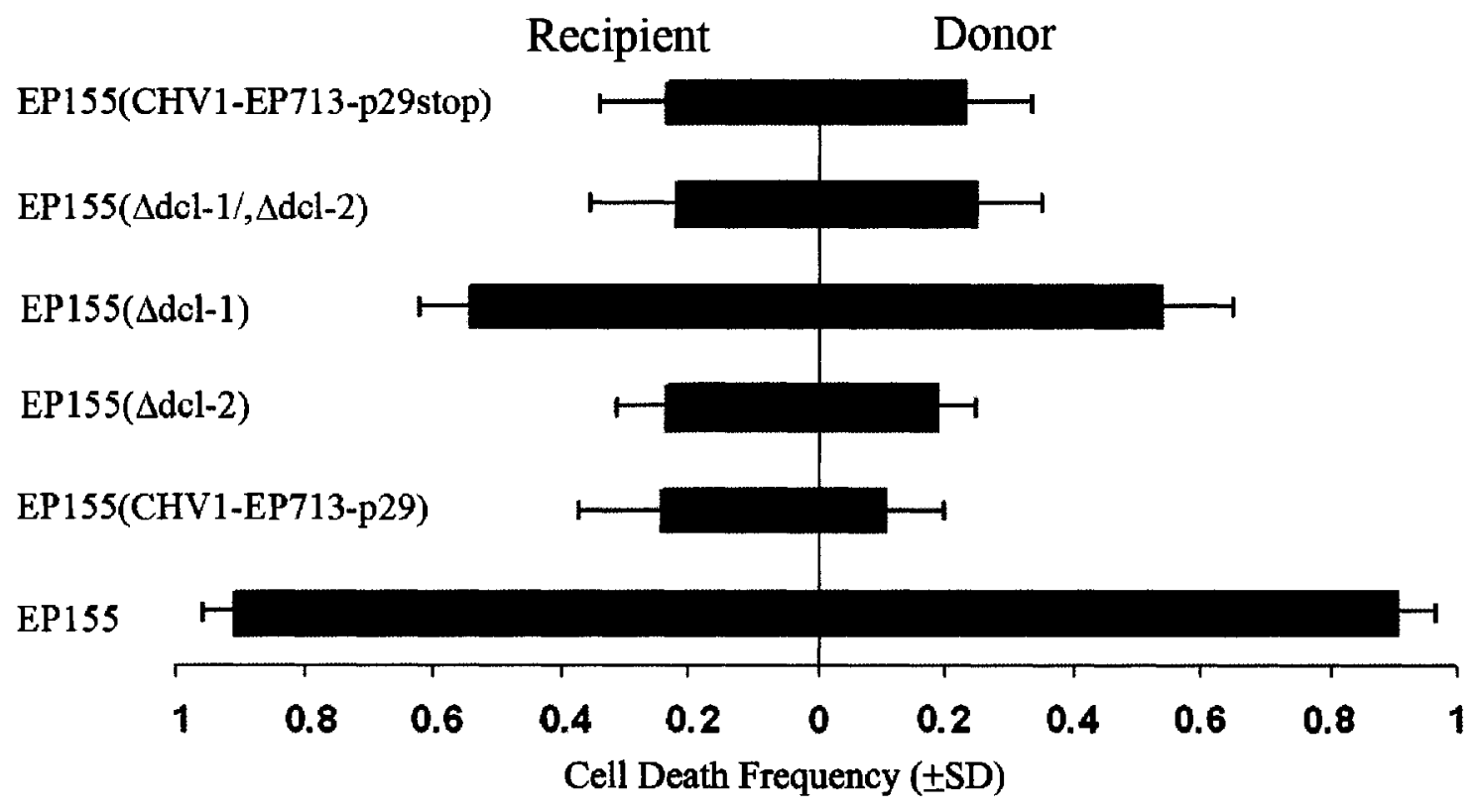


Figure 21. Sequence alignment of the wild-type CHV1-EP713-p29 and CHV1-EP713p29stop for first 60 bp of coding regions with corresponding amino acid sequences for each of three forward frames. Stop codons are shown by asterisks. Amino acid sequences of CHV1-EP713-p29stop confirmed the presence of translation termination sites in all three forward reading frames (below the line). Key functional amino acids encoded in frame 1 are shown in bold and numbered according to Figure 24. 


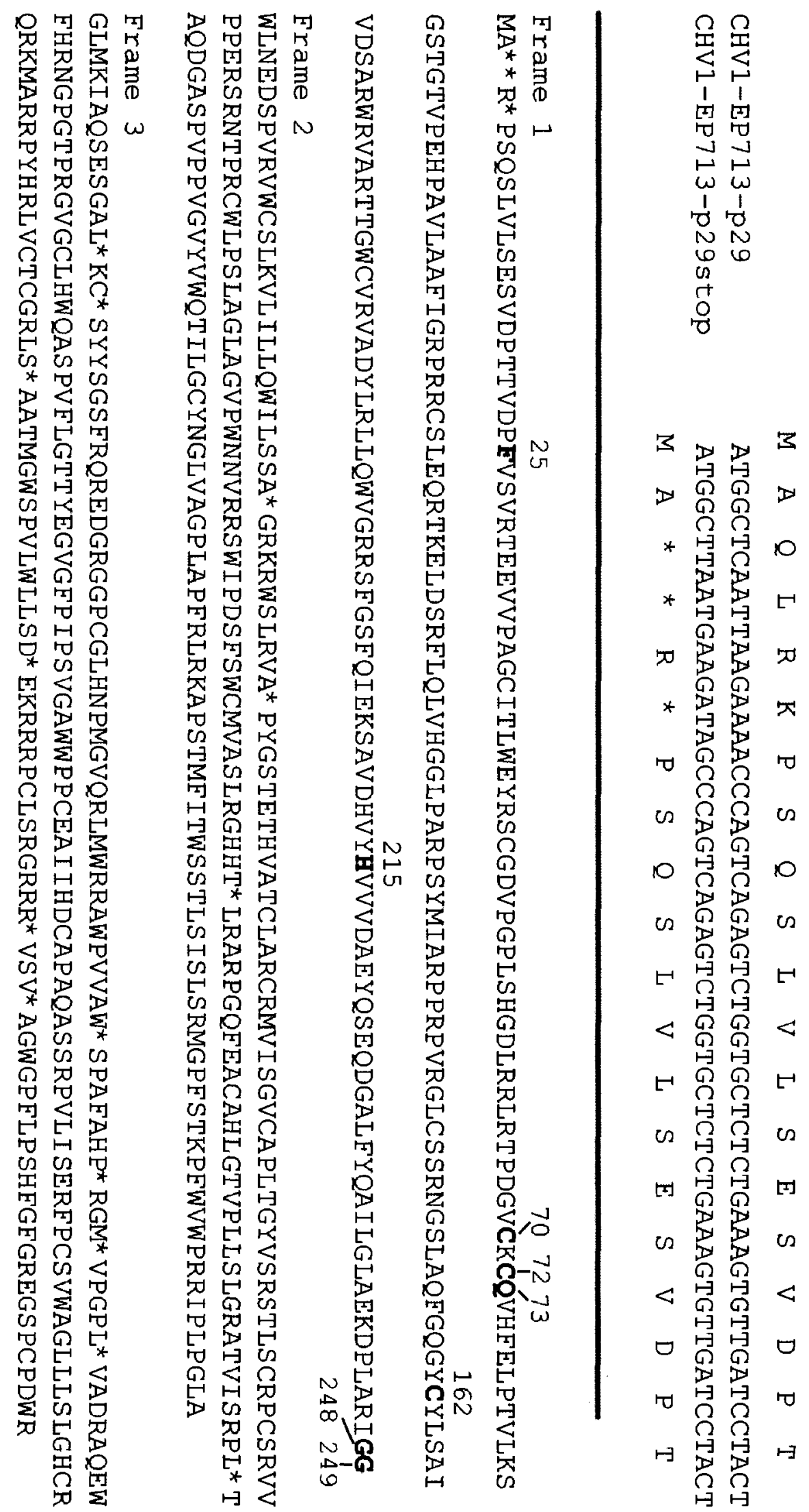


Figure 22: Colony morphology of EP155 virus-free (left), EP155 (CHV1-EP713p29stop) (middle) and EP155 (CHV1-EP713-p29) (right). All isolates were grown at room temperature for 10 days. 

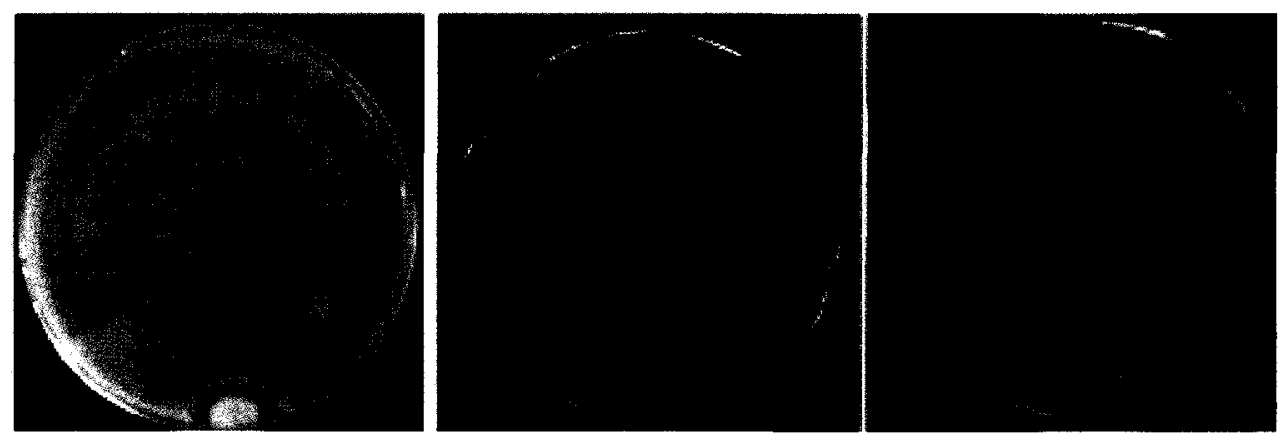
vic pathway dissection

In this section cell death frequencies were measured using pairs of isolates that differed at one of vic2, 3, 6 or 7 , as well as strain pairs having multiple vic differences. PCD frequencies for each pair were analyzed in the presence and absence of CHV1EP713-p29, expressed by the EP155 strain. All PCD frequencies were converted to a ratio of $1-\mathrm{i} / \mathrm{ni}$, where " $\mathrm{i}$ " is the PCD frequency from pairing in which $\mathrm{p} 29$ was expressed in EP155 strain and "ni" is the PCD frequency from the corresponding non-infected pairing (Table 4). These ratios are also plotted in Figure 23 where a higher value represents a more pronounced effect of the virus element on cell death reduction.

From Table 4 and Figure 23 it can be seen that the presence of p29 resulted in significant reductions in PCD for all confrontations tested in which there was a single vic gene difference. In some cases, but not in all, where there were multiple vic differences an increased rate of PCD was observed. For example, paired isolates that differed at one of vic2 or vic3 showed significant cell death reductions compared to the pairing in which there were differences at both vic 2 and vic3. Likewise, vic $3 \neq, 6 \neq, 7 \neq$ differences had relatively high PCD frequencies compared to the effects of single differences at each of these three loci. This suggests that there is a "weakening" of the virus (p29) effect on PCD-reduction when there are multiple vic differences. In contrast, pairings with differences at both vic6 and vic7 did not apparently differ in PCD frequencies from pairings that were incompatible for one of vic6 or vic 7 . While the interactions between multiple vic gene products and hypovirus factors are likely complex, this preliminary analysis suggests that insights into the pathways may be gained using hypovirus as a type of genetic probe. It may be hypothesized based on this data, for example, that vic 2 and 
vic3 act independently, and thus additively, while vic6 and vic7 operate within a common pathway. 
Table 4: Effect of p29 expression on cell death frequencies between pairs of isolates that differ at the single or multiple vic loci. For each confrontation, EP155 (donor) had or did not have p29 from CHV1-EP713, as indicated. $\mathrm{i}=$ PCD frequency when donor contains and expresses p29 construct. $\mathrm{ni}=$ PCD frequency when donor does not contain $\mathrm{p} 29$ construct 


\begin{tabular}{|c|c|c|c|c|c|}
\hline \multirow{2}{*}{ vic difference } & \multirow[t]{2}{*}{ Confrontation } & \multicolumn{2}{|c|}{ Cell Death Frequency $(+/-\mathrm{SD})$} & \multicolumn{2}{|c|}{$\operatorname{Ratio}(1-\mathrm{i} / \mathrm{ni})$} \\
\hline & & Donor & Recipient & Donor & Recipient \\
\hline \multirow{2}{*}{$\operatorname{vic} 2 \neq$} & $\mathrm{EP} 155+\mathrm{P} 1-6$ & $0.68 \pm 0.11$ & $0.63 \pm 0.14$ & \multirow{2}{*}{0.63} & \multirow{2}{*}{0.41} \\
\hline & $\mathrm{EP} 155(\mathrm{p} 29-\mathrm{EP} 713)+\mathrm{P} 1-6$ & $0.25 \pm 0.13$ & $0.37 \pm 0.15$ & & \\
\hline $\operatorname{vic} 3 \neq$ & $\begin{array}{l}\text { EP155 + P74-3 } \\
\text { FP155(n29-EP713)+P74-3 }\end{array}$ & $0.91 \pm 0.06$ & $0.91 \pm 0.05$ & 0.75 & 0.78 \\
\hline & & & & & \\
\hline \multirow{2}{*}{ vic $6 \neq$} & $\mathrm{EP} 155+\mathrm{P} 10-18$ & $0.50 \pm 0.17$ & $0.41 \pm 0.11$ & \multirow{2}{*}{0.44} & \multirow{2}{*}{0.29} \\
\hline & $\mathrm{EP} 155(\mathrm{p} 29-\mathrm{EP} 713)+\mathrm{P} 10-18$ & $0.28 \pm 0.09$ & $0.29 \pm 0.06$ & & \\
\hline \multirow{2}{*}{ vic $7 \neq$} & $\mathrm{EP} 155+\mathrm{P} 32-35$ & $0.51 \pm 0.14$ & $0.60 \pm 0.18$ & \multirow{2}{*}{0.63} & \multirow{2}{*}{0.52} \\
\hline & $\mathrm{EP} 155(\mathrm{p} 29-\mathrm{EP} 713)+\mathrm{P} 32-35$ & $0.19 \pm 0.05$ & $0.29 \pm 0.17$ & & \\
\hline \multirow{2}{*}{ vic $6 \neq 7 \neq$} & P74-3 + EP29 16L1 & $0.48 \pm 0.14$ & $0.57 \pm 0.11$ & \multirow{2}{*}{0.63} & \multirow{2}{*}{0.49} \\
\hline & P74-3(p29-EP713)+EP29 16L1 & $0.18 \pm 0.12$ & $0.29 \pm 0.21$ & & \\
\hline \multirow{2}{*}{ vic $3 \neq, 6 \neq, 7 \neq$} & $\mathrm{EP} 155+\mathrm{EP} 2916 \mathrm{~L} 1$ & $0.36 \pm 0.12$ & $0.50 \pm 0.07$ & \multirow{2}{*}{0.22} & \multirow{2}{*}{0.12} \\
\hline & EP155(p29-EP713) + EP29 16L1 & $0.28 \pm 0.06$ & $0.44 \pm 0.13$ & & \\
\hline \multirow{2}{*}{$\operatorname{vic} 2 \neq, 6 \neq, 7 \neq$} & EP155 + EP392 39L1 & $0.51 \pm 0.24$ & $0.42 \pm 0.21$ & \multirow{2}{*}{0.43} & \multirow{2}{*}{0.43} \\
\hline & EP155(p29-EP713) + EP392 39L1 & $0.29 \pm 0.13$ & $0.24 \pm 0.08$ & & \\
\hline \multirow{2}{*}{$v i c 2 \neq, 3 \neq$} & $\mathrm{EP} 155+\mathrm{P} 67-7$ & $0.53 \pm 0.18$ & $0.61 \pm 0.15$ & \multirow{2}{*}{0.25} & \multirow{2}{*}{0.13} \\
\hline & EP155(p29-EP713) + P67-7 & $0.40 \pm 0.00$ & $0.53 \pm 0.00$ & & \\
\hline \multirow{2}{*}{ vic $2 \neq, 3 \neq, 4 \neq$} & $\mathrm{EP} 155+\mathrm{P} 21-14$ & $0.72 \pm 0.17$ & $0.62 \pm 0.06$ & \multirow{2}{*}{0.42} & \multirow{2}{*}{0.18} \\
\hline & EP155(p29-EP713) + P21-14 & $0.42 \pm 0.26$ & $0.51 \pm 0.02$ & & \\
\hline
\end{tabular}


Figure 23. Scatter plot representing a comparison between cell death ratio of isolates involving single and double vic differences of vic6 and 7 (A) and vic2 and 3 (B). 
A
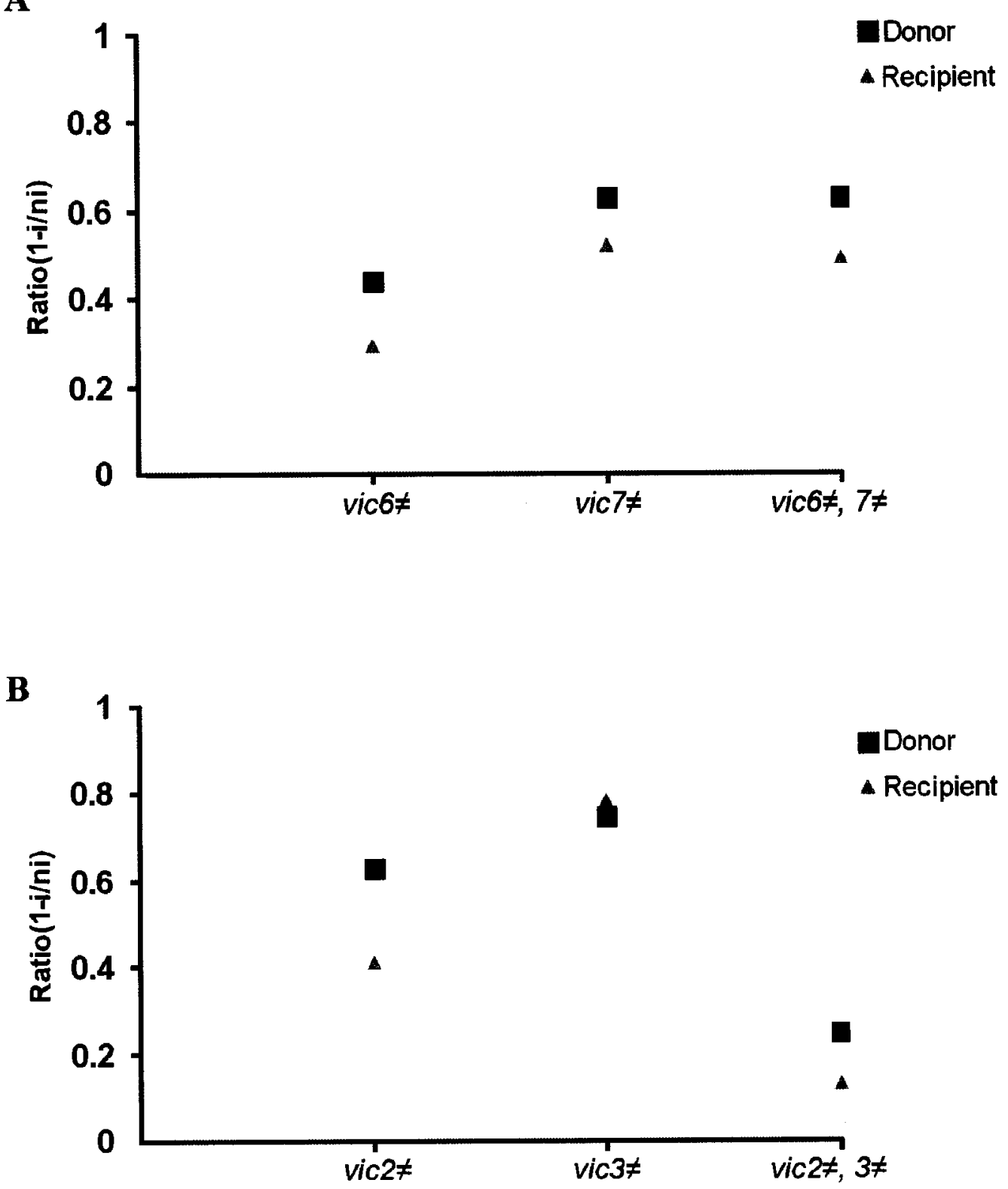


\section{DISCUSSION}

Devastation of the American chestnut tree by the parasitic fungus, C. parasitica, is one of the classical examples of a plant disease caused by introduction of an introduced species. The appearance of the hypovirulent fungal strains and their subsequent effects on chestnut blight prompted researchers to investigate this phenomenon. Preliminary investigations revealed that hypovirulent phenotype conversion is caused by the presence of dsRNA that was transmitted cytoplasmically from a hypovirulent to a virulent strain, and this set the stage for large scale biological control efforts. However, this program did not succeed apparently because of the fungal vegetative incompatibility system that slowed or prevented virus transfer between strains. Vegetative incompatibility in $C$. parasitica is associated with at least six unlinked vic loci (vic 1, 2,3,4,6, and 7), each with at least two alleles (Cortesi \& Milgroom, 1998). Microscopic examination of hyphal incompatible fusions revealed some common characteristics associated with vegetatively incompatible reactions such as; septal plugging, vacuolization of the cytoplasm, organelle degradation and shrinkage of the cytoplasm away from cell wall (Jacobson et al., 1998; Biella et al., 2002). These alterations in cells are similar to characteristics associated with eukaryotic PCD. Therefore, PCD in fungi can occur as a result of fusion between two vegetatively incompatible strains.

The occurrence of PCD under specific physiological and pathological conditions has been widely reported for the past 150 years (Bursch el al., 2000). PCD has been categorized into two main types: apoptosis and autophagy. Apoptosis was classified as a type of cell death that is triggered by physiological or pathological stimuli to regulate the cell population. Cells involved in apoptosis undergo specific biochemical and 
physiological changes. These changes can take place in the cytoplasm and nucleus, as well as plasma membrane. During the early stages of apoptosis, the cell integrity will be altered. This transformation is identified as shrinkage and distancing of cells from neighboring cells. Chromatin in the nucleus aggregates and is digested into fragments by endonucleases. The nucleus will break down into several fragments that become enclosed within apoptotic bodies. These apoptotic bodies are formed from intact membranes that prevent leakage during the process of apoptosis (Lawen, 2003). Autophagy is another type of programmed cell death that is involved in a wide range of biological processes such as pathogen attack or other environmental stimuli, and cellular remodeling during development (Yorimitsu \& Klionsky, 2005). This process involves sequestration of abnormal organelles in the cytoplasm followed by degradation and recycling by the lysosome/vacuole.

The correlation between vegetative incompatibility and PCD associated with the six vic genes in C. parasitica was investigated by Biella et al. (2002). They demonstrated that there is a negative correlation between cell death and viral transmission when pairs of isolates differed at single vic loci. Preliminary observations were also made by Biella and co-workers that indicated that viral activity altered vic-associated PCD. Our work first set out to verify these earlier findings. This was done through a series of microscopical examinations with virus infected and uninfected strains of EP155 paired with P74-3, two stains that carry different alleles at vic3. A significant reduction in cell death frequencies was observed in both the donor and recipient isolates upon fusion of P74-3 with EP155 (CHV1-EP713), in comparison to the corresponding virus-free isolates. Similarly, when P74-3 was paired with EP155 (CHV1-Euro7) a reduction in 
PCD frequency was observed, although this effect was less dramatic than for P74-3 + EP155 (CHV1-EP713) pairings. These observations corroborated earlier findings that a virus element(s) was interacting with the fungal nonself recognition system to reduce PCD.

In order to identify the virus element(s) responsible for vic3-associated PCD reduction, a set of chimeric hypoviruses of CHV1-Euro7 and CHV1-EP713 was used. These constructs were previously used by Chen et al. (2000) to determine the region of the viral genome responsible for modifying fungal growth rate, canker and colony morphology. In their study chimeras carrying specific regions of the virus genome showed similar phenotypic alteration to the parental virus type. These similarities allowed them to narrow down the genome to identify specific hypovirus domains that contribute to particular morphological characteristics.

Our microscopy analyses revealed that the presence of chimeras R1, R12 or R14 resulted in cell death frequencies that were similar to those of the parental virus, CHV1EP713. On the other hand, PCD frequencies in pairings with chimeras R13 and R6 were similar to those involving CHV1-Euro7. These data indicated that the ORF A region was involved in vic3-associated PCD reduction. This was further supported by results with $\triangle \mathrm{p} 69$, wherein the viral ORF A region was deleted. Expression of this construct resulted in no appreciable reduction in PCD in pairings of EP155 $(\Delta \mathrm{p} 69)+\mathrm{P} 74-3$. Pairings with $\Delta \mathrm{p} 29$ and $\Delta \mathrm{p} 40$ mutants from the CHV1-EP713 virus genome resulted in intermediate cell death frequencies, suggesting that these proteins interact cooperatively with a component(s) of the vic3-associated PCD pathway. Interestingly, compared to experiments with transfected strains, strains that express transformed copies of CHV1- 
EP713-p29 or CHV1-EP713-p40 had a more pronounced effect in reducing PCD frequencies.

One possible explanation for these minor discrepancies between pairings with transfected mutants and transformed strains could be due to the variable and unstable nature of transfected strains, compared to the stable nature of the transformants. Other evidence of instability of transfected strains is based on our morphological observations of EP155 infected with chimeras carrying the CHV1-EP713 ORF B (R2, R14, R12 and R6). Of these, only the morphology of EP155 carrying R2 was consistent with the previous reports (Chen et al., 2000). Discrepancies in colony morphology characteristics could be due to virus abundance following the transfection stage or to variable rates of loss of virus activity during subculturing since transfected strains tend to be quite unstable (Nuss, personal communications). For these reasons, we used strains for our experiments as soon as possible after transfection. Further instability of virus elements was documented when the p 29 or $\mathrm{p} 40$ regions were deleted from the viral genome (Suzuki el al., 2003). Such deletions were previously observed to result in a reduced accumulation of viral RNA. Changes in the viral RNA content in some of our deletion mutants may also have modified cell death frequency rates for some of the transfected strains. The same study by Suzuki el al. showed that expressing p29 protein in $\Delta$ p29 mutant strains increased the RNA accumulation level to that observed in wild-type virus (Suzuki el al., 2003). Analogous work could be done with our system to investigate if p29 expression in $\Delta$ p29 mutant strains would result in a more pronounced reduction in cell death frequencies. Regardless of these possible instability issues, our results with transfected strains were internally consistent, and were further supported by work with 
transformed strains in implicating ORF A as the region responsible for altering vic3associated PCD rates.

Within ORF A, the p29 protein has been given a lot of attention due to its multifunctionality (Suzuki et al., 1999, 2003; Choi et al. 1991; Konnin et al. 1991). Figure 24 shows a summary of the domains and essential residues identified for p29 from CHV1-EP713, including alteration of the host phenotype and autocatalytic cleavage. Studies on $\Delta$ p29 (lacking $88 \%$ of the P29 coding region) showed that, in addition to p29's contribution to virus replication, p29 plays a major role in altering fungal pigmentation patterns, conidiation, and laccase accumulation (Suzuki el al. 1999). Using a gain of function assay and through progressive repair of the $\Delta$ p29 mutant, Suzuki et al. (2003) assigned the symptom determinant domain to the region extending from Phe25 through Gln73. The N-terminus portion of $\mathrm{p} 29$ and the HC-Pro papain-like protease encoded by potyviruses were also shown to share sequence identity, specifically in four conserved cysteine residues; Cys38, Cys48, Cys70, and Cys72 (Choi et al. 1991; Konnin et al. 1991). Site-directed mutations of either residues Cys 70 or Cys 72 resulted in colony morphology changes as well as substantial reduction in mycelial growth (Suzuki el al. 1999). Therefore, it was proposed that the specific secondary or tertiary conformational constraints required for the functionality of the Phe25-GIn73 domain were dependent on Cys70 and Cys72 residues. Our results provide evidence for an additional function of the CHV1 ORF A, and specifically to the p29 protein coding region; that of modifying the host nonself recognition response. 
Figure 24. Schematic diagram of the CHV1-EP713 genome, showing essential domains and residues in p29 coding region (modified from Suzuki et al., 1999). See Figure 21 (Frame 1) for amino acid sequence. 


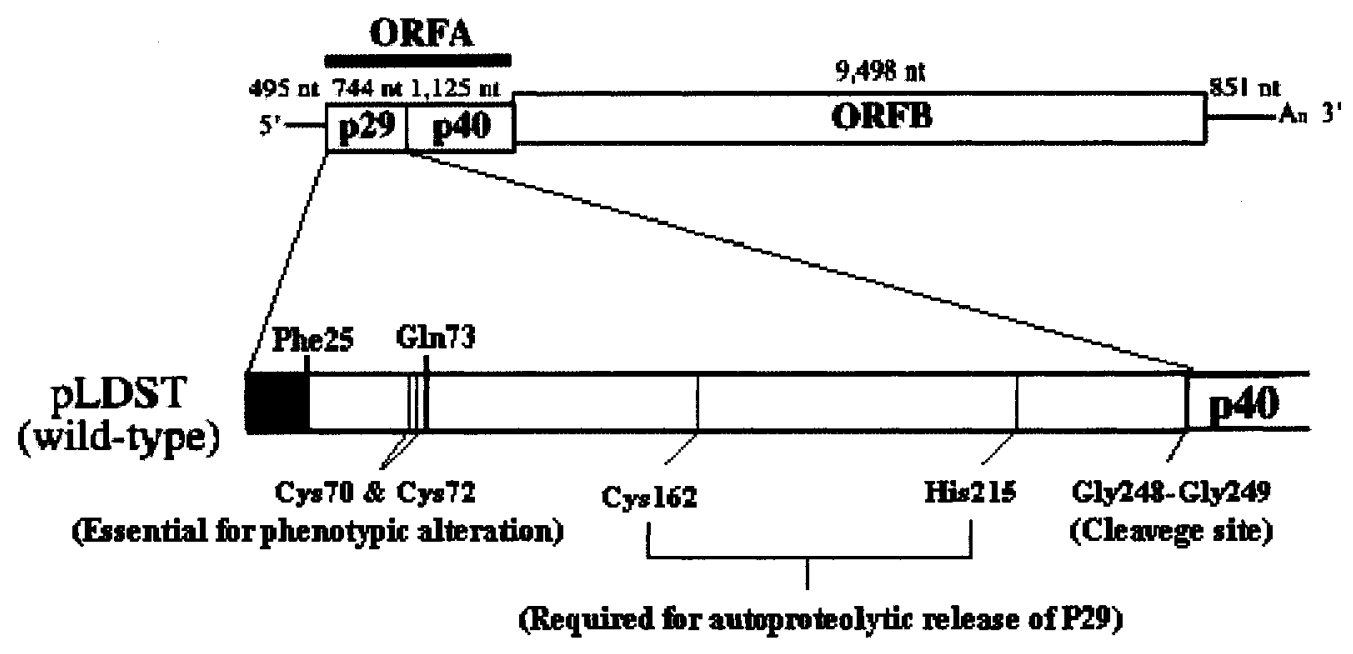

1-24aa (responsible for virus replication'translation)

$\square$ 25-73aa (suppression of pigmentation \& conidiation) 
Vegetative incompatibility

Vegetative incompatibility between fungal strains can be evaluated by heterokaryon incompatibility testing and barrage tests. Heterokaryon incompatibility tests determine whether two complementary nuclear types can be maintained in the same hypha to enable stable heterokaryotic growth. Barrage testing is done by confronting two strains to determine whether or not dead or dying cells and/or deposition of dark pigments develop in the zone of contact. Unlike heterokaryon incompatibility, barrage formation does not necessarily involve hyphal fusion. Contact between substances diffused from either, or both strains and their cellular receptors may facilitate barrage formation (Micali \& Smith, 2005).

The results presented in this thesis are consistent with those of Smith et al. (2006), which showed that heteroallelism at vic loci was associated with heterokaryon incompatibility function for all vic loci with the exception of vic4. Both studies found that differences at vic4, while causing barrage lines to form, did not impede heterokaryon formation, growth or stability. One explanation for this vic4 anomoly is that this locus may express extracellular factors that are toxic for isolates carrying the other allele. Such factors have not been identified, but Rizwana and Powell (1995) suggested that cell surface particles are involved in triggering heterokaryon incompatibility, by some vic loci. This hypothesis was based on their observation that vic1 and vic2 heterokaryon incompatibility was bypassed upon protoplast fusion. In contrast to our observation that expression of either $\mathrm{p} 29$ or $\mathrm{p} 40$ in the nuclear type significantly reduced vic 3 -associated PCD, heterokaryon and barrage test results were not significantly altered by virus factors. The only possible exception to this was that the barrage line between EP155(PXH1)+ P4- 
4, which differ at vic4, was indistinct or absent. This effect may be enhanced by expressing the virus factors in both strains, rather than in just EP155, as was done in this study.

Based on our comparisons of microscopy, heterokaryon and barrage assays, we hypothesize that p 29 and p 40 operate by reducing the "rate" rather than "frequency" of PCD. Figure 25 explains this point graphically. In this figure we plot hypothetical functions of the number of PCD through time. For "WT" pairings of uninfected strains, the number of cells undergoing PCD increases to a maximum and then levels out. Confrontations that involve an infected strain have fewer PCD evident at the time of microscopic examination. This could be accounted for by either a reduced rate of PCD or a reduced frequency of cells undergoing PCD. We surmise, however, that a reduced frequency of PCD would be evident as reduced severity in heterokaryon incompatibility test results and/or a less pronounced barrage. With time, barrages and heterokaryon incompatibility would still develop, however, even with a reduced rate of PCD. This hypothesis could be tested by monitoring the confrontation over the period of time using our microscopy assay. Unfortunately, slides cannot be re-examined after placing the cover slip over the colonies since this seems to inhibit further growth. Also, there is a narrow viewing window after hyphal contact, before the contact zone is overgrown and obscured. Heterokaryon and barrage incompatibility tests support the rate argument in the sense that presence of p29 did not change the final outcome. Therefore, we can speculate that p29 delays cell death and allows for some viral transmission even in incompatible fusions. 
Figure 25. Hypothetical representation showing the difference between the frequency (F) and rate $(\mathrm{R})$ of vic-associated PCD compared to virus-free confrontation (WT). Region A represents the time that microscopy analysis was performed. Region B corresponds to the period in which barrage and heterokaryon tests are observed. 


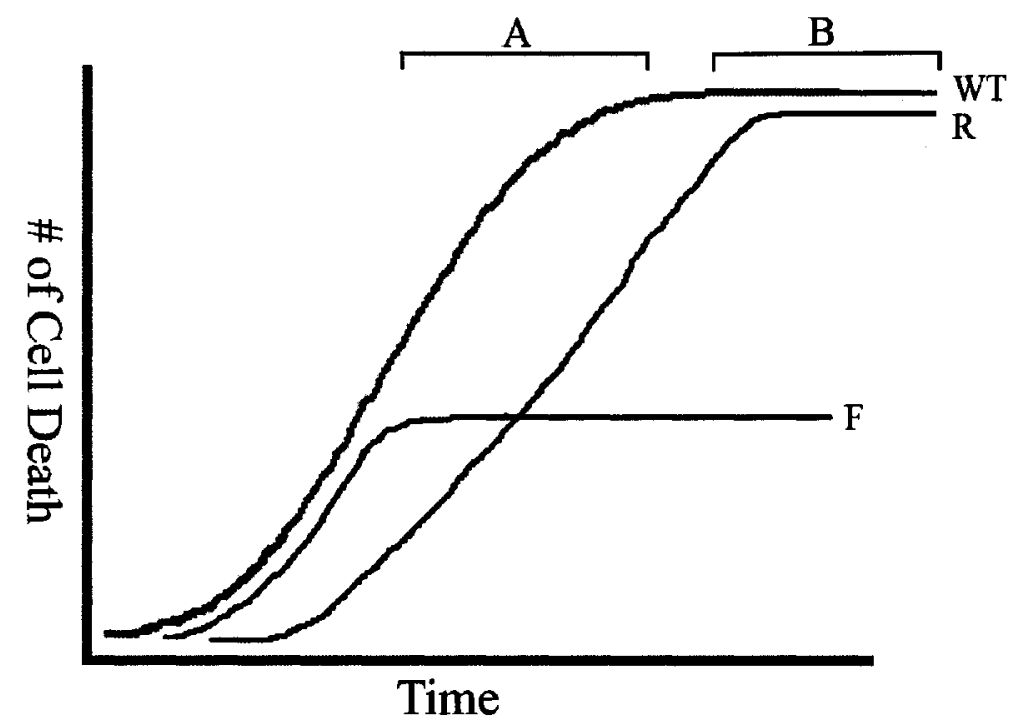


p29 protein and nucleotide sequence analysis

Following our finding that both $\mathrm{p} 29$ and $\mathrm{p} 40$ reduced vic3-associated $\mathrm{PCD}$, we focused in some detail on the effects of the p29 region. The mechanism of the p29-vic3 interaction was investigated by attempting to identify any possible host protein(s) that may associate with $\mathrm{p} 29$. For this purpose flag-tagged constructs of $\mathrm{p} 29$ from each of CHV1-EP713 and CHV1-Euro7 were made and expressed in the fungal host, EP155. The molecular weight of the p29-flag protein is approximately $30 \mathrm{KDa}$. Affinity purification from both constructs showed two bands with molecular weights of $60 \mathrm{KDa}$ and $30 \mathrm{KDa}$. Mass spectrometry of both bands revealed antibody fragment sequences. Therefore, it was not possible to identify any protein interaction. In a parallel study, Nuss and co-workers performed the yeast two-hybrid technique which only revealed dimerization of $\mathrm{p} 29$ (Nuss, personal communications) and may explain our observation of a $30 \mathrm{KDa}$ (monomer) band and a $60 \mathrm{KDa}$ (dimer) band provided that the dimmer is not dissociated by the reducing condition used in SDS-PAGE. In addition, this test should be performed under a non-denaturing condition to prevent the disruption of any nonvalent interactions involving $\mathrm{p} 29$.

The p29 nucleotide sequence was analyzed in order to determine the domain responsible for PCD reduction. For this purpose four constructs were generated, either by interchanging a segment between CHV1-EP713-p29 and CHV1-Euro7-p29 (CH1 and $\mathrm{CH} 2$ ) or by deleting a section of CHV1-EP713-p29 (CH4 and CH8). Expression of each of these constructs resulted in PCD frequency reductions compared to no-virus controls. However, no clear correlation was observed between regions of p29 and differences in 
PCD reduction characteristics, rather, the indications were that the entire region functions to reduce vic3-asociated PCD.

A possible p29-RNA silencing-nonself recognition connection

PCD is involved in different cellular processes during development, homeostasis and interaction with other system (Hamann et al., 2008). Here, we showed that PCD contributes to nonself recognition functions and interacts with pathogenicity factors. Similar to PCD, RNA silencing is a pathway that is involved in cellular development and functions by regulation of the gene expression system. RNA silencing occurs in a wide range of eukaryotic organisms including nematodes, flies, protozoa, insects and human cell lines, plants and fungi. This mechanism regulates the level of gene transcripts either through transcriptional gene silencing (TGS), or by posttranscriptional gene silencing (PTGS) involving a sequence-specific RNA degradation process (Agrawal el al., 2003).

The initial step of RNA silencing (recognition step) involves processing of double-stranded RNA or single-stranded RNA with step-loop structures and cleavage of RNA into small interfering RNA (siRNA) molecules ranging from 21 to 30 nucleotides by RNase III ribonuclease family (dicer proteins). Subsequently target RNA is degraded by incorporation of siRNA into a multi-protein complex, known as effector, through a homology dependent manner. There are three types of effector complexes: RNA-induced transcriptional silencing complex (RITS), siRNA-dependent RNA-induced silencing complex (siRISC) and miRNA-dependent RNA-induced silencing complex (miRISC) and each of them direct different pathways (Li \& Ding, 2006). The effector complex is composed of single stranded small RNAs known as guide strand, a protein from 
Argonaute family (AGO) and two RNA-binding proteins (Sioud, 2007; Ischizuka et al., 2002; Caudy et al., 2002).

In general RNA silencing can be triggered through different sources of RNA molecules such as RNA viruses, transposons, siRNA (which may be introduced exogenously or endogenously) and miRNA (Rana, 2007). Viruses are able to induce RNA silencing either by using their own RNA or encode a miRNA that engages the silencing machinery of the host. The notion of RNA silencing as an antiviral defense mechanism was supported by two important observations based on the plant genetic studies. First, RNA silencing appears to protect plant hosts against invasion by viruses. Key observations in support of this are based on mutant analyses of critical elements of the silencing pathway such as dicer and argonaute proteins (Morel et al., 2002). Such mutants are extremely susceptible to viral infection. Presence of Viral Suppressors of RNA silencing (VSRs) is the second indication to establish the RNA silencing as antiviral mechanism. VSR particles are encoded by viruses, which invade plants, vertebrates and invertebrates (Thornbury et al., 1985). VSRs mainly target steps of RNA silencing that involve small RNAs, and thus interfere with the production of siRNA, by sequestering siRNA or preventing long or short distance spread of RNA silencing. For example, p19 protein of tombusviruses interacts with 21-25 nucleotides double stranded siRNA and forms p19-siRNA complexes, which results in reducing the free siRNA in cells (Silhavy el al., 2002 and Lakatos el al., 2004). VSRs interfere with siRNA production either by binding to dsRNA, which consequently prevents the dicing process or by direct binding to dicer protein. Our results suggest the possibility that CHV1 
viruses produce RNA factors that interact with the host RNA silencing pathway to modulate vic-associated PCD, as discussed below.

Existing knowledge of quelling, a form of RNA silencing in fungi, has been mostly initiated from studies of $N$. crassa. Extensive analysis of mutant isolates of $N$. crassa identified some fundamental components of RNA silencing pathway. However, whether RNA silencing acts as a viral defence mechanism is difficult to experimentally test in $N$. crassa because of the absence of a well-developed virus pathogen system. On the other hand C. parasitica, a closely related species to $N$. crassa, provides a suitable experimental system due to the existence of hypoviruses. The p29 sequence of CHV1 shares similarities with HC-pro, a protein encoded by plant potyviruses. HC-pro protein of Tobacco etch virus interferes with RNA silencing by disrupting of dsRNA processing into siRNA through interfering with dicer function (Mallory et al., 2002). An important distinction between the two systems is our finding that it is likely the p29 RNA that acts to reduce vic3-associated $\mathrm{PCD}$. HC-pro was also reported to interfere with protease function (Jin et al., 2007). The proteasome is part of the ATP-dependent proteolytic pathway in eukaryotic cells which is involved in protein degradation associated with many cellular processes as well as with disrupting protein synthesis from viral RNAs in infected cells (Coux et al., 1996).

A recent study by Segers el al. (2007) provided evidence that RNA silencing in $C$. parasitica may act as an antiviral defense mechanism. In their study of two dicer-like proteins, $d c l-2$ mutants, but not $d c l-1$ mutants, showed a high level of susceptibility to viral infection. However, infection of $d c l-2$ mutants with a hypovirus CHV1-EP713 mutant that lacked p29 showed wild-type susceptibility levels. Similar viral RNA levels 
were observed in these $\Delta \mathrm{p} 29 / \Delta d c l-2$ infections as were observed in wild-type hosts infected with wild-type viruses. It was concluded that p29 acts as a suppressor of RNA silencing through direct or indirect neutralization of $d c l-2$ function. Our microscopy analysis of vic3-associated PCD using $d c l-1$ and $d c l-2$ mutants revealed similar patterns. Confrontations between strain P74-3 and the EP155-derived $\Delta d c l-2$ and $\Delta d c l-1 / \Delta d c l-2$ double mutants resulted in similar cell death frequencies as observed with the p29-EP713 infected strain. Similarity in outcome between disruption of $d c l-2$ gene and p29 may suggest that RNA silencing is engaged in nonself recognition system.

Unexpectedly, given its homology to HC-pro, the plant potyviral protein described above, inserting stop codons at the beginning of the p29 sequence did not compromise its effect and it showed a similar cell death frequency as the wild-type p29. This would suggest that in contrast to the HC-pro protein-based factor, RNA from the p29 region interferes with PCD. Whether this stop-construct also interferes with RNA silencing is not known, and should be tested. Such cases of RNA function were reported for members of the pathogenic human herpesvirus family that use small size RNAs with specific secondary structure to manipulate the RNA silencing pathway (Cai et al., 2005 and Pfeffer et al., 2004). Currently, we are taking two approaches to further test this result. First, we are using quantitative reverse transcriptase PCR to measure $d c l-2$ transcript levels in three isolates, EP155, EP155 (CHV1-EP713-p29) and EP155 (CHV1EP713-p29stop). We hypothesize that $d c l-2$ transcript levels in EP155 (CHV1-EP713p29) and EP155 (CHV1-EP713-p29stop) should be similar to each other but higher than EP155 wild-type. Our second approach involves the construction of small nucleotide segments of CHV1-EP713-p29 of approximately 100 nucleotides long to determine if 
any specific region(s) are involved in RNA silencing suppression. We note that involvement of p29 at the RNA level may explain our protein work in which no p29host-protein interaction was detected.

Dissecting the vic pathway using hypovirus p29 factor as a probe As mentioned in the introduction, vegetative incompatibility in C. parasitica is governed by at least six unlinked vic loci, each having at least two allelic forms. Pairs of isolates differing only at the vic 3 locus were used for previous studies in this report. In this section cell death frequencies were measured using pairs of isolates that differed at one or more of vic2, 3, 6 or 7. PCD frequencies for each pair were analyzed in the presence and absence of CHV1-EP713-p29, expressed by the EP155 strain. The objective of this part of the study was three-fold. First, to see whether the p29 factor influenced the rate of PCD elicited by vic genes in addition to vic3. Second, to investigate whether multiple vic differences would overcome the virus effects. Finally, we wanted to investigate whether we could learn something about the vic-incompatibility pathway(s) using the hypovirus as a "molecular probe". In this section, pairings involving isolates with vicl and 4 were not tested. We omitted these comparisons since the previous study by Biella et al. (2002) showed that there was no significant effect on vic1-or vic4-associated PCD rates when isolates were, or were not, infected with CHV1 virus. In addition, cell death frequencies between two non-infected isolates with vic4 difference were low to begin with, as previously reported. From confrontations involving single vic gene differences it can be concluded that p29 significantly reduces PCD associated with vic2, 3, 6 and 7 
While preliminary, microscopy analysis involving single and multiple vic differences suggest at least two different vic-incompatibility pathways. Non-additive effects of vic6 and vic7 suggested that these two loci relate to a single PCD pathway. The observed "additive" effects of vic2 and vic3 differences demonstrated that some vic genes may control the incompatibility pathway independently. Here, it appears that the virus effect of reducing PCD is diluted. 
Figure 26. Illustrates two different models for vic-incompatibility pathway. (a) Potentially epistatic interactions between vic 6 and vic 7 that results in non-additive vic effects. A virus factor would be able to modulate the entire pathway by interacting with vic 7 , for example. Such an interaction with this pathway would result in a PCD rates that are similar to when vic 7 alone differs between the paired strains. (b) Involvement of vic2 and vic3 genes in two independent pathways. A viral signal would be diluted since the virus has to manipulate the system at two different points. 


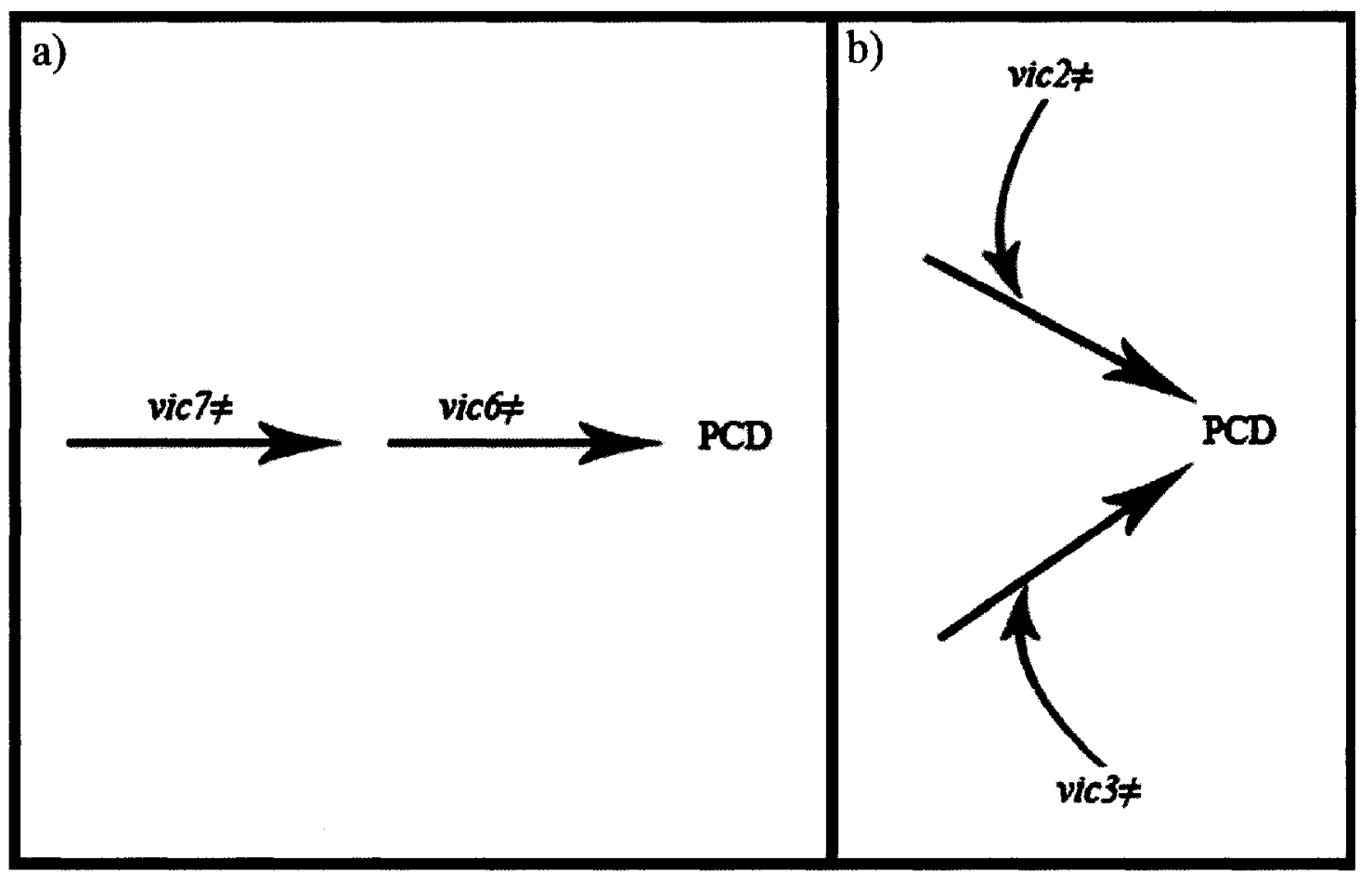




\section{SUMMARY AND CONCLUSIONS}

This thesis investigated how the nonself recognition system in $C$. parasitica is manipulated by $\mathrm{CHV} 1$ hypovirus. In fungi vegetative incompatibility is a nonself recognition system that triggers PCD as a defense mechanism. Using microscopy analysis, I characterized cases where the presence of CHV1-EP713 virus in one strain resulted in a significant reduction in rate of $\mathrm{PCD}$ associated with specific vic locus differences. I confirmed that the presence of hypovirus CHV1-EP713 clearly reduces the rate of vic3-associated PCD, as suggested previously by Biella et al. (2002), and similarly reduces PCD rates associated with differences at each of vic2, 6 and 7. I took advantage of what is known about the genome organization of hypovirus to further identify factors that interact with vic3-associated PCD. Using chimeric recombinant viruses I determined that $\mathrm{ORF} A$ is responsible for $\mathrm{PCD}$ reduction. Furthermore I identified that $\mathrm{p} 29$ and $\mathrm{p} 40$ regions of ORF A reduced the rate of vic3-associated PCD. I analyzed p29 further and determined that it is likely the p29 RNA that affects vic3-associated PCD rates. In spite of these significant reductions in PCD rates based on microscopy analyses, my results clearly indicated that p29 did not significantly alter heterokaryon incompatibility nor barrage reactions in vic-incompatible pairings. Microscopy analysis using EP155-derived $d c l$ mutants revealed the involvement of $d c l-2$ in vic3-associated PCD. Insertion of stop codons at the beginning of the p29 sequence showed similar cell death frequency as wildtype $\mathrm{p} 29$. Therefore, we may propose that the p29 RNA, rather than the protein, interferes with RNA silencing, possibly with $d c l-2$ function, and consequently reduces the rate of vic3-associated PCD. Finally, preliminary data was presented that indicates that vic genes operate independently on different pathways involved in triggering PCD. 


\section{LITERATURE CITED}

Agrawal, N., Dasaradhi, P. V. N., Mohmmed, A., Malhotra, P., Bhatnagar, R. K. and Mukherjee, S. K. 2003. RNA Interference: Biology, Mechanism, and Applications. Microbiology and Molecular Biology Review. 67: 657-685.

Anagnostakis, S. L. 2000. Revitalization of the Majestic Chestnut: Chestnut Blight Disease.Retrieved:February16/ 2006 from:

http://www.apsnet.org/online/feature/chestnut/top.html

Anagnostakis, S. L. \& Kranz, J. 1987. Population dynamics of Cryphonectria parasitica in mixed-hardwood forest in Connecticut. Phytopathology. 77: 751-54.

Anagnostakis, S. L. 1982. Biological control of chestnut blight. Science. 215: 466-71.

Anagnostakis, S. L. 2001. American chestnut sprout survival with biological control of the chestnut-blight fungus population. Forest Ecology and Management. 152:225-233.

Anagnostakis, S. L., Hau, B., Kranz, J. 1986. Diversity of vegetative compatibility groups of Cryphonectria parasitica in Connecticut and Europe. Plant Dis. 70: 536-38.

Biella, S., Smith, M. L., Aist, J. R., Cortesi, P. \& Milgroom, M. G. 2002. Programmed Cell Death correlates with virus transmission in a filamentous fungus. Proc, R. Soc. Lond. B. 269: 2269-2276.

Bio-Rad“Quick Start Bradford Protein Assay Instruction Manual” retrieved July 14, 2008 from: http://www.bio-rad.com/cmc_upload/Literature/55685/4110065A.pdf.

Buller, A. H. R. 1933. Researches on Fungi. London: Longman. Vol. 5, 416pp.

Bursch, W., Ellinger, a., Gerner, CH., Frohwein, U. and Schulte-hermann, R. 2000. Programmed cell death (PCD): Apoptosis, autophagic PCD, or others?. Ann. N.Y. Acad. Sci. 926: 1-12.

Cai, X., Lu, S., Zhang, Z., Gonzales, C. M., Damania, B. and Cullen, B. R. 2005. Kaposi's sarcoma-associated herpesvirus expresses an array of viral microRNAs in latently infected cells. PNAS. 102: 5570-5575.

Caten, C. E. 1972. Vegetative incompatibility and cytoplasmic infection in fungi. $J$. Gen. Microbiol. 72: 221-229.

Caudy, A. A., Myers, M. Hannon, G. J. and Hammond, S. M. 2002. Fragile X-related protein and VIG associate with RNA interference machinery. Genes Dev. 16:2491-2496.

Chen, B., Choi, G. H. \& Nuss, D. L. 1994. Attenuation of fungal virulence by synthetic infectious hypovirus transcripts. Science. 264: 1762-1764. 
Chen, B., Geletka, L. M. \& Nuss, D. L. 2000. Using chimeric hypoviruses to fine-tune the interaction between a pathogenic fungus and its plant host. J. virol. 74: 7562-7567.

Choi, G. H. R., Pawlyk, D. M. \& Nuss, D. L. 1991. The autocatalytic protease P29 encoded by a hypovirulence-associated virus of the chestnut blight fungus resembles the potyvirus-encoded protease HC-Pro. Virology. 183: 747-752.

Churchill, A. C. L., Ciuffetti, L. M., Hansen, D. R., Van Etten, H. D. \& Van Alfen, N. K. 1990. Transformation of the fungal pathogen Cryphonectria parasitica with a variety of heterologous plasmids. Current Genetics. 17: 25-31.

Cogoni, C. and Macino, G. 1999. Posttranscriptional gene silencing in Neurospora by a RecQ DNA Helicase. Science. 286: 2342-2344.

Cogoni, C. and Macino, Giuseppe. 1997. Isolation of quelling-defective (qde) mutants impaired in posttranscriptional transgene-induced gene silencing in Neurospora crassa. Proc. Natl. Acad. Sci. 94: 10233-10238.

Cortesi, P. \& Milgroom, M. G. 1998. Genetics of Vegetative Incompatibility in Cryphoneteria parasitica. Applied and Environmental Microbiology. 64: 2988-94.

Cortesi, P., McCulloch, C. E., Song, H., Lin, H., Migroom, M. G. 2001. Genetic control of horizontal virus transmission in the chestnut blight fungus, Cryphonecteria parasitica. Genetics. 159: 107-118.

Coux, O., Tanaka, K. and Goldberg, A. L. 1996. Structure and functions of the $20 \mathrm{~S}$ and 26S proteasomes. Annu Rev Biochem. 65: 801-847.

Cox, S. 1999. The American Chestnut Story. Retrieved February 15, 2006 from: http://lamar.colostate.edu/ samcox/chestnut.htm.

Craven, M. G., pawlyk, D. M., Choi, G. H. \& Nuss, D. L. 1993. Papain-like protease p29 as a symptom determinant encoded by a hypovirulence-associated virus of the chestnut blight fungus. J. Virology. 67: 6513-6521.

Cummings-Carlson, J., Fulbright, D. W., MacDonald, W. L., Milgroom, M. G. 1998. West Salem: a research update. J. Am. Chestnut Found. 12: 24-26.

Dawe, A. L., and Nuss, D. L. 2001. Hypoviruses and Chestnut Blight: Exploiting Viruses to Understand and Modulate Fungal pathogenesis. Annu. Rev. Genet. 35:1-29.

Duffy, B., Schouten, A. \& Raaijmakers, J. M. 2003. Pathogen Self-Defense: mechanisms to Counterac Microbial Antagonism. Annu. Rev. Phytopathol. 41:501-538.

Fraser, J. A. \& Heitman, J. 2003. Fungal mating-type loci. Curr. Biol. 13: R792-R795. 
Fulci, V. and Macino, G. 2007. Quelling: post-transcriptional gene silencing guided by small RNAs in Neurospora crassa. Current Opinion in Microbiology. 10: 199-203.

Glass, N. L., Jacobson, D. J. \& Shiu, P. K. T. 2000. The genetics of hyphal fusion and vegetative incompatibility in filamentous ascomycete fungi. Annu. Rev. Genet. 34: 16586.

Gregory, P. H. 1984. The fungal mycelium: an historical perspective. Trans. Br. Mycol. Soc. 82: 1-11.

Grente, J. \& Sauret, S. 1969. L'hpovirulence exclusive, est-elle controlee par des determinants cytoplasmiques ? C. R. Acad. Sci. Paris Ser. 268:3173-76.

Hamann, A., Brust, D. and Osiewacz, H. D. 2008. Apoptosis pathways in fungal growth, development and ageing. Trends in Microbiology. 16: 276-283.

Hannon, G. J. 2002. RNA interference. Nature. 418: 244-251.

Heiniger, U. \& Rigling, D. 1994. Biological control of chestnut blight in Europe. Annu. Rev. Phytopathol. 32: 581-99.

Hillman B. I., Halpern, B. T. \& Brown, M. P. 1994. A viral dsRNA element of the chestnut blight fungus with a distinct genetic organization. Virology. 201: 241-250.

Ischizuka, A., Siomi, M. C. and Siomi, H. 2002. A Drosophila fragile X protein interacts with components of RNAi and ribosomal proteins. Gene Dev. 16:2497-2508.

Jacobson, D. J., Beurkens, K. \& Klomparens, K. L. 1998. Microscopic and ultrastructural examination of vegetative incompatibility in partial diploids heterozygous at het loci in Neurospora crasssa. Fungal Genet. Biol. 23: 45-56.

Jin, Y., Ma, D., Dong, J., Jin, J., Li, D., Deng, C. and Wang, C. 2007. HC-Pro protein of Potato Virus $Y$ can interact with three Arabidopsis 20 S proteasome subunits in planta. Journal of Virology. 81:12881-12888.

Kerr, J.F.R., Wyllie, A. H. and Currie, A. R. 1972. Apoptosis: a basic biological phenomenon with wide-ranging implications in tissue kinetics. Br. J. Cancer. 26: 239257.

Koonin, E. V., Choi, G. H., Nuss, D. L., Shapira, R. \& Carrington, J. C. 1991. Evidence for common ancestry of the chestnut blight hypovirulence-associated double-stranded RNA and a group of positive-strand RNA plant viruses. Proc. Natl. Acad. Sci. USA. 88:10647-10651. 
Lakatos, L., Szittya, G., Silhavy, D. and Burgyan, J. 2004. Molecular mechanism ofRNAsilencing suppression mediated by 19 protein of tombusviruses. $E M B O J$. 23:876-84.

Lawen, A. 2003. Apoptosis: An introduction. Bioessays. 25:888-896.

Leslie, J. F. 1993. Fungal vegetative compatibility. Annu. Rev. Phytopathol. 31: 127-50

Li, F. and Ding, S. W. 2006. Virus counterdefense: diverse strategies for evading the RNA-silencing immunity. Annu. Rev. Microbiol. 60: 503-531.

Li, H., Li, W. X. and Ding, S. W. 2002. Induction and suppression of RNA silencing by an animal virus. Science. 296:1319-21.

Liu, Y. C. \& Milgroom, M. G. 1996. Correlation between hypovirus transmission and the number of vegetative incompatibility (vic) genes different among isolates from a natural population of Cryphonectria parasitica. Phytopathology. 86: 79-86.

Mallory, A. C., Reinhart, B. J., Bartel, D., Vance, V. B., Bowman, L. H. 2002. A viral suppressor of RNA silencing differentially regulates the accumulation of short interfering RNAs and micro-RNAs in tobacco. Proc. Natl. Acad. Sci. USA 99:15228-33.

Marek, S. M., Wu, J., Glass, N. L., Gilchrist, D .G., Bostock, R. M. 2003. Nuclear DNA degradation during heterrokaryon incompatibility in Neurospora crassa. Fungal Genetics and Biology. 40: 126-137.

Micali, C. O. \& Smith, M. L. 2003. On the independence of barrage formation and heterokaryon incompatibility in Neurospora crassa. Fungal Genetics and Biology. 38: 209-219.

Micali, O. C, \& Smith, M. L. 2005. Biological concepts of vegetative self and nonself recognition in fungi. In: Xu J. ed. Evolutionary Genetics of Fungi. Wymondham, UK: Horizon Bioscience: 63-85.

Milgroom, M. G. \& Cortesi, P. 2004. Biological Control of Chestnut Blight With Hypovirulence : A Critical Analysis. Annu. Rev. Phytopahol. 42: 311-38.

Milgroom, M. G., Lipari, S. E., Ennos, R. A. \& Liu, Y. 1993. Estimation of the outcrossing rate in the chestnut blight fungus, Cryphonecteria parasitica. Heredity. 70: 385-392.

Morel, J. B., Godon, C., Mourrain, P., Beclin, C., Boutet, S., Feuerback, F., Proux, F. and Vaucheret, H. 2002. Fertile hypomorphic ARGONAUTE (ago1) mutants impaired in post-transcriptional gene silencing and virus resistance. Plant Cell. 14:629-39.

Nuss, D. L. 1992. Biological control of chestnut blight: an example of virus-mediated attenuation of fungal pathogenesis. Microbio. Rev. 56: 561-576. 
Pfeffer, S., Zavolan, M., Gra"sser, F. A., Chien, M., Russo, J. J., Ju, J., John, B., Enright, A. J., Marks, D., Sander, C. and Tuschl, T. 2004. Identification of Virus-Encoded MicroRNAs. Science. 304: 734-736.

Mortenson, V. Disease diagram of chestnut blight caused by Cryphonectria parasitica. Retrieved August 17, 2008 from: http://lamar.colostate.edu/ samcox/chestnut.htm.

Powell, W. A. 1995. Vegetative incompatibility and mycelial death of Cryphonectria parasitica detected with a $\mathrm{pH}$ indicator. Mycologia. 87: 738-741.

Rana, T. M. 2007. Illuminating the silence: understanding the structure and function of small RNAs. Molecular cell biology. 8: 23-36.

Rizwana, R. \& Powell, W. A. 1992. Ultraviolet light-induced instability of vegetative compatibility groups of Cryphonecteria parasitica. Phytopathology. 82: 1206-1211.

Rizwana, R. \& Powell, W. A. 1995. Ultraviolet light-induced heterokaryon formation and parasexuality in Cryphonectria parasitica. Exp. Mycol. 19: 48-60.

Romano, N. and Macino, G. 1992. Quelling: transient inactivation of gene expression in Neurospora crassa by transformation with homologous sequences. Mol Microbiol. 6:3343-3353.

Saupe, S. J. 2000. Molecular Genetics of Heterokaryon Incompatibility in Filamentous Ascomycetes. Microbiology and molecular biology reviews. 64:489-502.

Segers, G. C., Zhang, X., Deng, F., Sun, Q. and Nuss, D. L. 2007. Evidence that RNA silencing functions as an antiviral defense mechanism in fungi. PNAS. 104: 12902-12906.

Silhavy, D., Molnar, A., Lucioli, A., Szittya, G., Hornyik, C., Tavazza, M. and Burgyan, J. 2002. A viral protein suppresses RNA silencing and binds silencing-generated, 21- to 25-nucleotide doublestranded RNAs. EMBO J. 21:3070-80.

Sioud, M. 2007. RNA interference and innate immunity. Advanced drug delivery reviews. 59: $153-163$.

Smith, M. L., Gibbs, C. C. \& Milgroom, M. G. 2006. Heterokaryon incompatibility function of barrage-associated vegetative incompatibility gene (vic) in Cryphonectria parasitica. Mycologia. 98: 49-56.

Suzuki, N. \& Nuss, D. L. 2002. Contribution of protein p40 to hypovirus-mediated modulation of fungal host phenotype and viral RNA accumulation. J. Virol. 76: 77477759 . 
Suzuki, N., Chen, B. \& Nuss, D. L. 1999. Mapping of a hypovirus P29 protease symptom determinant domain with sequence similarity to potyvirus HC-Proprotease. J. Virol. 73:9478-9484.

Suzuki, N., Maruyama, K., Moriyama, M. \& Nuss, D. L. 2003. Hypovirus papain-like protease P29 functions in trans to enhance viral double-stranded RNA accumulation and vertical transmission. J. Virol. 77: 11697-11707.

Thornbury, D. W., Hellmann, G. M., Rhoads, R. E. and Pirone, T. P. 1985. Purification and characterization of potyvirus helper component. Virology, 144: 260-267.

Waterhouse, P. M. and Fusaro, A. F. 2006. Plant science. Viruses face a double defense by plant small RNAs. Science. 313: 54-55.

Yorimitsu, T. and Klionsky, D. J. 2005. Autophagy: Molecular machinery for self-eating. Cell death and differentiation. 12: 1542-1552. 